\title{
A CASE STUDY OF THE GLOBAL FOOD SECURITY ACT OF 2016: INTERORGANIZATIONAL POLICYMAKING AND FOOD SECURITY d/DISCOURSES
}

A dissertation presented to the Faculty of the Graduate School

University of Missouri

Department of Communication

In Partial Fulfillment

Of the Requirements of the Degree

Doctor of Philosophy

by

MEGAN K. SCHRAEDLEY

Dr. Debbie Dougherty, Dissertation Supervisor

JULY 2018 
(C) Copyright by Megan K. Schraedley 2018

All Rights Reserved 
The undersigned, appointed by the Associate Vice Chancellor of the Office of Research and Graduate Studies, have examined the dissertation entitled

\title{
A CASE STUDY OF THE GLOBAL FOOD SECURITY ACT OF 2016: INTERORGANIZATIONAL POLICYMAKING AND FOOD SECURITY d/DISCOURSES
}

\author{
Presented by Megan K. Schraedley \\ A candidate for the degree of \\ Doctor of Philosophy
}

And hereby certify that, in their opinion, it is worthy of acceptance.

Debbie S. Dougherty, PhD.

Rebecca J. Meisenbach, PhD.

J. Brian Houston, PhD.

J. Sanford Rikoon, PhD. 


\section{ACKNOWLEDGEMENTS}

A dissertation takes a wealth of support and the collaboration of many parties.

To my participants: I felt so lucky to have the opportunity to learn more about the complex organization that is USAID. You are doing amazing work around solving one of the most complicated problems of our time. Thank you for your time, your insight, and your patience.

To my love: Eric, you have been my biggest supporter and the most patient listener these five years. Thank you for all the times you took over: walking the pup, doing dishes and laundry, cooking dinner, driving me to campus, and more. You have given me everything from pep talks to paintings, from music to hugs, to extra glasses of wine - and heaven knows I needed every one of them. We lived through one heck of a journey in Columbia, and I am looking forward to the next.

To my parents, Gwen, and RJ: I love you. Thank you for pushing me to find a path that matters. I have discovered new ways of being, developed stronger beliefs, and nurtured emerging passions throughout this program. Your collective optimism, strength, funny memes, and regular Columbia visits have made this manuscript possible.

To my dissertation committee, Dr. Dougherty, Dr. Meisenbach, Dr. Houston, and Dr. Rikoon: You've helped mold me into a better thinker, researcher, writer, and speaker. I appreciate the time each of you has taken to guide and mentor me through a difficult, yet satisfying, endeavor. Debbie, for the farm food and the "Nice!"'s written into my manuscript margins; Rebecca for real-talk over glasses of wine at conferences and Room38; Brian, for asking the hard questions during research projects and embracing a qualitative perspective; and Sandy, for encouraging both creativity and rigor as resistance 
to injustice through food research. I look forward to passing on the lessons I have learned from all of you.

To Woody: You kept my lap warm during the longest winter and brought me such joy during our trail walks and runs.

To my friends: Each of you have offered kindness and motivation when I needed it most. Julia, for believing in my "doctor-ing" first. Jackie, for letting me cry, laugh, and yell - sometimes all at once. Cristin, for your thoughtful advice and brilliant collaboration. Jessica, for living through the madness with me-we've got this. To Angela, Matt, and Allegra: your caring calls, texts, and visits have kept me grounded and believing in the process.

To those that helped me maintain my physical and mental health: Andrea, for the inspiring quotations that hit me right in the feels during each class; Monique, for taking me out of the "diss" mindset; Colissa, for helping me feel confident about my skills; and JV, for an unexpected friendship. To the strong FarmHers who fed me good food along the way and showed me what strength looks like: Liz, Jenn, and Mary. Thank you.

To our neighbors: Sharing a smile with you each morning before I rode my bike to campus helped make St. Christopher Street a "home."

To the MDWAP crew: The laughs that I got from your podcast literally kept me going when the going was toughest. Thank you for making that possible during this program.

To myself: You've done it! Now, no more doubting. Go ahead and make the world a better place. 


\section{TABLE OF CONTENTS}

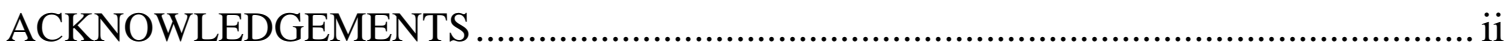

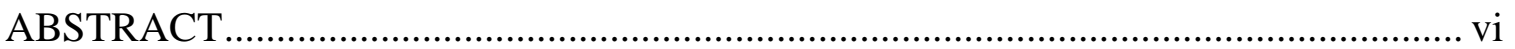

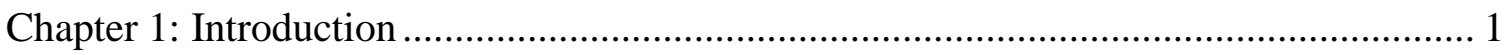

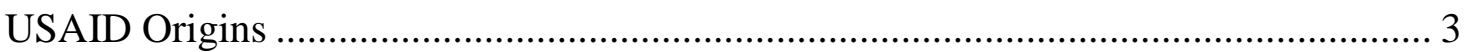

USAID's food security agenda and sustainable development goals. ....................... 5

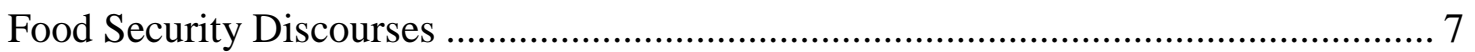

Language Convergence/Meaning Divergence and Organizational Discourse .............. 9

Policy and Food Security Intersections............................................................. 12

Case Study: Analyzing Food Security Meanings through Qualitative Methods .......... 16

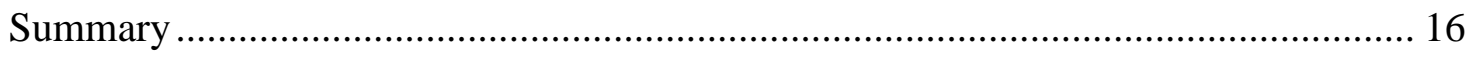

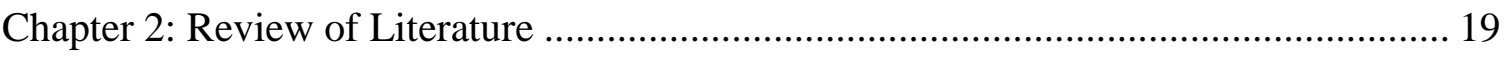

Intertwining Food Security and Hunger Discourses ........................................... 20

Tracing the historical usage and contested meanings of food security................... 23

Comparing "food security" discourses to "hunger" discourses.............................. 28

Linking Food and Communication ...................................................................... 31

Language convergence/meaning divergence: A communicative lens of food security. .

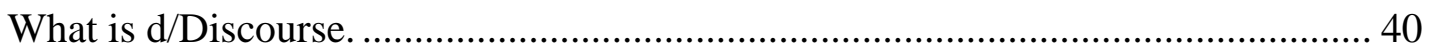

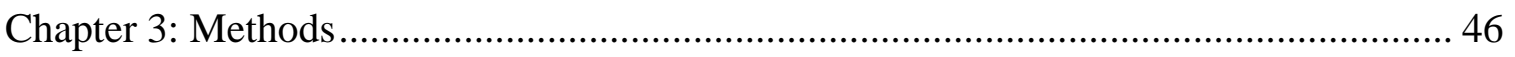

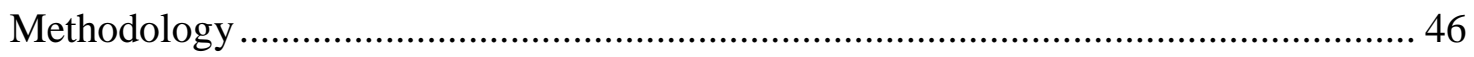

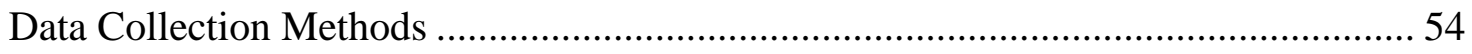

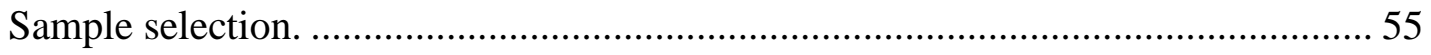

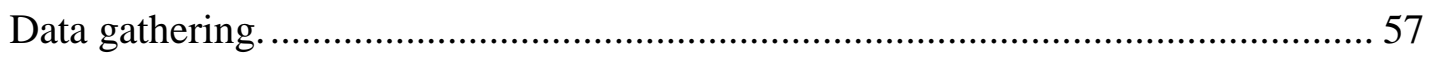

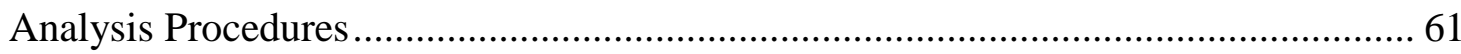

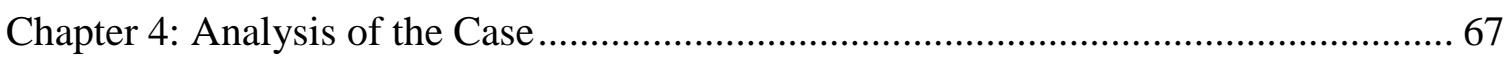

Vignette \#1: Dissertation Writing Creates Transformation ....................................... 70

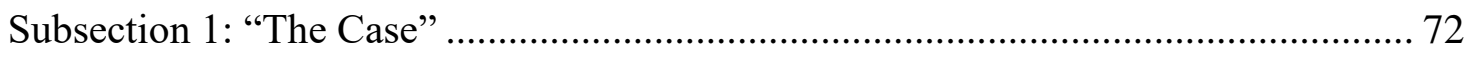

Foreign Assistance Act of 1961 and USAID beginnings. ................................... 73

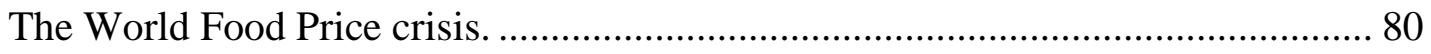

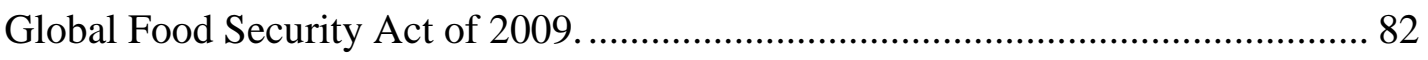

Shifting the d/Discourse: Arguments for turning program into policy................... 85

Structuring d/Discursive support for the 2016 Global Food Security Act................ 95

Communicative idealizing: Making sense of policymaking recollections. ............ 105 
Chapter 5: Managing Meanings ................................................................................ 112

Vignette \#2: Project Paranoia ......................................................................... 112

Subsection 2: Converging/Diverging Meanings around Food Security Policy .......... 127

Discursive maneuvering: Multiple and divergent food security meanings. ............ 136

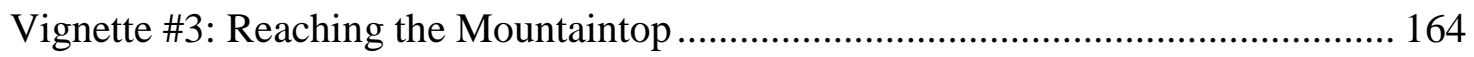

Subsection 3: Global Food Security through National Security: Making the Case for Food Security as Defense............................................................................... 166

Making the case for food security as a national security issue: Strategically

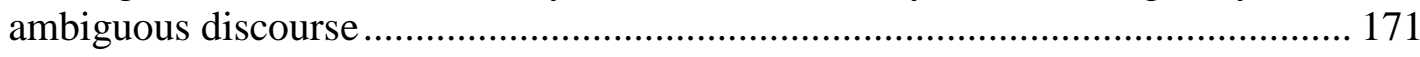

Chapter 6: Discussion and Conclusion ………………............................................... 185

Implications for Food Security Scholarship .......................................................... 192

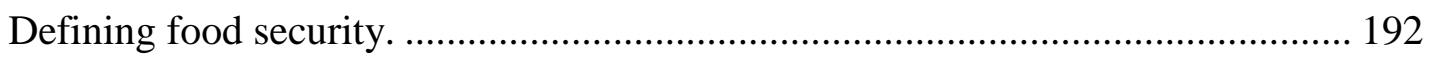

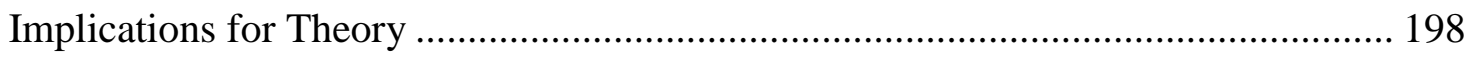

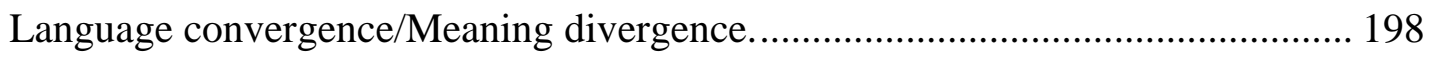

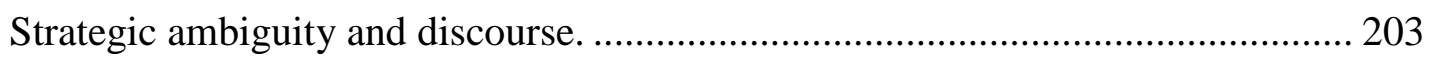

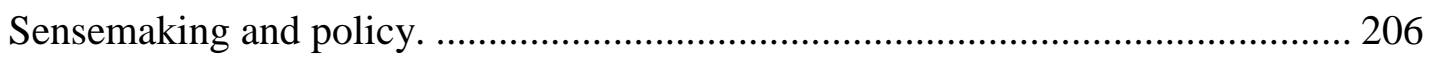

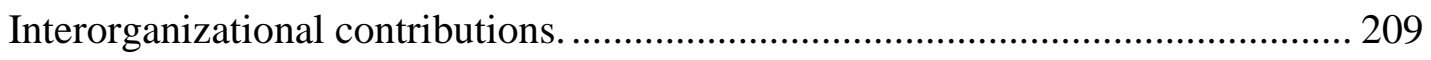

Language, Organizing, and Food Security: Implications for Practice........................ 210

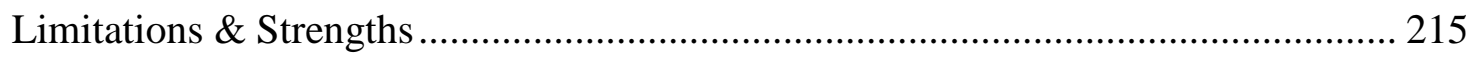

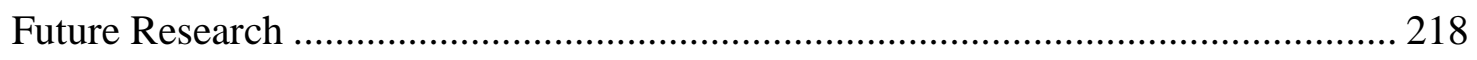

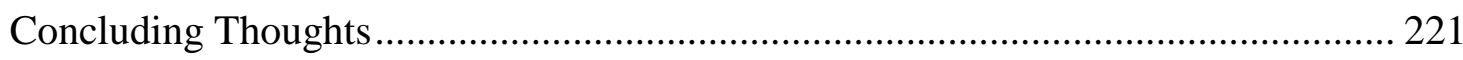

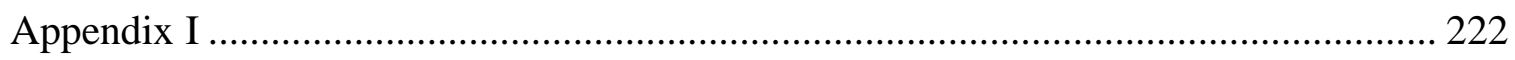

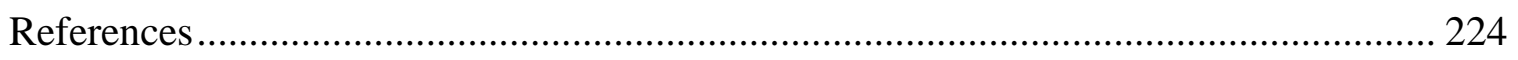

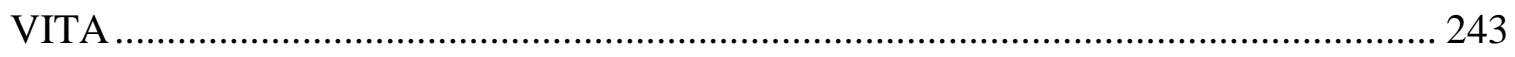




\begin{abstract}
For this dissertation case study, I examined how individuals, especially those who worked on interorganizational food security programming and policymaking, discussed organizational policy messaging and the discursively constructed meanings around their work related to food security. I focused on the communicative linkages between a US government development organization and the problem of food insecurity because this condition continues to plague nearly a billion people around the world. Specifically, I investigated the communicative processes leading up to the passage of the Global Food Security Act (2016), including the organizational construction of meaning that helped get the bipartisan legislation passed at a contentious time in our government's history. I conducted in-depth, qualitative interviews with food security professionals and coded documents related to the passage of the GFSA. This study serves a dual purpose: 1) The findings provide evidence of language convergence/meaning divergence that adds to a deeper scholarly understanding of how policies are created and interpreted differently, and 2) the findings offer insight into the ways in which a US government organization uses strategic ambiguity to persuade stakeholders to fund food security programming and support impactful international programming.
\end{abstract}




\section{Chapter 1: Introduction}

Food insecurity is a situation that exists when people lack secure access to sufficient amounts of safe and nutritious food for the normal growth and development necessary for an active and healthy life (Food and Agriculture Organization, International Fund for Agricultural Development, \& World Food Programme, 2015, p. 53). Hunger, undernourishment, and malnutrition—conditions related to food insecurity—affect an estimated 795 million people worldwide (The State of Food Insecurity, 2015). Over ten percent of the world's population struggles to survive, in part, due to food insecurity. And yet, this food insecurity remains because communities, governments, and organizations know that identifying the root causes of food insecurity at both the local and global level has become increasingly complex over time. Studies from several fields investigating the various facets of food insecurity tell us this issue is urgent and serious (Gottlieb \& Joshi, 2010; Hadley, Lindstrom, Tessema, \& Belachew, 2008; Jarosz, 2011; Misselhorn, 2005). Perplexity around identifying food security's root causes arises because food insecure populations struggle simultaneously with poverty, trade policies, fluctuating food prices, geographical access to food, climate change, food waste, and natural and manmade disasters (Pinstrup-Andersen, 2009).

While these factors together contribute to material, or the bodily/physical side of, food insecurity, these constituting factors also expose an opening for further investigation into the communicative struggle for meaning around food insecurity. The struggle for meaning around food insecurity, and ultimately the pathway toward local and global solutions to food insecurity, becomes discursively negotiated among interorganizational actors. Interorganizational actors fighting for food security locally and globally include 
numerous and diverse organizations, groups, and individuals. Just a few examples of food security stakeholders include: international non-governmental organizations (the United Nations Food and Agriculture Organization, the United Nations World Food Programme and the United Nations International Fund for Agricultural Development); national and local governments and legislative bodies (e.g., United States Department of Agriculture; the United States Agency for International Development) not-for-profit and humanitarian organizations (e.g., Action Against Hunger; Feeding America); university departments, researcher partnerships, and extension programs; think tanks (e.g., Food Tank; the Aspen Institute); corporations (e.g., Monsanto; DuPont; Cargill); lobbying organizations (InterAction); local policy groups (e.g., KC Healthy Kids, New Mexico Food and Ag Policy Council); and individuals making daily decisions for themselves, their families, their schools, and communities. In fact, the number of groups addressing food security in combination with other missions becomes overwhelming to try to track and sort. Each stakeholder brings their own, and sometimes competing, meanings of food security to discussions of action, policy, funding, programming, etc.

I have used this organizational case study investigation as an opportunity to research the competing and overlapping meanings of food security. In other words, I have examined what the concept, 'food security,' means to individuals from USAID and members from the associated Board for International Food and Agriculture Development (BIFAD). The ways that 'food security' takes on meaning and diverse interpretations at several levels of d/Discourse partly depends upon how humans discursively co-construct this organizing concept. As part of determining and deconstructing how these discourses 
multiply, compete, and overlap, I have examined the ways in which USAID has created and replicated communicative meanings connected to food (in)security discourses.

In the US, federal government agencies have materially and discursively involved themselves in fighting food insecurity at several levels: from local communities within the US to international communities struggling to maintain security or become food secure. For example, at a national level within the US, the United States Department of Agriculture (USDA) has worked alongside other departments (e.g., Department of Commerce, Department of State, Department of the Treasury) for two decades to mitigate the US population's food insecurity. At a global level, the United States Agency for International Development (USAID) has directly funded development and food insecurity programs for over fifty years and more recently, has received a congressional mandate to implement a Global Food Security Strategy (GFSS) with the express purpose of tackling food security collaboratively. Throughout my case study analysis, I critique the cross-agency collaborative meanings of food security discursively embedded within USAID's policies, individual level discourses, and program frameworks. The organization's food security efforts have long been tied up with the US government's international development agenda (Who We Are, 2017).

\section{USAID Origins}

When I examined USAID's long-standing connections to food insecurity, I saw competing and multiple meanings at play. USAID is a US State Department-affiliated government organization working to end worldwide poverty by building resilient, democratic societies around the world. The US government has long concerned itself with preserving national economic growth and the safety of its citizens (Riley, 2017). The 
end of World War II ushered in a significant era of change in terms of how nations would negotiate with each other about the best ways to achieve growth and safety. The USAID history section of the organization's website states, "The modern-day concept of international development assistance took shape after World War II ended in $1945 \ldots$ the Marshall Plan was a successful effort that allowed Europe to rebuild its infrastructure, strengthen its economy, and stabilize the region" (Who We Are, 2017, para. 4). The Marshall Plan became a model for other international aid efforts championed by the US government and private foundations, like the Rockefeller Foundation. In 1961, President John F. Kennedy signed the Foreign Assistance Act, creating the USAID organization with the express goal of providing technical and capital assistance to other countries that required help attending to basic human needs (ex., food and nutrition, health, education). USAID goals have shifted and expanded over the last five decades with each new US president, new USAID director, and the changing global challenges that accompany new administrations.

The USAID organizational description on its website continues, "In 2013, USAID launched a new mission statement to end extreme poverty and promote resilient, democratic societies" (Who We Are, 2017, para. 17). USAID breaks down this two-fold mission into eleven sectors, including the sector run by the Bureau for Food Security that I examined closely: agriculture and food security. Within agriculture and food security, USAID has established eight initiatives for improving food security. Some of the initiatives have been designated with titles like, "Agricultural Markets and Trade"; "Global Nutrition"; "Sustainable Agriculture" and "Food Assistance." These programs are now tied to the 2016 Global Food Security Act passed by the US Congress in July 
2016, at the end of President Barack Obama's tenure in the White House. International food security and food assistance have recently been pushed to the top of USAID's agenda. In turn, USAID has "scaled up" a comprehensive, whole-of-government approach to fighting hunger and strengthening global food security.

USAID's food security agenda and sustainable development goals.

The USAID's food security agenda can be broadly summarized with an overview of two governmental agreements leading up to the GFSA's passage. First, the 2009 G8 summit meeting in L'Aquila, Italy brought world leaders from Canada, the European Commission, France, Germany, Italy, Japan, Russia, the United Kingdom, and the United States together to discuss prominent world issues including counter-terrorism efforts, climate change, peace building, and food security. The 2009 summit heavily emphasized food security after world food prices had skyrocketed and the Great Recession (20072009) negatively impacted the world's economy. At the end of the summit, the eight world leaders made a joint statement promising to collectively renew their efforts to end world food insecurity (L'Aquila Joint Statement, 2009). The second important agreement developed out of the United Nations" "Sustainable Development Goals" (SDGs). In 2015, world leaders agreed to adopt and implement the SDGs that are part of the 2030 Agenda for Sustainable Development.

The Global Food Security Act (GFSA) passed in 2016 and implemented a wholeof-government global food security strategy, known as GFSS, to USAID and other government members. USAID's development program funding and purpose has shifted and evolved out of these three key agreements. In sum, these documents unite countries around the world in an aim to end all forms of poverty, build economic growth, and 
address social needs of their respective populations, including education, health, etc. (The Sustainable Development Agenda, 2017, para. 2). I elaborate more upon the connections between USAID and other food security organizations in the coming chapters of the dissertation, but it is important here to acknowledge the interwoven nature of international development agencies as well as the discursive power they wield when developing policies and influencing the issue agendas of governments, companies, NGOs, and other organizations. USAID staff and their stakeholders discursively drew upon the above events to justify fulfilling their original 1961 mandate.

Overall, the core mission and values espoused on USAID's website have an intriguing connection to America's foreign policy:

Our objective is to support partners to become self-reliant and capable of leading their own development journeys. We make progress toward this by reducing the reach of conflict, preventing the spread of pandemic disease, and counteracting the drivers of violence, instability, transnational crime and other security threats. We promote American prosperity through investments that expand markets for U.S. exports; create a level playing field for U.S. businesses; and support more stable, resilient, and democratic societies. We stand with people when disaster strikes or crisis emerges as the world leader in humanitarian assistance. (Mission, Vision and Values, 2018, para. 2)

Explaining and critiquing the competing and multiple meanings of food security embedded in USAID's organizational discourses is necessary considering the crucial connection between food and peaceful order around the world (Lang \& Heasman, 2015; Schanbacher, 2010). 
In this first chapter, I provide an overview of the 1) Reasons for analyzing the creation, use, and implications of USAID's food security discourses; 2) A theoretical introduction to the language convergence/meaning divergence (LC/MD) theory (Dougherty, Kramer, Klatzke, \& Rogers, 2009), covering the ways LC/MD works in concert with organizational d/Discourse and policy communication studies; 3) A summary of how I analyzed contemporary food security discourses at USAID by using case study methods (Merriam, 2009; Stake, 1995). Throughout this dissertation, I uncovered how competing and multiple meanings embedded in food security discourses informed and influenced USAID interorganizational communication. The USAID members fulfill Congress's mandate to enact food security programs and initiatives each year to end hunger and malnutrition abroad through international aid and development assistance.

\section{Food Security Discourses}

Food security discourses include the talk, text, and permeating cultural conversations around what achieving a "state of food (in)security" means (Jarosz, 2011). Achieving a state of food security is fundamental to the mental, social, physical, and emotional health of all individuals (Belasco, 2008). Individual and/or community food security is possible when food is 1) available 2) accessible 3) nutritionally utilizable and 4) stable, or when the former three conditions remain constant over time (FAO, IFAD, \& WFP, 2015). Attaining these four so-called 'pillars' of food security necessitates a considerable amount of communication at the organizational level - a feat that becomes all the more incredible when one reflects upon the interwoven cultures, relational 
networks, political systems, and economic structures concurrently at play when USAID tackles food insecurity.

Food insecurity challenges currently confronting developing communities and nations are closely tied to the ways in which interconnecting global food systems operate, according to the US Government Global Food Security Strategy (USAID, 2016). Consequently, the complexity of these international food systems has led scholars to urge other researchers, government staff, and food work practitioners to pay special attention to food security discourses (Jarosz, 2011; LeGreco, 2012). Tim Lang, a professor of sociology and founder of City University London's Centre for Food Policy, gives researchers a strong reason for better understanding food security discourses and critiquing the function and meaning of food discourses. Food security discourses can ultimately shape action and policy decisions: "Food systems are the outcome of policy and political choices. Food is contested territory. There are conflicts of analysis and interest between diverse groups and sectors" (Lang, 1999, p. 169). Individuals working for organizations such as USAID create, share, repeat, and reinvent food security-related discourses, thereby shaping and reinforcing long-term social and material outcomes, including poverty and hunger. Essentially, organizational discourses can both help and hurt food insecure individuals: helping individuals move out of poverty and hunger through opportunities eased by capitalism and democracy yet hurting individuals through those very same institutional avenues.

Food security discourses facilitate the establishment of rules and resources for ongoing organizational and cultural relationships that have the power to enhance and limit food access. As Lang, Barling, and Caraher (2009) have argued, investigating food 
discourses offers scholars a valuable and complicated place to begin questioning critical issues facing local/global food systems. A close analysis of these discourses will help scholars and practitioners "unravel the complex relations between food and these other domains of existence in order to make what is otherwise implicit (or hidden behind doors) more explicit, open and democratically available" (loc. 7870). An organizational communication inquiry into the ways that competing and multiple food security D/discourses lead to changes in US government policy and USAID's organizational agenda gives scholars a space to better understand and evaluate how individuals organize around food issues. One way to inquire into these food security discourses is through language convergence/meaning divergence theory (Dougherty et al., 2009).

\section{Language Convergence/Meaning Divergence and Organizational Discourse}

Because I am interested specifically in the meanings organizations and their stakeholders discursively co-construct around food security (Teubert, 2010), I used language convergence/meaning divergence (LC/MD) theory (Dougherty et al., 2009) alongside Alvesson and Kärreman's levels of discourse (2000a). The basic premise of LC/MD states that individuals sharing language also share information by using the same words (Dougherty et al., 2010). However, just because these individuals use the same words does not equate to them sharing the same, or even similar, meanings. Shared language offers individuals a shortcut to mutual understanding, which typically helps humans organize together to accomplish shared goals. But shared language around larger interculturally significant concepts, like food security, can expose fissures in the discourses, showing where meaning converges and diverges. Dougherty et al. (2009) argue convergence of language around more ambiguous concepts can create the illusion 
of shared meaning. Throughout my dissertation analysis, I point to moments where the illusion of shared meaning has led to misunderstandings. Misunderstandings, especially in legislative or policymaking processes, can lead to polarized views on issues where policymakers must come to agreement in order to avoid disasters and crises. Divergent meanings can lead to organizational successes and failures based upon the multiple and competing meanings in food security discourses. The findings of this dissertation will help policymakers reconsider why communication is important to furthering their goals.

Exploring and analyzing organizational discourse has grown increasingly popular among communication, linguistics, critical management, and organizational scholars (e.g., Alvesson \& Kärreman, 2011b; Dougherty \& Goldstein Hode, 2016; Fairhurst \& Putnam, 2004; Jian, Schmisseur, \& Fairhurst, 2008; Potter, 2003). Further, scholars have recently noted important areas of overlap between organizational discourse studies and organizational communication studies (Jian, Schmisseur, \& Fairhurst, 2008). Although the distinct areas of overlap and dissimilarity between discourse and communication will be discussed in greater detail in the literature review of chapter two, the primary ways that discourse/communication inform and interact with each other include: 1) discourse as one of the many elements of communication; 2) $D / d$ iscourse as the resources for communication; 3) discourse and communication as synonymous; and 4) Discourse as operating through communication (Putnam, 2008). Taylor (2008) has proposed using 'language' as the bridge between discourse and communication, and Alvesson and Kärreman (2011b) urge the placement of greater attention upon intersections of meaning and language. Therefore, LC/MD clearly offers me a way to examine meaning and language through levels of $\mathrm{D} /$ discourse. The combination of organizational discourses 
and LC/MD allows me to explore the multiple and competing USAID food security discourses transforming (Bargiela-Chiappini, 2004) over time. For this research project, illuminating how meaning and action become discursively tied to the US government's food security policy development offers new directions for international development agencies faced with budget constraints, new leadership, and shifting policies.

At the intersection of communication and discourse studies, there are several emerging issues that I address in this dissertation. First, discourse and communication studies can tell us how organizations function as systems of relationships, but we must "develop useful and sophisticated ways of facilitating our organized relationships and mitigating the apparent consequences" (Barker, 2008, p. 335). Upon completion of this project, I expect to share communicative insights with USAID and other organizational scholars on better ways of engaging the multiple meanings of 'food security' with interorganizational stakeholders. Second, scholars have argued that discourse studies tend to leave out the researcher's experience of interacting with the text or research site (Barker, 2008; Carbaugh, 2007; Phillips, Lawrence, \& Hardy, 2004). I have recorded and written about my research experience of interacting with food security language/meaning (through texts and interviews with USAID members) in this dissertation in the form of vignettes before each subsection in the findings (Stake, 1995). Food security discourses have also have material impacts, which lead me to a third issue: ethics. As a critical scholar — as in, someone who investigates and assesses areas of concern (Craig, 1999) engaging with 'ethics' in research reminds me to document the value-driven benefits and drawbacks of multiple and competing communicative/discursive meanings impacting individuals in contradictory ways. Scholars have shown that individuals interpret 
organizational texts, including policies, in a variety of ways (Canary, 2010b; Cooren, 2004; Dougherty \& Goldstein Hode, 2016). After conducting this case study, I found that the variety of ways in which policymakers communicatively construct organizational texts, such as policies, also matters for persuading diverse audiences.

Finally, organizational texts "operate as discursive guides to make sense of the material conditions of our organized lives" (Trethewey, Scott, \& LeGreco, 2006, p. 136). Therefore, my background in organizational communication has helped me unpack the competing meanings embedded in texts, discourses, and conversations which assist and hinder USAID organizational members working separately, together, and with other stakeholders to improve international food security. My expertise in organizational communication and food security discourses has led me to rely upon policy knowledge frameworks and social theories of meaning to explain how diverse groups intersect, clash, dominate, and create multiple levels of meaning through interaction.

\section{Policy and Food Security Intersections}

Food security is not apolitical. And food insecurity inherently points to unequal discursive and material power dynamics existing in an unequal world. 'Food policy' studies typically merge agricultural concerns, food safety issues, and trade debates. In addition, food policies establish the rules and resources for ongoing organizational and cultural networks that powerfully enhance and limit food access. Communicative inquiries into food policy processes can help scholars better understand and evaluate how individuals organize around food issues to create change that will impact individuals' social and material existence. 
Policy communication has become increasingly scrutinized within the field of organizational and discursive studies (i.e., Kirby \& Krone, 2002; Canary, 2010a; Canary, Blevins, \& Ghorbani, 2015; Dougherty \& Goldstein Hode, 2016). Policies are persuasive organizational texts that discursively guide the actions, behaviors, thoughts, and the sensemaking processes of organizational members. Some scholars (see Canary, 2010a; Cooren, 2004) have argued that texts, like policies, can "act" on their own, making a difference in how human agency plays out in the constitution of organizations. Other scholars (Canary \& McPhee, 2009; LeGreco, 2012) have proposed that individuals communicatively construct (or mediate) knowledge through policy to create lasting change. Communication research on policy construction suggests that policy texts can become sites of discursive struggle: this signifies that the individuals and organizations creating and interpreting policy both battle and negotiate with each other to construct meaning (Dougherty \& Goldstein Hode, 2016). In this particular case, illuminating how meaning gets created through food policy matters because most scholarly food policy journals omit the fact that our material reality is also a social construction.

At the intersection of communication and policy studies, there are several emerging issues that I address in my dissertation. In a metatheoretical analysis, Canary, Blevins, and Ghorbani (2015) pointed to three areas that informed how I structured a project investigating food insecurity through food policy: First, the researchers noticed that materiality has not adequately been accounted for in policy research about communication processes. Communication scholars could center the "socio-material processes" that bring policies to life through organizational interactions (p. 57). Food insecurity has both social and material consequences for humans. I addressed materiality 
in this dissertation by accounting for my body and the experiences of dissertating in the vignettes of chapter 4 . Second, several communication policy studies adopt negative critiques of the policymaking process. Canary et. al (2015) argue that just as much could be learned from studies taking a positive approach: "Articles that highlighted effective policy processes noted the importance of deliberate policy framing to relevant audiences and the incorporation of technology to connect people and ideas" (p. 57). I address some of the effective policy processes in chapter 5. Finally, Canary et al. (2015) argued that few studies tackled issues of social justice. They write, “There remains much theoretically grounded work to be done to investigate issues of values, rights, and ethics throughout the policy process" (p. 58). Food insecurity inherently points to unequal power dynamics and existing inequalities in the world.

Policy interventions have the potential to bring about real change, including a more equitable and food secure world (Gottlieb \& Joshi, 2010). Food security, supported through policy regulations, could direct beneficial shifts in health, education, government, and the economy. One struggle I managed as I analyzed policy language and organizational policymaking processes was reflecting and recording unequal assemblages of power in the verbal and nonverbal interactions between USAID staff. I spoke to this struggle through a theoretical grounding in previous LC/MD and d/Discourse research, arguing for the appropriateness of this case study. These theories together have allowed me to capture, analyze, and assess disorganized convergences of power, materiality, and discourse present in policy documents and the communicative practices individuals use to create food security policies. 
Lastly, policies provide helpful guides to humans in many areas, but food security policies are particularly useful in that they offer a system of boundaries and structures informing communities on what to do about food insecurity, including how to provide increased access to agricultural resources and food (Lang, Barling, \& Caraher, 2009). Organizational texts help organizational actors make sense of their lived conditions (Trethewey et al., 2006). Therefore, an organizational communication framework indicates the ways in which texts, discourses, and conversations can assist or hinder actors working separately and together to improve food security through policy creation.

When I investigated these unequal assemblages of power through language and discourse, I shaped my study based upon justifications from Dutta, Thaker and Sun's (2014) article on the importance of listening to alternative voices and urging for the use of communication research to enact social change:

In other words, the dominant framework of communication, from its historical roots to its contemporary forms of practices, remains complicit within the dominant structures of corporatization, commoditization, and incorporation of subaltern lives into the market logics of transnational capital, albeit shrouded in the narrative of development. One critical question that needs to be continually foregrounded is whose purpose does communication research serve? (p. 4). Communication research should serve as a bold pathway for transformation between individuals and organizations (Alvesson \& Kärreman, 2011b). Food policy research will encourage scholarly gains in the pursuit of assessing and critiquing food insecurity discourses. Next, I outline how I examined and analyzed multiple and competing food security meanings in a qualitative case study. 


\section{Case Study: Analyzing Food Security Meanings through Qualitative Methods}

For my dissertation, I designed a case study where I analyzed food security discourses that have become increasingly complex across the organization, influencing USAID's conversations with internal and external development stakeholders. I followed the ways USAID strategically developed the Global Food Security Act by analyzing food security d/Discourses through various texts (e.g., government bills, newspaper articles, conference proceedings, policies, blogs, Web sites, etc.), and semi-structured interviews with individuals from USAID and BIFAD (USAID's Board for International Food and Agricultural Development), fluent and familiar with USAID's food security work.

I used case study methods (Creswell, 2013; Stake, 1995) to analyze a case bounded organizationally, by those who worked either for or with USAID and by the passage of the Global Food Security Act (2016). Following Stake's (1995) methodological version of qualitative case study, I defined this case by setting certain boundaries and examined how the case changed over time. Through case studies, researchers can expect to preserve the participants' multiple realities and organizational texts as they become reflected in the data. The researcher may also approach a case from a critical perspective, as I did, and advocate for some issue, cause, or change within a system which I do in chapter 5. I discuss the particulars of this case study in further detail in chapter 3 .

\section{Summary}

Scholars have investigated how the definition of food security has shifted over time, but no one has yet examined the multiple and competing meaning $(s)$ embedded within (or assigned to) discourses of food security as justification for carrying out an 
organizational development agenda (Jarosz, 2009; Maxwell, 1996). Exploring a narrow case using qualitative methods can help scholars investigate questions about a unique instance, or "a specific, complex functioning thing" (Stake, 1995, p. 2). USAID is a complex functioning organization with multiple interorganizational relationships, food security programs, and individuals involved in contributing to the policymaking process. Gaining access to the employees of USAID to talk about food security has required significant time and collaboration. I engaged in triangulation through interviews, document review, and the use of multiple theories to describe, critique, and present new information about how humans make meaning, and in this case, negotiate and develop competing meanings around food security (Creswell, 2013). Case study also allows for researchers to inductively develop an analysis and the methods permitted reflexivity in the form of incorporating personal history, beliefs, and values during the research data collection and write-up process.

I spent my time immersed in researching how multiple and competing food security meanings develop, shaping the international USAID food security agenda. Conversations with individuals from USAID and BIFAD, reading through government policy and organizational documents, and researching theories of language/meaning have given me a sense for how USAID discursively functions. These data collection methods provided insight into the ways that organizational communication research might provide benefits to USAID.

Stake (1995) recommended intensive interviewing and thoughtful observation to complete a successful case study. To fulfill these requirements, I constructed a list of semi-structured questions that guided my conversations about the ways in which 
individuals think "food security" has shaped international development and aid programs at USAID. Case study was particularly suited to my interests in food security and organizational discourses allowing me to collect and analyze documents, like public records, organizational policies, organizational newsletters and memos, as well as spend time observing and interviewing organizational members engaged in social organizational processes, like meetings and conversations. In addition, case studies should be bounded by certain factors such as time, location, and purpose. I provide more details describing the bounded qualities of the case in chapter 3 .

This case study achieved three goals 1) Findings provided evidence that adds to our academic understanding of how organizations and their stakeholders craft and interpret multiple and competing meanings by employing food security discourses; 2) I expect to offer USAID knowledgeable information and feedback about organizational communication and discourse management issues; and 3) This study adds to our practical/scholarly knowledge of how food security discourses shape international organizational policy and development programs. In organizational discourse studies, there is little research explaining and critiquing how stakeholders produce divergent/shared meanings around shared language. Knowing this gap exists, I plan to investigate and assess how USAID communicates about food security with its employees. This issue is critical because of USAID's central role in effectively eliminating hunger and poverty in the contemporary era. Finally, combining theoretical and practical information about how food security discursively happens may help policymakers in the future construct clearer policy language. 


\section{Chapter 2: Review of Literature}

Several areas of academic literature have guided this dissertation project. In this literature review, I discuss the principal concepts and theories I drew upon during the dissertation project data analysis. First, I explain how discussions around what food security is have become increasingly complex for scholars and practitioners. This complexity has been shaped and reshaped over time by scholars who discursively use 'food security' as an umbrella term to resolve complicated local and global challenges ranging from poverty and globalization to international development and the reduction of social and material inequalities. These increasingly complex food security discourses became central to my project as I traced how their divergent meanings have shaped the USAID's, and in turn governmental, food security agenda over time.

Second, I tied food and communication literatures together and then connected these areas to the communicative theory of language convergence/meaning divergence, or LC/MD (Dougherty et al., 2009). I explain the central features of LC/MD and how this theory can tell scholars more about the meanings different stakeholders assign to food security. LC/MD has helped me systematically consider how food security communication, and specifically, how food security D/discourses shape local/international development agendas. I engaged the academic debate of the similarities and differences between organizational communication and organizational discourse in this section. The ways in which I focused in on USAID's organizational discourse/communication has helped me set organize my methodological overview in chapter three. My argument is that specific food security D/discourses inform international development organizations, such as USAID and others, and are typically led 
by stakeholders who are also involved in policymaking. Policies are the formalized communication products that eventually come out of these changing, flexible, and emergent discourses.

These broader areas of literature, including food security discourses, LC/MD, and organizational policy have influenced how I will theoretically and methodologically approach the structure of my dissertation project. In the first part of this chapter, I examine the historical development of the term "food insecurity" and how the changing usage of food insecurity has intersected with public and organizational discourses of hunger.

\section{Intertwining Food Security and Hunger Discourses}

"Food security," and its conceptual meanings, have increased in complexity since the 1960s and diverged significantly from the more widely known, and related, concept of "hunger" (Pinstrup-Andersen, 2009). Over the last half century, scholars have periodically defined and redefined nuances in the meanings, differences, and similarities between food security and hunger. Now, the time is again ripe for considering points of intersection and division between these concepts. Devoting time to the convergences and divergences in meaning between hunger and food insecurity allows me to delve into complexities surrounding "food insecurity" with the participants I will interview and documents I will analyze. A discursive comparison of food security and hunger discourses is particularly timely because the ways in which we conceptualize similar terms have social and material consequences, impacting how we behave and communicate (Dougherty et al., 2009). 
There are three key reasons for delineating distinctions between these concepts and engaging with their discursive richness. First, food insecurity is both a local/transnational problem that requires the communicative collaboration of culturally, economically, and politically diverse groups (Gottlieb \& Joshi, 2010). Although conceptual divergence means that perfect agreement on food security issues remains unlikely, multiple stakeholders should continue communicating together as economic, political and social conditions constantly shift across time and space (Booth, 2014). Communicative interactions can guide individuals towards organized, communityappropriate solutions, such as policy change for problems like local food insecurity and hunger (Resnick, Babu, Haggblade, Hendriks, \& Mather, 2015). By conducting a case study, I confronted the social contexts and consequences of food security policy. Analyzing the meanings behind food security discourses offers scholars and practitioners a deeper understanding and critique of the ways organizational discourses influence social/material conditions around the world.

Second, international governments recently passed a landmark year by which they had promised to reduce hunger worldwide. The Committee on World Food Security (2001) composed the following goal at the 1996 World Food Summit. According to the influential United Nations Food and Agricultural Organization, an entity that specializes in food security research:

The 1996 World Food Summit (WFS), attended by 185 countries plus the European Community, pledged to achieve a measurable and monitorable goal “... to eradicate hunger in all countries, with an immediate view to reducing the number of undernourished people to half their present level no later than 2015." 
(para. 1)

Unfortunately, the 185 countries did not reach their collective goal. While countries with food security-focused organizations and programs have made progress towards reducing worldwide hunger and undernourishment, there is still significant work to do if the goal is to be approached or accomplished. Future opportunities include addressing how renewed efforts to reduce hunger and food insecurity will successfully coincide with a rising global population, diminishing soil quality, and increasing population movement from rural to urban areas (Satterthwaite, McGranahan, \& Tacoli, 2010). While the World Food Summit goal could not be achieved by 2015, the UN's Sustainable Development Goals have replaced the former food security goals. 'Zero Hunger,' a global initiative to manage food insecurity, has been prioritized by international governments and is a material/discursive concept around which these governments can (re)organize. Because poverty, hunger and food insecurity remain intertwined, reducing all three shall require a social paradigm shift towards a critical discourse about the ethics of our global food system (e.g., human health and suffering, environmental sustainability, and animal health) (Singer \& Mason, 2006).

The third reason for examining food insecurity and hunger meanings/discourses is that the World Food Price crisis (2007-2009) and Great Recession (2008-2010) have revealed a shift in the way people experience food insecurity (Dougherty, Schraedley, Gist, \& Wickert, 2014). From 2007 to 2010, global food prices increased (especially cereal and grain prices). Droughts, famine, and war brought instability to developing nations and unemployment rose significantly (Mittal, 2009). Subsequently, food insecurity struck new groups of individuals and afflicted other populations more severely. 
Many nations, including the US through development-focused organizations like USAID, have started to change how they address shifting food security challenges. Other economically disadvantaged nations continue to battle even harsher forms of food insecurity and hunger (Thurow, 2012). With the knowledge that material food security realities and food security discourses are changing, scholars must work towards new solutions for the unknown and inevitable disasters that lie in our future.

\section{Tracing the historical usage and contested meanings of food security.}

International organizations and governments have agreed upon the following definition of food security: the "access to - and availability, utilization, and stability ofsufficient food to meet caloric and nutritional needs for an active and healthy life" (USAID, 2016). The four pillars of food security, as overviewed in chapter 1, have become the foundation upon which the US and international organizations build food security programming and policy. Food accessibility refers to the economic affordability and individuals' ability to physically access food. For example, the shifting dynamics of economic markets and rising/falling food prices influence household expenditures on food. Food availability refers to the physical supply of food, stock levels, and global trade. Food utilization refers to how the human body absorbs micro and macronutrients, turning them into usable calories. The final dimension, stability, takes into account how (in)stable the other three dimensions remain over time. Factors like weather disasters, political corruption, unemployment, and rising food prices all impact food stability.

Despite the seemingly straightforward nature of the food security pillars summarized in this conceptual definition, the term and its meanings have actually been a site of intense contestation and increasing complexity over the last five decades 
(Maxwell, 1996). Starting in the 1960s, international development organizations began using "food security" to debate how national food needs could be met consistently (Anderson \& Cook, 1999). Then in 1974, the World Food Conference delegates met to discuss pressing issues including worldwide food supplies, the rapidly growing population, and the ways in which poverty would impact food supply and demand. This World Food Conference led to an increased usage of "food security" with consistent references in policy language and media reports to stable food prices and an adequate supply of food for all.

Throughout the late 1960s and into the 1970s, scientists and government leaders hailed the success of the Green Revolution, a time when the introduction of pesticides, fertilizers, and high-yielding varieties of seeds greatly increased worldwide agricultural output. However, international researchers at the UN and its newly established financial branch, the International Fund for Agricultural Development (IFAD), noticed that an increase in the national food stocks of developing countries did not necessarily mean individuals had better access to food (Anderson \& Cook, 1999). Government leaders, scientists, and others expressed concern when they recognized a significant gap between nations having enough stored food and having the means to distribute that food to people in need.

In the 1980s, "food security" shifted and expanded in two fundamental ways. First, the operational definition of food security became more complex as researchers created indicators to measure not only individual and household food (in)security but also food security on a macro scale. Government researchers and scientists already knew the importance of measuring individual and household levels of food security, but they also 
realized that measuring national and international levels of food security might lead to new understandings and interpretations of how populations would struggle differently with local food issues (Knezevic, Hunter, Watt, Williams, \& Anderson, 2014).

Second, researchers assigned both a broader and deeper meaning to food security. Previously, researchers had primarily thought of food security as a "food first" issue, meaning organizations concentrated on providing food temporarily to populations in need (because of disasters, drought, war, famine, etc.). Eventually, researchers changed their viewpoint from thinking about food security as a "food first" issue to viewing food security as a national "livelihood" issue (Anderson \& Cook, 1999). The material/discursive shift constructing food security as a "livelihood" issue meant something new. This new meaning indicated that governmental figures and researchers recognized that merely keeping their populations from starving would not improve their nation's other connected systems (education, health, economic, and political). These networked systems, when functioning healthily and together, contribute to an overall higher quality of living. Governments acknowledged they would need to invest in regular, nutritional support of their populations through several avenues such as agricultural policy changes, community education, research and development, and other tactics. Around the same time, researchers added the "stability" pillar to the overall food security concept (refer back to the four pillars—access, availability, utilization, and stability). Governments around the world began prioritizing the creation of nutritious, adequate and accessible food across time.

In the 1990s, the overall measurability of food security as a variable became even more complex (Maxwell, 1996). Measurements of food (in)security had previously 
emphasized quantitative calculations that took into account food prices, amounts of food available (especially, grain stores), and the purchasing power of local economies. However, in order for scholars to better understand the experience of food insecurity for those suffering from malnutrition and hunger, governments began adding qualitative indicators and questions to their surveys. For example, research surveys asked individuals about the perceived quality of their food and how they felt about obtaining their food (ex., feelings of anxiety or uncertainty about where their food would come from).

Since the 2000s, national and international discussions about food security have turned towards discourses of developing community food security. These communityfocused discourses have centered on themes like localizing food production (smaller, local farms) and increasing the number of local farmers markets (Knezevic et. al, 2014). Privileging discourses that focus on "local" and "community" food (including farms, markets and distributors) means more individuals appear to be expressing an interest in the production, selling, and preparation of their food (Lyons, 2014). This movement towards building strong, food secure communities has put localized institutions, like food banks, churches, and not-for-profits in charge of feeding vulnerable and marginalized populations such as immigrants, refugees, the developmentally disabled, and veterans (Alkon \& Agyeman, 2011).

Other scholars have traced food security discourses according to their scale (Jarosz, 2011) and breadth (Maxwell, 1996). These researchers followed food security discourses through international organizations, like the United Nations, and individual case study reports. While these scholars and others (Shaw, 2007) have recorded the hundreds of evolving and changing definitions of food security, I argue policymakers, 
organizations, and individuals would benefit from a discourse tracing project tracking how food security discourses have shaped the changing United States governmental food security agenda. A project following these discourses could prove particularly useful as the US federal government manages a transition from former president Barack Obama to current President Donald Trump and his staff.

Because I examined food security discourses from a US-centric perspective, albeit one connected to international aid and development, the United States Agency for International Development made sense as a starting point for investigating interorganizational food security discourses. For example, USAID's mission and values state that food security can be achieved through a combination of food security policy, agricultural programming, and research. On the USAID's "Mission, Vision, and Values" webpage (2016), the organization describes how democratic nations, like the US, can offer solutions to societies marked by poverty, hunger, and non-democratic forms of government: "Resilient, democratic societies feature broadbased economic growth; healthy, well-nourished, and educated populations; and environmental sustainability...These societies are equipped to ensure that pathways out of poverty are sustained" (para. 3). This value statement propagates the idea that US partnerships (particularly between government and business) have successfully delivered a better life to individuals living within a democracy. Further down on the same webpage, USAID provides a sweeping overview of how the organization's initiatives (including food security and international development) lead to material security and safety:

USAID's efforts directly enhance American—and global—security and prosperity. The United States is safer and stronger when fewer people face 
destitution, when our trading partners are flourishing, when nations around the world can withstand crisis, and when societies are freer, more democratic, and more inclusive, protecting the basic rights and human dignity of all citizens (para. $5)$.

USAID's discursive promise that improved, global security and safety can be achievedat least in part through food security—has me interested in examining how shared and diverging discourses fulfill these goals. Through the project, I expect to closely analyze various levels of discourse (Alvesson \& Kärreman, 2000a) and the meanings embedded within food security.

\section{Comparing "food security" discourses to "hunger" discourses.}

In the section above, I detailed the four dimensions of food security (access, availability, utilization, and stability), as well as the ways this concept has become more complex over time. Food insecurity and hunger do share overlapping characteristics, but they should not be confused with one another. It is important for readers of this chapter to understand that international organizations have, for the most part, agreed that food (in)security is a measurable condition, while hunger cannot yet be consistently measured and evaluated. However, outside of the government and organizational populations that discuss food security regularly, much of the broader public is unfamiliar with the deepening intricacies of food security, including its definition and dimensions. Hunger, on the other hand, is an affective condition lay audiences are familiar with discussing and/or experiencing, yet many organizations have trouble measuring hunger as a reliable scientific variable. 
Hunger has been equated more with a feeling or prolonged state of food insecurity. In fact, the FAO defines chronic hunger and undernourishment synonymously: "Undernourishment means that a person is not able to acquire enough food to meet the daily minimum dietary energy requirements, over a period of one year.” (The State of Food Security in the World, 2015, para. 1). Chronic hunger signals only two of the four food security dimensions: access and utilization, or how a person is able to acquire food and how that person's body is able to use the calories and nutrients from food. Similarly, the World Food Programme (WFP) — another UN organization responsible for distributing food during crises and disasters - hints at a relationship between hunger and malnutrition without providing a direct definition of hunger: "Eradicating hunger and malnutrition is one of the great challenges of our time. Not only do the consequences of not enough - or the wrong - food cause suffering and poor health, they also slow progress in many other areas of development..." (Zero Hunger, 2017, para. 2). Again, the organization places hunger and malnutrition side by side to provide a more detailed context for readers who might not understand the effects of long-term hunger.

USAID broadly defines food security using the dimensions I have already outlined, situating hunger within food security:

Food security means [bolded emphasis in original text] having, at all times, both physical and economic access to sufficient food to meet dietary needs for a productive and healthy life. A family is food secure when its members do not live in hunger or fear of hunger. Food insecurity is often rooted in poverty and has long-term impacts on the ability of families, communities and countries to develop. Prolonged undernourishment stunts growth, slows cognitive 
development and increases susceptibility to illness. (Feed the Future, 2017, para. 3)

The first part of the description overlaps with other international organizations (FAO and WFP) with the reference to food access and availability. The second sentence closely ties food security to the social relationships (family) that can help prevent hunger. USAID does not directly communicate the definition of hunger, using a similar associative strategy that WFP used in relating hunger to malnutrition. Then, USAID addresses some of the causes of hunger (poverty) and effects (development of social communities as well as the stunting of human growth). While these definitions typically reference the individual or family food security experience, I will extend the research by focusing on how large "Discourses" and small "discourses" related to multiple and competing food security meanings shape USAID's organizational development agenda (Alvesson \& Kärreman, 2000a).

Perhaps because hunger can wildly range from a light yet distracting pang in one's stomach before lunch to the direct cause of death from malnutrition, it remains an elusive concept compared to the complex but more easily measurable dimensions of food security. Despite the indefinable nature of hunger, both food insecurity and hunger are inexorably intertwined, materially and discursively, as I have shown, by directing attention to the ways organizations, like USAID, approach these difficult concepts. Examined together, the discursive and material relationship between hunger and food insecurity sets certain standards for organizations creating policies that bridge disparate interests of those in agriculture, government, law, trade, and community development. Throughout the analysis, I referred to these discourses of hunger and food insecurity. The 
discursive intersection and complexity between hunger and food security played key roles in interorganizational policy construction. I argue that this relationship matters for the individuals who drawing upon both little "d" and big "D" discourses of food insecurity and hunger.

Moving from the discourses of food security and hunger to the ways that discursive meanings can converge and diverge, I emphasize that texts, messaging, conversations and cultural discourses shape our day-to-day lives. In this second section of the chapter, I first provide reasons for investigating food security through communication. Then I weave together literatures on the language convergence/meaning divergence theory and organizational discourse, helping my readers understand the importance and timeliness of a dissertation project that analyzes converging/diverging food security meanings and how those meanings may ultimately lead to different policy outcomes.

\section{Linking Food and Communication}

Many scholars consider "food studies" an important area for renewed investigation because there exists a multitude of possibilities for explanation and criticism of how, what, why, where, and when we eat (Albala, Belasco, Bentley, Heldke, $\&$ McIntosh, 2017). Food, including material food products and the ways in which we discursively organize around food, impacts nearly every facet of human life (Belasco, 2008). Communication scholars tell us that food says much about our identities, our history, our organizational systems, our values and beliefs (Cramer, Greene, \& Walters, 2011). Food is essentially the material outcome of individuals organizing around shared 
and conflicting goals, and food and communication become intertwined in the contexts of food security and food policy.

As an organizational communication scholar, I argue food and communication must be brought together to better understand and offer critiques of how humans organize around food security discourses. My dissertation focuses on these intersections through a case study analyzing organizational texts and social practices, particularly those practices that inform food security development funding and policymaking. The intersections linking food and communication have only recently received attention as a legitimate area of concern by organizational scholars (Cramer, et. al, 2011; Dougherty, 2011). Before the turn of the century, food organizations often represented merely interesting research sites for organizational communication studies (see Dutta, Anaele, \& Jones, 2013; LeGreco, 2012; Lynch, 2009; Ulmer \& Sellnow, 2000 for examples).

While organizational food sites have undoubtedly enhanced communication scholars' understanding of organizational and management practices, scholars have not yet centered on food organizing processes to more deeply comprehend interactions between humans and their food sources (Broad, 2016). Instead of focusing on just a single food organization, food organizing includes the discursive processes and patterns that constitute social interactions and allowing individuals to organize, work together, and accomplish goals. These practices could include communicative processes such as policymaking or conversational interactions (Cooren, 2004). Part of any discussion involving an in-depth analysis of social relationships and organizing occurs must also include a nod to "power" and how power functions through communication (Mumby, 1998). Food studies, and more specifically, food security studies, rely upon 
organizational power to create change. Food security studies inherently include unavoidable issues involving systems of power, such as hunger, poverty, and gender inequality, that require interdisciplinary solutions. As an example of how food and discourse come together, powerful actors, like wealthy national governments or influential international organizations, may lobby for certain food policies but also unintentionally marginalize agricultural laborers and their families (Holmes, 2013). In sum, there are material consequences to the ways that competing meanings around food security become manifest in policy and political action.

Dougherty (2011) has posited that power functions like a web, where different 'strands' of social life (race, age, ability, sexuality, etc.) communicatively constrain individuals in specific ways, similar to the stickiness of a spider's web. Furthermore, critical organizational structures are communicated in ways described by Deleuze and Guattari's "rhizome" (1987). In other words, power is analogous to a rhizome. A rhizomatic structure might bring to mind metaphors such as grass or bamboo, plants with roots shooting off and up in multiple ways and directions, much in the way that multiple and competing discursive meanings develop over time. The landscape of communication is rich in expression and meaning because assemblages of power (Ogden, 2011) come together at certain points (in space and time) but then quickly dissolve. By approaching organizational discourses and power through the lens of rhizomatic and web-like structures, I was able to tease out multiple and competing food security meanings. Next, I introduce the theoretical approach that guided how I analyzed and organized food security discourses: Language Convergence/Meaning Divergence. 


\section{Language convergence/meaning divergence: A communicative lens of food} security.

In order to better understand how humans organize around food security issues, I used Dougherty et al.'s (2009) Language Convergence/Meaning Divergence theory. This theory helps researchers examine how meaning systems are created through communicative processes. Because I am interested in analyzing how food security discourses converge and diverge among people and between organizations, LC/MD was a useful framework for guiding this investigation. Importantly, LC/MD "highlights contexts in which meaning can diverge while maintaining an illusion of convergence" (Dixon \& Dougherty, 2014, p. 3). I discuss the illusion of convergence, or a seemingly mutual understanding of discursive meanings, more in chapters 4 and 5 . There are three primary theoretical components to understand LC/MD: 1) Language convergence means that common labels are used to facilitate meaning-making between individuals, 2) Meaning divergence happens when people use the same labels to identify differing meanings, and 3) Combining language convergence and meaning divergence can function as an illusion of shared meaning.

Evidence from other researchers suggests "food security" has had significantly divergent meanings across time and space (Jarosz, 2011; Maxwell, 1996). LC/MD helped me unpack the complex contextual issues that shape food security's divergent meanings. Further, Dougherty et al. (2009) argue that researchers should identify the processes by which meaning differences emerge and the ways these differences could be obscured in interaction (p. 22). First, this study offered a new interpretation of how food security discourses have been connected to US international development aid. Second, USAID 
organizational members have suggested that a study broadly identifying how discourses shape or influence the US government's food security agenda would be particularly valuable (Raquel Gomes and Emily Wann, personal communication, 2017).

Dougherty et al. (2009) proposed expanding LC/MD by creating a call for new studies that would "Explore the ways in which various contexts influence LC/MD, the ways in which meaning divergence can be recognized, the ways in which an illusion of agreement is created, and the ways in which common language and meaning can be crafted" (p. 43). Using LC/MD, I explored how political, economic, and cultural contexts influenced the ways food security meanings converged and diverged, and how agreement on the meanings behind food security created an illusion of agreement between organizations and individuals and the goals they set to minimize food insecurity. Additionally, I propose recommendations for opening up discourse about food security in order to help organizations craft clearer messages which would accomplish their expressed goals. As a result of this study, I developed some discursive strategies to help USAID and their affiliated food security organizational collaborators. By examining how food security discourses shifted as a result of GFSA's passage, I found that these organizational discourses also impact different stakeholders involved in mitigating global food insecurity. These stakeholders included government organizations, non-for-profit organizations, community groups, individuals, corporations, lobbying organizations, nongovernmental organizations, and others.

Dougherty, Mobley, and Smith (2010) anticipated that LC/MD would become increasingly useful for examining diverse intercultural contexts. Their proposition also fit the scope of this study. Food security organizational texts, like US governmental policies, 
must include language that speaks to individuals with different experiences and understandings of shared concepts such as hunger and food insecurity. The discursive spread of these concepts through translation and mediated channels (including the Internet) provides opportunities for multiple and competing meanings to emerge, miscommunication, misunderstanding, and silencing. With LC/MD as a lens, my analysis interpreted scenarios where organizational power and language intersected, which closed off opportunities for unifying what Dougherty et al. (2010) referred to as the "languagemeaning-culture relationship" in intercultural interactions (p. 184). Below, I describe how LC/MD theory functions, identifying areas where I offer theoretical extensions.

\section{How LC/MD functions.}

Dougherty et al. (2010) established a theoretical grounding for LC/MD: the theory derives from an understanding that communication involves symbols that people typically rely upon to communicate with each other, share meaning, manage relationships, and more. Communicating through symbols and striving for shared meaning is equivalent to 'language convergence.' In other words, language converges around individuals' shared meanings (p. 171), and a shared language offers individuals a communication shortcut to mutual understanding. On the other hand, the meanings within shared symbols can also diverge. The sharing and divergence of meaning can be analyzed by qualitative researchers in two ways: through meaning clusters and meaning fragments.

Meaning clusters and fragments are related. Meaning clusters allow researchers to simultaneously examine how individuals construct similar and different meanings around the same word, phrase, or concept. Meaning clusters are constituted by meaning fragments: the smaller, individual units of meaning individuals draw upon to make sense 
of the world. I will use "hunger" as an example because earlier I explained discourses associated with hunger. "Hunger" functions as a meaning fragment when different individuals use the word hunger in day-to-day talk to express different experiences. For instance, I might skip breakfast and later around lunchtime, exclaim to an office colleague "Wow, I'm hungry!" This type of hunger and the meaning embedded within this fragment will be qualitatively different than another's meaning and use of the same language. A man wandering up and down the median of a highway with a cardboard sign written with, "I'm hungry" is sure to mean something distinct from my same lunchtime exclamation.

The final thing to understand about this theory is how the illusion of shared meaning develops out of meaning clusters and fragments. Meanings can converge and diverge in varying ways. Individuals can continue to use the same language while divergent meanings can expand, go unnoticed, or remain unchallenged. Figure 1 represents how meaning clusters can be completely divergent. This means common language is used in reference to totally separate meaning clusters (Dougherty et al., 2010, 
p. 174). In this case, individuals share almost no meaning fragments and have perhaps very few shared or similar life experiences.
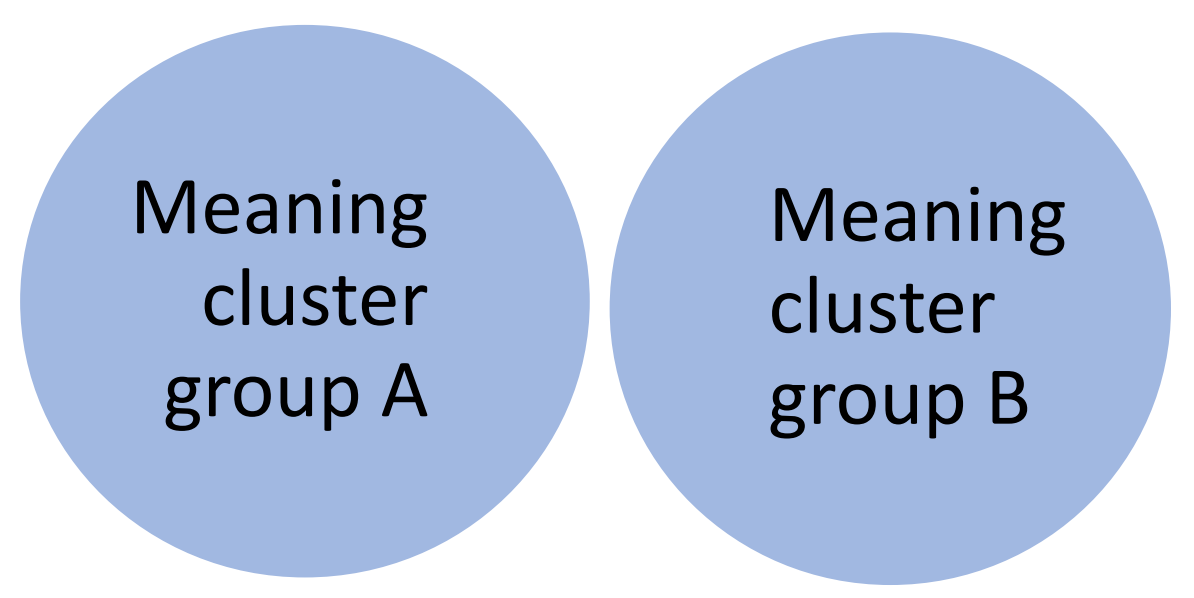

Figure 1. Total meaning divergence.

The meaning clusters in figure 1 represent total meaning divergence. Figure 2 represents how meaning clusters overlap and penetrate each other. Figure 2 also shows that when meaning clusters overlap, there is significant shared meaning and very little divergence. Instances of meaning divergence that are subtler might go undetected for longer than more noticeable instances of meaning divergence. 


\section{Mearing Meaning cluster cluster group A group B}

Figure 2. Subtle cluster divergence.

The component I find most interesting about LC/MD in relation to this project is the way meaning is placed at the center of the theoretical process. By examining how individuals communicatively construct different meanings while using the same language, I explain how organizational values become central to the meaning-making process (p. 183).

My dissertation project leads to deeper theoretical development and extension of LC/MD. My project contributes to the theory in four key ways. First, Dougherty et al. (2010) examined how language converges, but also noted that language diverges and meaning converges around the same language. I captured how meaning unfolded as I analyzed food security discourses in organizational texts and interview dialogues.

Second, LC/MD can show scholars the ways in which meanings can not only expand but also contract. By unpacking competing and multiple food security meanings, as well as how these discourses become tied to government development aid, I created new spaces for increased discursive understanding. Dougherty et al. (2010) coupled linguistic and meaning convergence with people's sense of cultural security. Cultural security can be disrupted when "othering" happens. Othering, Dougherty et al. noted, has been addressed 
in intercultural and feminist literatures (e.g., P.H. Collins, 2000; hooks, 1981), and "appears to be a highly developed tendency to construct others in negative ways" (p. 175). As cultures meld and clash during US-driven food security programs, othering may become an important component of food security discourse divergence. The more that food security meanings diverge over time, I may find that discursive othering also happens in that process. The third way I extend LC/MD's usefulness is by applying the theory as a unifying framework - linking food and communication to bring greater security to all — to understand and analyze interorganizational relationships. Finally, Dougherty et al. suggested exploring new possibilities for LC/MD: the use of this theory in a food security setting impacts how competing meanings can be discursively managed.

Central to comprehending the importance of LC/MD to this project is an overview of discourse. LC/MD and discourse tracing methods (LeGreco \& Tracy, 2009) together give scholars a fresh way of analyzing different levels of D/discourse in society. The scholars working with discourse have spent years debating how organizational and individual discourse shape meaning and materiality. The following section introduces organizational discourse debates and themes that tie the language and meaning components of LC/MD to my project.

\section{What is $d / D i s c o u r s e$.}

Many scholars (see Clegg, 1989; Deetz, 1992; Potter \& Wetherell, 1987 for examples) over the past thirty years have used linguistics methods and discourse analyses to examine the crucial ways in which language functions in organizing. Other scholars (Alvesson \& Kärreman, 2000a; Hardy, Grant, Oswick, \& Putnam, 2005; and Mumby, 2011) have argued for specifying what "discourse" actually represents and how (and if?) 
discourses can be rigorously studied. I point to some of the key themes in these debates around discursive organizing vs. communicative organizing as well as Alvesson and Kärreman's (2011b) advice for analyzing discourse in future studies.

Alvesson and Kärreman (2000a) have pointed out that "discourse" can frustratingly mean nearly everything and nothing: "the word discourse has no agreedupon definition, and confusingly many uses" (p. 1127). To help scholars break down the vagueness of discourse, Alvesson and Kärreman developed a framework of the practical, core dimensions of discourse to show the range of how meaning gets tied to discourse. In addition, Alvesson and Kärreman delineated four levels of discourse, which I used to research food security meanings. The core dimensions that explain the relationship between discourse and meaning include a range from "transient discourse" to "durable discourse.” By transient, Alvesson and Kärreman meant discourse "emerging from specific interaction, and durable meaning, existing so to speak 'beyond' specific linguistic interaction, in a more or less inert and stable manner" (p. 1130). This range of discourses complements my interest in looking at how the multiple meanings of food security become shaped and increasingly complex over time. One can think of discourse that functions and happens across a spectrum: from the micro, small d "discourse" levels at one end through the macro, large D "Discourse" levels at another end.

Little "d" discourse operates under the following assumptions: 1) Language is used for a variety of functions and has a variety of consequences; 2) Language is both constructed and constructive; 3) The same phenomenon can be described in several different ways; 4) Consequently there will be considerable variations in the accounts of it; 5) There is no foolproof way yet of handling these variations or of distinguishing 
accounts that are 'literal' or 'accurate' from those which are rhetorical and incorrect, thus avoiding the problem of variation that faces researchers working with a more 'realistic' language model' 6) The constructive and flexible ways in which language is used should themselves be a central subject of study (Alvesson and Kärreman, 2011b, p. 1127). In sum, examining small "d" discourses means "the study of talk and text in social practices" (Fairhurst, 2007, p. 6). On the other side of the spectrum, big "D" Discourses operate through the "power and knowledge relations [that] are established... by constellations of talk patterns, ideas, logics, and assumptions that constitute objects and subjects" (Fairhurst, 2007, p. 7). Essentially "discourse" can do many things across a broad spectrum.

To give my readers a sense for what discourse can do, Alvesson and Kärreman (2011b, pp. 1140-1141) have created a list of discourse's effects and functions:

- Discourse is ephemeral talk - language use has no significant constitutive agency, apart from communicating transient meaning;

- Discourse varnishes - the discourse is a minor, final moment of naming something that makes a certain difference in terms of attention-shaping, agendasetting and sometimes action-implying;

- Discourse gestures - something out there is placed in a new context and, as figure forms ground, meaning is revised and subjectivity affected;

- Discourse connects - discourse provides terminals for avenues of meanings, thus making it possible to connect social elements; 
- Discourse instructs - discourse provides templates for action, with actual agency residing outside discourse (c.f. the relationship between recipes and actual dishes);

- Discourse frames - something is preformed, or via discourse, this something gets its shape;

- Discourse produces - discourse provides most of the constitutive agency in recreating social reality;

- Discourse creates - discourse provides (almost) all the constitutive agency in creating changes in social reality

By knowing the functions of d/Discourse, I have the option to approach discourse(s) from varying levels: 1) micro-discourse approach - social texts, micro-contexts; person-toperson conversations; 2) meso-discourse - finding broader patterns going beyond the details of a certain text; 3) Grand Discourse - an assembly of discourses; referring to organizational culture or ideology; 4) Mega-Discourse - universal connection of discourse material; standardized way of referring to a certain phenomenon (Alvesson \& Kärreman, 2000a, pp. 1133-1134). I found food security meanings being constructed and negotiated at primarily the micro-discourse level and the Grand/Mega Discourse level. Micro-discourses were drawn from interviews and conversations where I probed participants for the meaning(s) they ascribed to "food security." Meso-discourses were pulled from organizational policy texts and conference proceedings. Grand and MegaDiscourses became clearer as I gathered micro-discourses together into meaning clusters which explained how the USAID's employees and their many stakeholders used food security meanings in multiple and competing ways. 
Scholars do not need to focus on only one end of the d/Discourse spectrum. In fact, Jian et al. (2008) point out that researchers should investigate the interplay between small $d$ iscourses and larger $D$ iscourses. When I began this study, I was particularly interested in the interplay between d/Discourses. For example, Jian et al. imagined researchers examining the ways " $D$ iscourses take effect through talk-in-interaction and how discourses enable a space of action for self-positioning, subversion, change, and resistance against such Discourses" (p. 306). Although my findings start the process of unpacking how Discourses take effect through talk-in-interaction, there is room for analysis of how discourses enable spaces of action for subversion, change, and resistance. I expect to continue researching $\mathrm{d} /$ Discourse interplay in these ways. The interplay between different levels of d/Discourse should become more concrete as I place different renderings of meaning associated with food security side by side for future research manuscripts.

The final piece to address in this section on organizational discourses is the relationship between discourse and communication. From a metatheoretical review on the relationship between organizational discourse and communication, four perspectives emerged: 1) D/discourse as the resources for communication; 2) Discourse as operating through communication; 3) discourse as one of the many elements of communication; and 4) discourse and communication as synonymous (Jian et al, 2008, p. 310). For this study, I primarily followed the first perspective where both Discourses and discourses were viewed as resources for communication: they are the "building blocks or resources that enable and constitute communication as a social process of meaning construction and maintenance" (p. 310). The dynamic interactions that get created by humans through text 
and talk create also openings for multiple and new meanings as well as spaces of contestation for divergent meanings.

In chapter three, I descriptively recount the methods I used for a qualitative case study project (Stake, 1995). Stake, a social science expert in qualitative case studies (1995) asserted that the best research questions often evolve over the course of the research (p. 33). Keeping this assertion in mind, the following research questions guided my data collection and analysis:

RQ1: How do the meanings people attribute to food security converge? RQ1a: How do the meanings people attribute to food security diverge?

RQ2: What food security meanings shape the USAID international food security agenda?

RQ2a: How do food security meanings shape the USAID international food security agenda? 


\section{Chapter 3: Methods}

In this section, I introduce case study, the qualitative methodology (Creswell, 2013; Stake, 1995; Yin, 2009) guiding my data collection and analysis. Following a case study framework helped me determine the most relevant texts to examine and choose effective individuals for interviews. First, I justify why I chose to conduct a case studyan appropriate methodology for this type of dissertation project where I examined the multiple and competing meanings that developed out of organizational food security policies and interviews. The case study methodology served two explorative purposes: 1) to construct a historical and contextual report that will assist others in understanding the organizational and linguistic features of the case; and 2) case study helped me interpret the structuring of discourse and meaning systems employed by professionals who collaborated on US food security policymaking. Then, I discuss the data collection procedures and techniques used that prepared me for the dissertation analysis. Finally, I explain the steps I followed to analyze the collected qualitative data.

\section{Methodology}

I conducted a case study examining the United States Agency for International Development's communication and interorganizational collaboration on the Global Food Security Act (2016). Creswell (2013), a sociology professor and expert in a variety of qualitative methodologies, provides a clear overview of the central components that make case study unique from other qualitative methodologies. Case study is:

... a qualitative approach in which the investigator explores a real-life, contemporary bounded system (a case) ... over time, through detailed in-depth data collection involving multiple sources of information (e.g., observations, 
interviews, audiovisual material, and documents and reports) and reports a case description and case themes. (p. 97)

Stake (1995), another expert in qualitative case study and an emeritus professor of education, does not consider case study a methodology but instead he argues that employing case study methods requires the researcher to make a strategic choice about what should be studied. However, Yin (2009) and Merriam (2009), two case study scholars, argue that case studies can refer both to the unit of study, the case, and the product, or outcome/report, of a scholarly investigation (p. 40). Creswell (2013) has described case study's rich historical tradition that crosses several scientific disciplines including psychology, medicine, law, and political science. Overall, scholars have approached case study data collection through various means: these different approaches have led to many interpretations of how case study research should be conducted. For this case, I integrate the case study practices that have been systematically described and used by other social scientists, leaning most heavily upon Stake's (1995) qualitative data collection and analysis procedures. I explain the central characteristics of Stake's case study procedures below.

Primarily, case study has a few unique characteristics, separating it from other qualitative methodologies. Some of these characteristics are recognizable across researchers and disciplines while other facets have differed from researcher to researcher. The first characteristic relates to narrowing down the type of case. Stake (1995) urged researchers to focus on the type of case under investigation. The types of cases include 1) Intrinsic cases: where the researcher studies a particular case, not a general problem or to learn about general cases 2) Instrumental cases: where the researcher seeks a general 
understanding through the study of a particular case and 3) Collective cases: where the researcher studies the effects of issues/policies/etc. on several cases, typically designed with the goal of representation. For this project, I determined that the case under study fits best within the "instrumental" category. I developed a general understanding of the ways interorganizational actors associated with USAID used multiple and competing food security meanings to create the Global Food Security Act.

The second important characteristic for Stake and other qualitative case study researchers is that a case must be defined as a bounded system (Merriam, 2009). A case's boundedness might be determined partially by the researcher and partially through uncontrollable, external factors (geographic boundaries, time, individuals willing to participate in the research, etc.). The bounded features of this case include: 1) the participants interviewed 2) the organizations involved in constituting the GFSA and 3) the GFSA policy, linking both participants and organizations. The participants I interviewed had to be tied to USAID and associated with some aspect of the Global Food Security Act. For example, ten of the 24 participants worked or had worked for USAID in a food security-related capacity. Four other participants included the members of BIFAD, the Board for International Food and Agricultural Development. BIFAD worked directly with USAID staff on the Global Food Security Act and the board acted as an intermediary body between university agricultural research and the government. Other participants who worked with USAID on the GFSA held positions at NGOs; with legislators; and at universities. I return to an explanation in the findings of chapter four detailing the interorganizational relationships and collaboration on the construction of the GFSA. 
Through a case study investigation, I achieved a richer understanding of the ways in which multiple meanings of food security constituted the GFSA (Merriam, 2009). In addition, explaining the historical events contextualizing the passage of the GFSA provided a foundation for comprehending how food security meanings have multiplied and become more complex. By integrating LC/MD with other communication theories, like sensemaking and strategic ambiguity, I challenge previous interpretations of the ways interorganizational members use persuasive language to construct policy.

Third, by conducting a case study, I uncovered "the interaction of significant factors characteristic of the phenomenon" related to the structure of policy discourses and food security meaning-making (Merriam, p. 43). Through an in-depth investigation of the discursive interplay at various levels, I uncovered how USAID members and their interorganizational stakeholders contributed to the construction of multiple and competing meanings. The interpretive and/or critical conclusions gained from case studies are referred to as "assertions" by (Stake, 1995) or a building of "patterns" or “explanations" by Yin (2009). These assertions and explanations are included in the findings of chapter four.

Fourth, Creswell (2013) and others argue that a good case study involves rich description and an in-depth understanding of a specific case. The researcher can accomplish both description and understanding by including "as many variables as possible" to "portray their interaction, often over a period of time" (Merriam, 2009, p. 13). In the analysis and discussion sections of this dissertation, I incorporate rich description and evidence of a thorough understanding of the case in the following ways: by including excerpts from interviews, synthesizing organizational texts, describing 
observations, and triangulating theoretical perspectives (LC/MD, sensemaking, strategic ambiguity) to inform the findings. The data collection process lasted about nine months. Over that time period, I brought together data sources, reflected upon the language connecting USAID and interorganizational food security professionals, and interrogated the communicative processes behind emergent meanings in food security conversations and texts.

These four characteristics set case study apart from other qualitative methodologies like narrative grounded theory, narrative, or phenomenology. Case study also offers several benefits and some limitations to qualitative researchers. Speaking first to the benefits of case study, this methodology allows for an inductive exploration of a specific case. Inductive exploration means that the goal of the research should not center on predicting behavior or generalizing outcomes. Instead, I looked at the different ways food security meanings were discursively constructed by interorganizational members who worked with USAID and on the Global Food Security Act. A second benefit to case study report is that I can incorporate several types of analysis in the final dissertation report. Contextual information, such as organizational charts, timelines, policy history, and organizational descriptions, gives readers a deeper understanding of the case. This kind of contextual information allowed me to present a "holistic account" (Merriam, 2009, p. 51) of multiple and overlapping food security meanings. A final reason why conducting a case study appealed to me was that the dissertation provided several opportunities to 1) write in a layered and descriptive way about the case's results and 2) elaborate upon the process of research as it unfolded, giving readers a detailed portrait of how food security meanings have changed. 
Despite the many strengths of this research method, I prepared myself for the limitations of case study. Considering limitations ahead of time as part of the dissertation prospectus did prepare me for the challenges associated with this project. Merriam (2009) discussed certain difficulties that tend to coincide with a researcher's ability to provide a rich, thick description and analysis. Two of the roadblocks Merriam discussed were time and money. During data collection and analysis, I have kept in mind that dissertations should be completed within an appropriate timeline. The timeline allotted for completion of my data collection and analysis has been bounded by competing schedules (i.e., myself, my partner, my committee members, the Department of Communication faculty, my immediate family members, the family members of my committee, the study participants, the participants' families, etc.). Furthermore, I had to devote sufficient time to researching without allowing the data collection and analysis processes to extend indefinitely. For the case to be completed, I had to stop interviewing interorganizational participants at some point. This point came in December 2017 when I noticed I was hearing familiar and similar responses across the final four interviews. December 2017 also happened to be a good time to stop interviewing because many of my participants had shifted their attention away from the construction of the GFSA and had started working on reauthorizing the GFSA. Participants were focused on constructing and writing the GFSA between 2015 and 2016. Once the bill passed, the legislators and USAID members began implementing the Global Food Security Strategy and thinking about reauthorizing the GFSA. The GFSA reauthorization bill was introduced in January 2018. 
In my prospectus, I discussed how minimal funding could have posed a personal limitation to this project. Although I have been somewhat limited by the graduate student salary, I was fortunate to receive financial aid in the form of a research grant from the department's Verser \& Alumni Fund Award. This award helped me complete the transcription process quickly and efficiently. Also, I traveled to Washington D. C. to meet two interview participants. During the trip to Washington, D.C., I was invited to meet with policymaking staff members of a US senator who had worked on educating the Senator's constituents about the GFSA and implementing the Global Food Security Strategy. I spoke with these two participants in a dyadic in-person interview.

One challenge related to data collection that I did not expect could be described as transcription interference. This transcription interference is described in much more detail as part of a case study vignette in-between the first and second sections of chapter four. To give an overview, what happened was some of the audio in a few of the participant interview recordings went missing. The missing audio from these interviews presented unique limitations during data analysis and the coding phases of my research as well as writing up findings when I wanted to use excerpts from these interviews. One limitation I did anticipate was related to the accessibility of interview participants. Gaining access to members of USAID and their interorganizational collaborators who had worked on the GFSA proved to be slow and challenging. I relied significantly on snowball sampling methods (discussed below) and had to tailor my schedule to the availability of participants.

Finally, as the primary researcher for this project, I am also the primary instrument of analysis. The responsibility of ethical involvement in this case rested solely 
upon my judgements. While I felt confident in my abilities during data collection and analysis over the past year, I did run into dilemmas and quandaries that required the advice of my advisor and committee members. As an example of one dilemma I ran into, several interviewees asked to see my interview questions ahead of time so that our interview would be "productive," as they often explained. I agreed to let participants see the questions ahead of time via email if they asked to see them. While some researchers might argue that sending the questions to the participants ahead of time is not preferable to letting the questions appear during the interview for the first time, my goal was not to surprise the interviewees. My goal was to engage in a deliberate, fruitful discussion about food security discourses and policymaking processes. Often, I found that when participants had a chance to think about the questions ahead of time, they were able to respond with more detail than those who received the questions on-the-spot. For guidance and feedback on this process, I met with my committee advisor periodically over the summer and fall of 2017. These meetings helped keep my sensibilities heightened to specific biases, beliefs, and the inherent values that I brought into the data collection and research process.

In sum, I conducted a case study exploring the multiple and competing meanings that emerged out of food security d/Discourse between interorganizational members and policymaking processes. Case study was an appropriate methodological choice for this dissertation project because I identified a bounded system that would be interesting to explore for a deeper, general understanding of what was happening. Case studies are suited for explorations of the "how" types of questions I constructed after completing an extensive literature review. In the findings, I take an interpretive and critical approach to 
the data analysis. I write an in-depth description of the case and interpret findings and themes. I point towards openings for discursive change and transformation, particularly for interorganizational collaborators, in chapter 5. In the next section, I offer more detail about the data collection procedures and analysis steps taken to complete this project.

\section{Data Collection Methods}

Qualitative research, in general, is marked by an investigator's ability to systematically enter and examine a situation with the express purpose of exploring what, why, how, when and where social processes, and in my case communicative processes, happen. Qualitative researchers do not know precisely what they will end up discovering, but scholars and researchers experienced in qualitative projects (Tracy, 2013) have traditionally suggested approaching case studies with a well-developed research plan so that findings can later be interpreted and explained clearly for multiple and diverse audiences. In fact, Stake (1995) gives elegant advice to case study researchers:

We need some deep thinking, perhaps a data-gathering plan, a plan that protects time for the less attractive work, such as writing up observations, yet that expects reallocations along the way. It needs to be a plan rooted in the research questions (p. 51).

Research, a rigorous and systematic process, is composed of moments of exciting discovery as well as tedious repetition. Stake's advice emphasizes the tension inherent in creating balance between structure and flexibility with a data-gathering plan. My own research plan incorporated a balance between structure and flexibility from the Institutional Review Board (IRB) application to the data collection and analysis. Case study research provided a structure that accounted for ambiguity at the outset of my 
project because I could not predict the full complexity of USAID's organizational structure and interrelated connections with other organizations ahead of time. While setting up this case study, I incorporated the phases appropriate for collecting discourse data according to Stake's (1995) outlined strategies.

\section{Sample selection.}

Stake (1995) describes the first step necessary to a case study project as defining the case, which I outlined in chapter one and at the beginning of this chapter. I selected my case after careful evaluation of the literature related to food security, LC/MD and policy construction. The case study experts I reviewed (Creswell, 2013; Merriam, 2009; Stake, 1995; Yin, 2009) recommend developing research questions and a theoretical grounding before examining a case. I developed a rationale for this project in chapter one and highlighted key extensions to the literature. These processes informed my decision to proceed with a dissertation case study. To select the case, I emailed and had phone and face-to-face conversations with individuals from around the world working in food security organizations (e.g., FAO, IFAD, USAID, and BIFAD) about the merits and drawbacks of this specific project. After several months of interactions, I built trust and created relationships with staff members at the USAID Bureau for Food Security who had worked on food security policy as well as members of the Board for International Food and Agricultural Development (the USAID advisory board that links university researchers and government staff). These contacts introduced me to other USAID staff and interorganizational stakeholders who helped guide me towards what, where, when, and whom to interview (Merriam, 2009, p. 76). 
Stake (1995) emphasized that in the development and planning stages of a project, the researcher must carefully select the "best" data sources to construct a worthwhile report of findings (p. 56). By "best" Stake meant researchers should not settle for interviewing whomever might be convenient or available; rather, the researcher must seek out either the typical or unique individuals who can provide in-depth information about the case. Merriam (2009) provides even more detail about selecting data sources suggesting nonprobability-sampling methods to answer the "how" and "why" research questions. An example of nonprobability sampling includes purposeful sampling. Purposeful sampling can be broken down into various types: typical, unique, convenience, and snowball. I used a mixture of all these sampling procedures to select participants for this research project. To give examples of these different sampling procedures of participants, my first interviewee was a member of BIFAD. I considered him a convenience sample because I had worked with this person in other food security related capacities. Then, from the individuals I contacted in Spring 2017, I used snowball sampling methods to interview USAID staff who regularly worked on the Global Food Security Act. These individuals explained how food security meanings changed during policymaking meetings and discussions. Because of the complex, interorganizational nature of USAID's relationships with individuals who worked on constructing the GFSA, I used unique and typical sampling methods to gain contact and speak with individuals from other organizations who had worked with USAID members from, for example, lobbying organizations and congress. The sampling methods speak to the multi-pronged procedures I used to interview individuals connected to USAID and the GFSA. The 
interviews were only one part of the data gathering process. A chart citing general information about participants is included below:

\begin{tabular}{|c|c|c|c|c|}
\hline Participant & Job Title/Position & ex/Gende & $\underline{\text { Age }}$ & Race/Ethnicity \\
\hline Interviewee 1 & BIFAD & Male & 74 & White \\
\hline Interviewee 2 & USAID & Female & Mid 30s & White \\
\hline Interviewee 3 & BIFAD & Male & 60 & White \\
\hline Interviewee 4 & BIFAD & Female & 61 & White \\
\hline Interviewee 5 & USAID & Female & 37 & Black; African American \\
\hline Interviewee 6 & USAID & Female & 50 & Caucasian \\
\hline Interviewee 7 & USAID & Male & Unknown & White \\
\hline Interviewee 8 & USAID & Male & 52 & Caucasian \\
\hline Interviewee 9 & USAID & Female & 61 & White \\
\hline Interviewee 10 & BIFAD & Male & 67 & Black; African \\
\hline Interviewee 11 & USAID & Female & 33 & White \\
\hline Interviewee 12 & Academic (worked with BIFAD/USAID) & Female & 59 & African American \\
\hline Interviewee 13 & Academic (worked with BIFAD/USAID) & Male & 58 & African American \\
\hline Interviewee 14 & Legislative Assistant to Senator & Female & $30 \mathrm{~s}$ & Unknown \\
\hline Interviewee 15 & Legislative Correspondent for Senator & Female & $30 \mathrm{~s}$ & White \\
\hline Interviewee 16 & USAID & Female & 34 & White \\
\hline Interviewee 17 & USAID & Female & 30 & White Caucasian \\
\hline Interviewee 18 & The Lugar Center & Female & 56 & Caucasian \\
\hline Interviewee 19 & USAID; now independent consultant & Female & $70-75$ & Caucasian \\
\hline Interviewee 20 & The Lugar Center & Female & 57 & Caucasian \\
\hline Interviewee 21 & InterAction & Female & 29 & White \\
\hline Interviewee 22 & Legislative Director at U.S. House of Representatives & Male & 53 & Caucasian \\
\hline Interviewee 23 & Counsel to House of Representatives & Male & $51-52$ & Caucasian \\
\hline Interviewee 24 & USAID; now academic & Male & $70 \mathrm{~s}$ & Caucasian \\
\hline
\end{tabular}

I also used other types of data to fully flesh out the organizational case and final research report.

\section{Data gathering.}

Case study methodological experts suggest gathering and using multiple sources of data to shed light on different facets of the investigator's research questions. Stake (1995) advised researchers to use multiple methods including interviews, document review, and observation. I followed Stake's multiple methods advice and gathered interviews, organizational documents, and observations to have a holistic understanding of the broader case. I detail data gathering procedures for these different methods. First, I relied on phone and in-person interviews to gain an understanding of the convergent and 
divergent food security meanings at play during the construction of the GFSA. I interviewed 24 participants over a seven-month period between June and December of 2017. The participants had all worked on global food security, especially related to the GFSA, either primarily for or with USAID. In their job titles, they identified as staff or members of six larger organizational bodies (including, USAID; BIFAD; an Agricultural and Technical State University; US Congress; the Lugar Center; InterAction. Two participants had worked for USAID for 20 and 30 years respectively but worked as independent consultants at the time of the interview). I asked the participants for demographic information during the interviews; some participants provided this information and others did not, based upon the sensitive or revealing nature of the interview content. Interviews lasted between 31 minutes and 135 minutes with a mean of 50 minutes per interview. The transcripts totaled 558 double-spaced pages of data.

Conducting semi-structured interviews with USAID organizational members and other food security stakeholders who regularly interacted with USAID allowed me to probe for information related to the complex ways in which food security meanings converge, diverge, multiply and compete. Stake (1995) argued that interviewing is an important data gathering method for case study because interviewing is "the main road to multiple realities" (p. 64). I had gained experience writing these types of interview questions and conducting semi-structured interviews in person and over the phone after participating in several qualitative research projects under the guidance of my committee members over the last four years. I received advice on the wording of my questions from my dissertation committee, as well as food security scholars, researchers, and peers (Dr. Willi Meyers, an agricultural economist who worked for FAO; Dr. Lucy Jarosz, a 
geography scholar at the University of Washington researching food security discourse; Yassine Dguidegue, a rural sociology doctoral candidate studying poverty and food insecurity who had also worked for Heifer International, and Kathlee Freeman, a rural sociology doctoral candidate examining household food insecurity in Africa). These individuals assisted in the construction of appropriate interview questions. Consequently, my list of questions were validated, understandable, and effective for this project. By consulting these scholars and peers about my interview questions ahead of the interviews, I received valuable advice on the questions' wording, language, and style. Like Stake suggested in his book, The Art of Case Study Research, I found "informants" by connecting with individuals familiar with food security issues and comfortable using food security discourses.

Next, I collected and reviewed organizational artifacts, documents, and extraorganizational texts for information about food security issues related to the construction of the GFSA. These artifacts helped explain the multiple and competing food security meanings that emerged during the interviews. In addition, the texts provided me with crucial contextual information about global food security work done through USAID. Examples of the texts collected and examined include: BIFAD meeting minutes between 2015 and 2017; USAID budgets for 2016 and 2017; the US government Global Food Security Strategy (2016); the Global Food Security Strategy implementation report (2017); the FAO Voices of the Hungry Food Insecurity Experience Scale report (2016); the Food Insecurity Experience Scale technical paper measuring hunger; the USAID Measuring Food Insecurity: Going Beyond Indicators of Income and Anthropometry report (2003); Title XII reports to Congress (2009-2016); and USAID's extensive food 
security web and blog pages (USAID's Agrilinks blog and Impact blog detailing food security programs and projects). These reports and organizational artifacts each ranged in length from one page to over 100 pages. Other integral documents examined for this dissertation included different versions or drafts of policy, especially the Global Food Security Act. For example, a previous version of the 2016 GFSA bill appeared in 2009 and was known as the Global Food Security Act of 2009 (38 pp). This older version of the GFSA bill was created as an extension to the Foreign Assistance Act of 1961 (FAA) which set aside funding for the creation of USAID; I also examined the FAA (284 pp) carefully in preparation for interviews and further research into the policymaking around the GFSA of 2016. I coded and referred to the original Global Food Security Act of 2016 (10 pp) throughout the data gathering process. Finally, I gathered the 2018 reappropriation bill drafts of the GFSA introduced by Congress to extend the funding for food security programming.

Finally, I observed, took field notes, and conducted informal ethnographic interviews (Tracy, 2014) at the annual World Food Prize meeting in Des Moines, Iowa over a three-day period in October 2017. This meeting brought together many participants from the organizations I was interested in examining, including: USAID, BIFAD and other food security experts. I spent three days attending talks and research panels on food security measurement practices, the state of world food insecurity, and global trends and solutions for food insecure regions. From speaking with various contacts and USAID participants before this event, I discovered that this conference was one of the central places for USAID staff to connect and network with interorganizational members. I found it important to attend the conference because the panels and talks given 
by USAID staff began to reveal how larger Discourses emerged from the interactions between government, university, development, corporate, and non-profit actors. Staying in regular contact with USAID staff and other organizational members through emails, interviews and conferences like the World Food Prize helped solidify trust and built credibility.

Stake (1995) insists that the researcher should not wait to start analyzing data until all of the data has been gathered. Investigators should begin looking for patterns, themes, and interesting points for further inquiry throughout all stages of involvement, interviewing, and text gathering. As one example, during my first informal (two-hour long) information-gathering conversation on the phone with a member of USAID's Bureau for Food Security, I took several pages of handwritten notes. I circled points of interest and highlighted sections from the notes as reminders to investigate these emerging concepts more deeply during our future interviews. Throughout the data gathering process, USAID members and I exchanged dozens of emails with scholarly articles, suggestions of webinars, blogs, and new ideas for future directions of research. These continued interactions provide evidence that the qualitative research journey is ongoing: these relationships will evolve over the course of my career.

\section{Analysis Procedures}

To reemphasize Stake's advice for the interpretation of case study data analysis, I provide a pertinent quotation from his methodological book (1995) below:

There is no particular moment when data analysis begins. Analysis is a matter of giving meaning to first impressions as well as to final compilations. Analysis essentially means taking something apart. We take our impressions, our 
observations, apart... Not beginning, middle, and end, not those parts but the parts that are important to us...Analysis and interpretation are the making sense of all this. How is this part related to that part? Analysis goes on and on (p. 71). Stake's poetic summary of the analytical and interpretive procedures of case study underline the importance of creating meaning for the reader of the final case report. According to Stake, researchers should take several steps to analyze interviews, documents, and observations so that the case can be explained and then developed into a comprehensive and interesting report.

Stake says that researchers can use two strategies to reach new meanings about the case. First, researchers can utilize direct interpretation of individual instances that occur in the data and second, researchers can practice categorical aggregation, meaning the collection of similar instances in the data until the research can say something meaningful about them as a class (p. 74). When categorical aggregation is used, researchers note emerging variables and categories based upon theoretical grounding and the researcher's interpretation rather than prescribed questions or assumed outcomes.

Throughout the findings of chapter four, I utilized both direct and categorical aggregation to explain the importance of individual instances and to make sense of the meaning of many similar instances in the data. I identified emergent variables and categories in a similar manner to a qualitative thematic analysis (Miles \& Huberman, 1994). I interviewed all the participants myself, starting with the first interview in June 2017. I sent the audio recordings to a service called 3PlayMedia to be transcribed. To check for transcription errors and become more familiar with the data, I listened back through each interview at least once while going through each transcript carefully, 
making changes and corrections when necessary. With the interview data transcribed, I followed a systematic set of procedures to include direct and categorical aggregate examples in the findings. During each of the interviews, I took handwritten and typed notes on participants' answers, noting anything that seemed new, interesting, or repetitive (appearing throughout multiple interviews). Every few interviews, I created a memo where I wrote in more detail about direct interpretation of examples and the categorical aggregation of emergent ideas and concepts.

While Stake does not specifically address detailed coding procedures for case study data, I followed coding recommendations from other case study experts (Merriam, 2009; Yin, 2009) to develop the direct interpretations and categorical aggregations that informed my findings. I used MAXQDA analytic software to record all codes and several memos. After receiving each interview back from the transcription service and listening for accuracy, I did an initial round of coding where I combed through the first few interviews, section by section. I highlighted sections (which ranged in length from one sentence to a couple of sentences) and labeled them with broad, simple codes (ex., Food Aid, Food Security, Government, Policy, USAID, BIFAD). Next, as I conducted more interviews, I read through the interviews several times and highlighted specific sections, noting processes of discursive interaction. This step helped me closely examine "what" was going on and "how" the participants accomplished communication around food security issues. The discursive process codes were labeled with titles like, "clear consensus," "clarification," "closing off information," "ambiguity," "explaining food security," "differentiating," and "informing," among others. I created many of these codes as subheads of the broader categories so that I could see how the sections 
interacted across both larger and smaller chunks of data. For example, under the "Policy" category, I included what the policy was discursively doing for the participants: "policy as guide," "policy constrains," and "policy enables." Codes overlapped where I saw several processes happening in a single section.

I coded all transcripts within a week of the interview so that the conversations would be fresh in my mind and memos would accurately convey emerging categories. To give readers a sense for the codes created, I developed 93 separate codes over the 24 interviews and highlighted over 4350 sections across larger categories and smaller categories. The memoing process helped me narrow down the most interesting and pertinent direct interpretation and categorical aggregation examples to include in the findings. While memoing, I drew examples from the documents I had analyzed to support my arguments about the meaning-making processes I had seen happening in conversations, texts, and observations.

During the data analysis phase, I spent a significant amount of time considering each specific or unique instance that stuck out to me. When analyzing case study data, the researcher should not look at specific instances solely for their regularity of occurrences or frequency. I analyzed the data in order to understand and evaluate how interorganizational professionals communicated multiple and competing food security meanings that emerged from policymaking and development conversations and organizational texts. Throughout analysis, I played with separating, combining, and intermingling the complex discursive meanings using interviews, texts, and field notes. In in the findings, I provide examples of interpretive and theoretical significance that were derived from both single instances and repetitive behaviors or messages. 
Lastly, Stake describes the findings and conclusions of research as the naturalistic generalizations in a case study report (Stake \& Trumbull, 1982). Naturalistic generalizations are "conclusions arrived at through personal engagement in life's affairs [during the case] or by vicarious experiences so well constructed that the person feels as if it happened to themselves" (Stake, 1995, p. 85). Stake's suggestions for translating naturalistic generalizations for audiences involved the following: 1) Including accounts of matters, such as hunger or policymaking in this case, the readers might already be familiar with to orient them to the project 2) Providing adequate raw data, including excerpts from interviews, in the findings report prior to researcher interpretation 3) Describing the methods in ordinary language 4) Making information about myself, the researcher, available to readers and 5) De-emphasizing the idea that validity is based on what every observer might see, i.e., simple replication. Instead, the researcher should emphasize whether the reported happenings could have or could not have been seen and interpreted from the case (p. 87). In the findings and discussion chapters of the dissertation, I followed Stake's suggestions. For example, I provide historical and contextual information about USAID and their interorganizational collaborations. I also include raw data excerpts from interviewees explaining policy construction of the GFSA. I use excerpts from interorganizational texts to provide adequate information for readers. I added case study "vignettes" between sections in the findings which made information about myself and the research process available to readers. I emphasize that transferability of my findings are not based solely upon simple replication.

To summarize, I outlined the methodological assumptions guiding the data gathering and analysis of this case study. I provided justification for a holistic analysis of 
a bounded case, including the construction of the GFSA and the convergence and divergence of multiple and competing meanings of food security by individuals who work for or with USAID. After gathering data over several months, I wrote a detailed description of the case. From this case report in chapters four and five, I knitted together specific examples and accounts explaining the importance of understanding how multiple and competing food security d/Discourses become policy and impact international development projects. In the findings and discussion, I describe and interpret key aspects of the case, including what I have learned about USAID's involvement in food security policymaking as well as their reasons for continuing to build and support an international food security agenda. 


\section{Chapter 4: Analysis of the Case}

For this case study, I examined how organizational members who worked for and with USAID created multiple food security meanings during discussions about the Global Food Security Act (2016). When organizational members construct meaning around concepts, like food (in)security, both misunderstandings and opportunities for shared understanding can happen. Over the past year and half, I carefully examined possible converging and diverging food security meanings by: speaking with 24 organizational members about the Global Food Security Act; reading GFSA drafts and analyzing organizational documents; interpreting government accountability reports; highlighting food security-related language in government strategy reports, frameworks, budgets, and reports to Congress; and scanning food security indicators and measures constructed by government and academic researchers. A food security communication analysis could impact future policymaking processes such as the Farm Bill, internal/external organizational persuasion, and interorganizational interactions about other USAID programs like Feed the Future.

Food security organizations, including the United States Agency for International Development, as well as the food insecure populations receiving food assistance in regions far from congressional decision-makers, may benefit from the findings of this study. The findings offer one way to make sense of food security discourses. A qualitative case study (Stake, 1995) should present a fresh explanation of the interesting and meaningful findings for audiences. These findings will helps readers understand what is going on in "the case", how it (in this case, communication) is being accomplished, and why events happened in the ways that they did. I explain the "what," "how," and "why" 
through categorical aggregation and direct interpretation of the data (Stake, 1995, p. 74). In other words, the primary task is to gain a better understanding of "the case." I help readers understand the case by breaking down the analysis into three "vignettes" and three subsections. Each subsection is preceded by a vignette. Stake recommends including vignettes - short stories - in the case as a means of creative translation for readers (p. 127). I build upon Stake's recommendation by incorporating vignettes that reconstruct the confusing and frustrating facets of data collection, analysis, and writing the dissertation. The vignettes are written in the first person to artfully convey what the social and material interruptions in the flow of qualitative analysis felt like. Each subsection after the vignettes explains the data in-depth by combining communication theory with interpretation.

In the first subsection, I explain "the case." The case covers a brief overview of the history of the Foreign Assistant Act which led to the creation of USAID. I also piece together government legislation, world events, and interorganizational relationships to build an argument for examining food security discourses and the Global Food Security Act. After presenting the case, I address my first research question by describing the convergent and divergent contradictory $\mathrm{d} /$ Discourses government members used to construct and explain the Global Food Security Act. I utilize a sensemaking (Weick, 1995) framework to unpack how participants structured food security discourses.

In the second vignette, I tell a story of paranoia in the research process. Paranoid concern seeped into my participants' discussions about food security and consequently, my own observations and data collection. After the second vignette, I use LC/MD (Dougherty et al., 2009) to explain converging and diverging food security meanings. I 
extend LC/MD by describing how divergence happens through "discursive maneuvering" in two particular ways: equivocation and differentiation. In the third vignette, a short poem, I express the emotional and physical tolls of dissertating which coincided with the academic job search. The final subsection illustrates how USAID members used strategic ambiguity to organize discourses of food security and conflict. Strategic ambiguity functioned to protect organizational members and gives them an argument for drawing upon national security language as a means to global food security. 


\section{Vignette \#1: Dissertation Writing Creates Transformation}

\section{Mucking through the Trappings of "Diss Life"}

Blood-soaked band-aid face down

At the base of our tree.

Its rubbered wing uncharacteristically folded and stuck

upon itself,

Probably inseparable now.

Making a sticky and furry texture smooth, as memories

Do-

Binding layers of sound, smell, sight, touch, taste:

Damp wooden bridge

To honeysuckle

To whiskey

To that spot behind your ear where the hairdresser

Shaves a perfect boundary line /

The stubble

stubbornly

breaking through.

The story likely unchangeable now?

What does blood offer to the soil

that rain cannot?

I saw the grass grow greener where 
His bones and carcass laid.

Transform-ing isn't so hard

It's the permanence of "-ation" that scares

Us from ripping off old layers and

Seeing fresh scars. 


\section{Subsection 1: "The Case"}

The Global Food Security Act S.B. 1252 (GFSA), a piece of legislation with bipartisan Congressional support, was passed by the Senate and signed into law by former President Obama during the summer of 2016. Participants of this study (i.e., organizational members of USAID, congressional foreign policy analysts, BIFAD [Board for International Food and Agricultural Development] members, NGO advocates, and development officers) argued that the GFSA was the first food security policy of its kind to be passed in the US. Because GFSA stands out as a unique piece of food security and international development legislation — especially one that received broad bipartisan congressional support - it calls for a deeper understanding of the communicative processes preceding its passage. The very term "food security" distinguishes this legislation from other food aid and assistance policies of the past. In this first subsection, I describe the historical context surrounding the GFSA's passage. Then, I examine how interorganizational participants used food security language to create alternative meanings that eventually communicatively constituted the GFSA.

In analyzing the historical context leading to the GFSA's passage, I acknowledge that everything from legislators' personalities to political tensions, and global events could have influenced the communicative construction and passage of the GFSA. While I could not include everything related to the GFSA's passage, I address major pieces of legislation and historical events leading up to July 2016. A description of food security events and history is necessary to later understand the emergent organizational discourses and persuasive meaning-making that developed around the GFSA. Several participants suggested including a clear outline of key events, informed by a close reading of 
organizational documents. I expect that this outline will aid readers who would like to understand the multiple and convergent/divergent meanings unfolding during the communicative constitution of GFSA. Below, I overview the first subsection.

First, I outline the Foreign Assistance Act of 1961 (FAA), an historical legislation mandating government-driven international research and development. President Kennedy had determined international countries needed support that the US could provide, and USAID was born. USAID also intensified US engagement in global food aid and security issues. Next, I move from legislation to the World Food Price Crisis, a worldwide exigency that spurred the creation of USAID's Feed the Future (FTF) program. Feed the Future's success, especially in addressing food insecurity challenges across dozens of countries, set in motion a series of discussions about permanently creating global food security programming. Then, I discuss how interorganizational conversations turned a presidential food security initiative and temporary food security program into law. I explain how an earlier legislative draft, the Global Food Security Act of 2009, was unsuccessful in the Senate. Although this legislation did not pass either house in 2009, the interorganizational discussions around global food insecurity intensified interest in keeping these discussions alive. Lastly, I examine recollections and conversations about GFSA through a sensemaking lens. Sensemaking clarifies what organizational discourses led to the failure of the Global Food Security Act of 2009, which was a precursor to the GFSA of 2016.

\section{Foreign Assistance Act of 1961 and USAID beginnings.}

Former president John F. Kennedy passed the Foreign Assistance Act (FAA) in 1961. This legislation emerged out of international conversations about how development 
could prevent violence and increase global security, particularly as an extension of the Marshall Plan post-World War II. The FAA provided legislative guidance and nonmilitary-associated funding for involvement in foreign affairs. President Kennedy recognized the possibility of future global wars, crises, and circumstances of political instability could be thwarted not just through defense and military mechanisms, but development and aid programs led by individuals affiliated with the US Government (USG). Essentially, FAA created new regulatory guidance for foreign assistance programs, reorganized non-military aid, and established a new agency as part of the State Department: The United States Agency for International Development (USAID) (figure 1, A). The primary goals of FAA, as stated within the text, are "To promote the foreign policy, security, and general welfare of the United States by assisting peoples of the world in their efforts toward economic development and internal and external security, and for other purposes" (2017, para. 1). Because of the expansive language used in the FAA, USAID has extended its international reach and accommodated several development initiatives including: agriculture and food security, democracy, human rights and governance, education, economic growth and trade, environment and global climate change, gender equality and women's empowerment, global health, water and sanitation, and crises and conflict. 


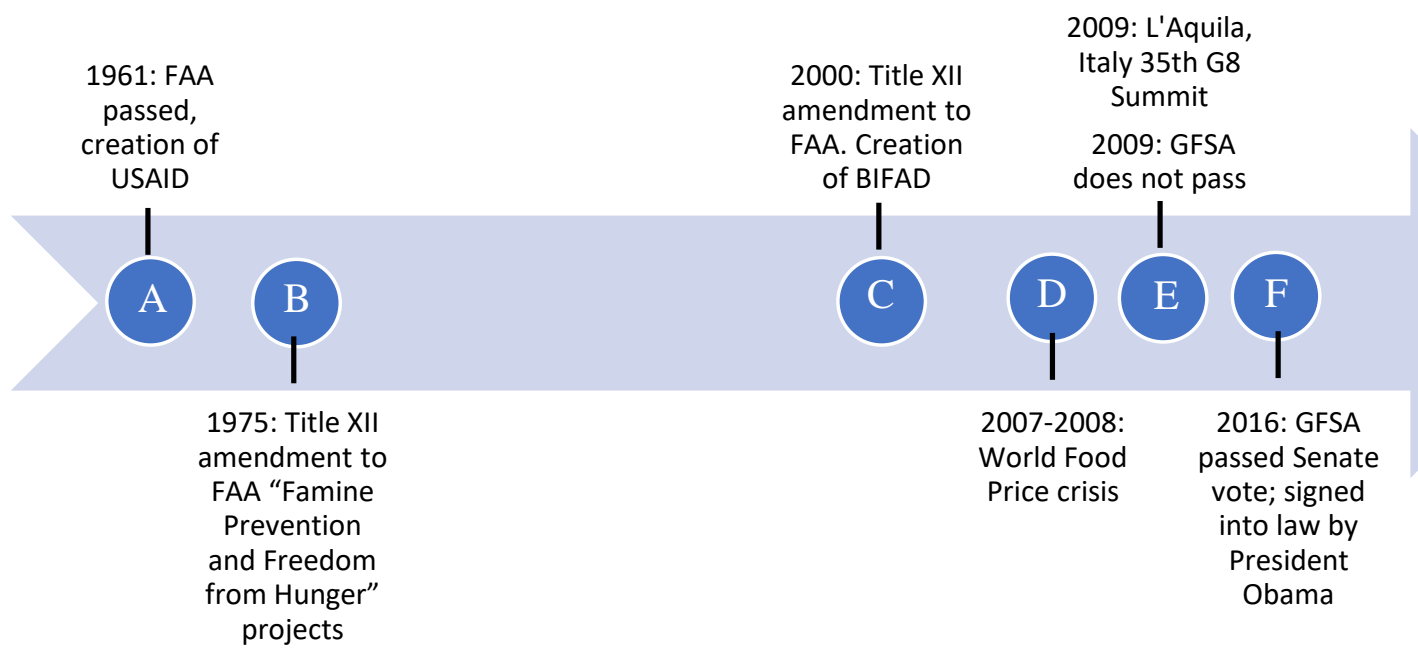

Figure 1. Timeline of US government food security-related legislation and world events.

Since 1961, the guidance within the Foreign Assistance Act has allowed USAID foreign development staff to address major world crises. For example, using the FAA discourses mandating international aid as justification, USAID staff have implemented ongoing projects concerning US securitization and democratization goals critical to US diplomatic efforts. To keep up with evolving national security and democratizing goals across the world, the US Congress has amended the FAA several times since the 1960s. For instance, Congress passed the Title XII amendment, "Famine Prevention and Freedom from Hunger" in 1975 to involve universities more directly in fighting hunger and implementing a global research agenda in partnership with USAID (figure 1, B).

The FAA legislation is important to this dissertation project because the textual discourses created USAID's regulatory guidance and set the stage for food security and agricultural policy to be implemented in 2016. USAID has continued offering international food security programs, aid, and assistance partly based on Congress's 
enduring usage of the FAA. Congress's willingness to keep drawing upon the text of the FAA speaks to the legislation's lasting legitimacy. Title XII was further amended in 2000 to create the Board for International Food and Agriculture Development, also known as BIFAD (Figure 1, C). BIFAD helps inform USAID about university research and activities related to food security. According to a brief created by the Association of Public \& Land-Grant Universities, “The presidentially-appointed Board for International Food and Agriculture Development, advises and assists the USAID Administrator on agricultural and food security issues including the administration, implementation, and monitoring of U.S. university-led Title XII activities" (Wilson, 2007, para. 2). BIFAD has acted as the communicative liaison between USAID (government) and university institutions, responsible for discussing important agriculture and food security research with government staff.

The Title XII amendment created a key shift for Congress and the broader US government. The State Department would move from focusing on food aid (i.e., sending food from the US to other countries during short-term crises) to food security (i.e., implementing long-term programs to address food-related challenges in partnership with other countries). Discursively, Title XII gave Congress the power to rename and reorganize foreign food aid and assistance. Additionally, Congress could shift how they would decide to fund food aid and foreign assistance. These decisions have caused tensions within Congress. Deciding upon whether to send funds expressly for the purpose of foreign food aid and assistance has become a polarizing issue for many members of Congress - an issue that began in the 1970s and has continued until today (Riley, 2017). 
Food aid and food security have become more complicated as government organizations tackling food security and hunger have proliferated and become enmeshed in international affairs. For example, because many of USAID's programs now emphasize long-term community involvement, US development officers often work abroad for some or most of their careers. USAID officers who are interested in food security policy often interact with members of Congress, bringing descriptive of their reports into the policymaking process. In the past, members of Congress could draw upon two simpler discourses to justify food aid policy: 1) the US helped foreign countries address food aid for moral and charitable reasons (ex., "fighting hunger is the right thing to do") and/or 2) sending food aid gave US farmers an economic incentive and outlet for agricultural overproduction (Riley, 2017). Communicatively constructing a third discourse to justify food aid would begin a new era for the US government and international development. USAID, as part of the State Department, would make the argument that food assistance should be discussed and viewed as an essential national security issue, and not just a moral or economic issue. 


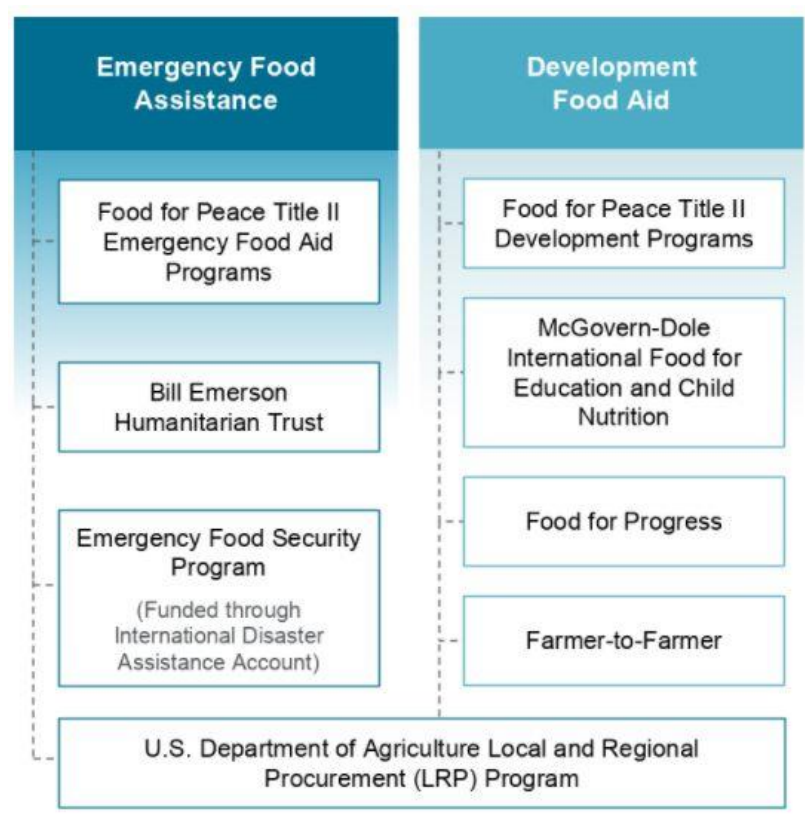

"U.S. contributions to the World Food Program come from a number of the Emergency Food Assistance and Development Food Aid accounts above.

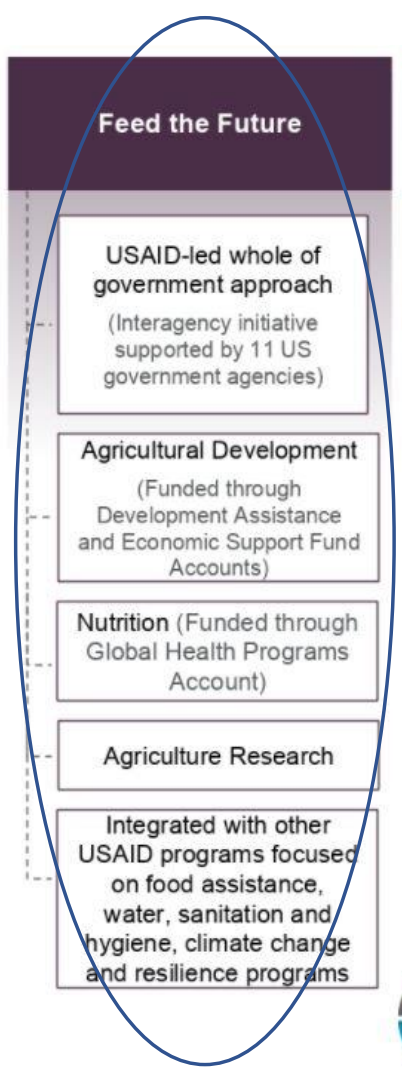

U.S. Contributions to

Multilateral Assistance for

Food Security

World Food Program
(WFP)*
and

Food and Agriculture Organization (FAO)

Multilateral

Development Banks

Consultative Group on International Agriculture Research (CGIAR)

International Fund for Agricultural Development (IFAD)

Global Agriculture and Food Security Program (GAFSP)

InterAction

Figure 2. A simplified sampling of US government contributions to global food security.

This chart represents the complex relationships between the United States Department of

Agriculture, USAID, and international NGOs, including the United Nations. Adapted

from "U.S. Support for Global Food Security: Programs and Contributions," by Eric

Munoz, 2015, retrieved from https://www.interaction.org/document/us-government-food-

security-programs-and-contributions-chart. Copyright 2015 by InterAction: A United

Voice for Global Change organization.

As seen in Figure 2, Feed the Future, a USAID Obama-era programmatic

initiative to fight global food insecurity is what eventually incentivized Congress to pass

a Global Food Security Act. What is important to notice in the chart of Figure 2 are the

complex and overlapping programs meant to fight hunger both in the US and abroad. The 
USDA mostly handles food aid and assistance (two blue columns on the left), while USAID manages food insecurity through international development programs and multilateral engagement (two columns on the right). I began this dissertation project because I was interested in finding out how food security policymaking discursively unfolds through the collaboration of many organizations. USAID's structure is so complex because the agency members work with researchers, universities, corporations, small businesses, NGOs, in-country partners, faith-based organizations, donors, humanitarian responders, and US government agencies and military. Because my specific interest homes in on communicative policymaking and interorganizational processes, I started with an examination of the role(s) USAID's Bureau for Food Security and BIFAD members played in contributing to the construction of global food security legislation.

In the years leading up to the passage of the GFSA, President Obama argued that new food security programming and policy should expand the government's “development and use of modern technology, working in collaboration with U.S. landgrant universities and strengthened host country research institutions" (Title XII Report to Congress, 2013, p. 25). USAID's reliance on Title XII, a policy amendment to the FAA, and advice of the members of BIFAD became increasingly important during Obama's presidency which coincided with the global food insecurity crisis. President Obama's personal interest in tackling food insecurity in the US and worldwide pushed the US deeper into foreign development territory. Global events, like the World Food Price crisis, shifted public and congressional attention to figuring out how to communicate differently around the creation of stable and permanent food security solutions. 
Renewed interest in the creation of global food security legislation and interorganizational program implementation emerged in response to the World Food Price crisis. Leaders, like President Obama, had begun searching for new ways the US could approach age-old problems of hunger and poverty. One answer to the creation of stable and permanent food security solutions came about through USAID's long-term commitment to global development and interorganizational collaboration. In addition, USAID was well-situated to address heightened government and public concerns about increasingly fragile states and market destabilization, including international crises that would have unforeseen rippling effects.

\section{The World Food Price crisis.}

The systemic causes of the World Food Price crisis have been traced back to an unfortunate intersection of several global challenges (see figure 1, D). These challenges ranged from prolonged droughts in developing nations that were brought on by climate change, to markets being oversaturated with huge quantities of grain, and to rising oil prices and the increasing costs of fertilizers and pesticides for agricultural inputs and gas for food transportation, according to the International Food Policy Research Institute report (2012). The causes and consequences of the World Food Price crisis are complex and still being contested in academic and research circles. Still, international governments and those who experienced and saw the spread of hunger connected the food price spikes and state volatility between 2007-2008 back to these simultaneous global challenges (von Grebmer, Torero, Olofinbiyi, Fritschel, Wiesmann, \& ... von Oppeln, 2011). The World Food Price crisis had pulled the US government back into 
sending foreign food aid and assistance, a sector that the US government had slowly backed away from since the 1980s.

The US international food aid and assistance government programs had dwindled throughout the 1980 s to just three food aid programs by 2008 at the time of the food price crisis (Riley, 2017). These remaining three government food aid programs were primarily run and overseen by the US Department of Agriculture (USDA) rather than the State Department and USAID. As the food price crisis spread worldwide in 2007, President George W. Bush promised emergency relief in the form of American grain shipments and aid dollars would be sent to those countries struck by high food prices. President Bush had only partially fulfilled those promises by the end of his term. But, President Obama urged other nations to join the US on a broader and more complicated mission to find solutions to cross-cutting issues of hunger, nutrition, and food insecurity at the 2009 L'Aquila 35th Summit of the G8, consisting of global leaders from the US, Canada, France, Germany, Italy, Japan, Russia, and the UK, in Italy (see figure 1, E).

The L'Aquila 35th G8 Summit brought about an agreement between these global leaders promising to contribute $\$ 20$ billion to the issue of food security over three years. This investment created renewed interest in food security issues. One example of how the renewed interest in food security led to change can be seen in the creation of President Obama's Global Hunger and Food Security Initiative (GHSFI). Part of the GHFSI turned into the USAID-led program called Feed the Future, a program that would eventually be institutionalized in the GFSA (see figure 2). The mission of Feed the Future, as described in the Title XII Report to Congress (2011), targeted specific countries and implemented "relevant missions and regional programming units" giving USAID staff "food security 
budget controls appropriate to each country's conditions" (p. 9). The Feed the Future program began in 2010 as a temporary presidential initiative, not as a permanent USAID program. However, Feed the Future continues to receive funding from the US government and operates on an international scale even today, thanks to passage of the GFSA in 2016. Feed the Future has operated under the USAID's Bureau for Food Security (BFS), explaining why several members of BFS became invested in communicating the importance of why the legislation should be passed between 20152016.

In 2009, around the same time President Obama spoke forcefully about world hunger at the L'Aquila Summit, other members of Congress and USAID staff had been debating on whether or not to increase levels of food aid funding. Likewise, government members and food security advocates had been searching for permanent solutions to food insecurity through the power of legislation. While many in the development arena championed the successes seen from the President's Feed the Future initiative, others also understood that a presidential initiative like Feed the Future could only be viable in the short-term until a new president stepped in and either continued or ended the initiative. In the following section, I discuss the communicative construction of a failed legislative precursor to the GFSA, the Global Food Security Act of 2009 (see figure 1, E).

\section{Global Food Security Act of 2009.}

Senators Lugar, Casey, Durbin, Harkin, Collins, Kerry, and Begich introduced S. 384, known as the "Global Food Security Act of 2009" in February 2009, just a few months before President Obama would make a plea for cooperative food security funding at the L'Aquila Summit. Even though the 2009 bill failed to pass in the Senate, much of 
the food security-related language within its text ended up in the 2016 bill. Although these two bills had overlapping language and similar goals, only one participant from USAID (Participant \#5) and one participant from BIFAD (Participant \#1) mentioned this important precursor to the GFSA during interviews. I did not come across discussions of the 2009 bill in my research about US food aid and assistance. Near the end of interview data collection, someone recommended that I reach out to individuals from The Lugar Center-a nonprofit advocacy organization in Washington DC founded by former Senator Lugar. Senator Lugar was the primary author of the 2009 Senate version of the Global Food Security Act. The Lugar Center has become a space for debate on global issues, such as food security, foreign assistance, and the nonproliferation of weapons of mass destruction (The Lugar Center, 2018). At the Center, senior policy experts come together, discuss their research on these issues with experts from international universities, and spend time advocating for specific policy proposals to be adopted by Congress. For this study, I spoke with food security policy experts from The Lugar Center. One of the participants had been instrumental in drafting the original Global Food Security Act of 2009 while Senator Lugar was still active in office. Taken from the opening lines of the legislative text, the express purpose of the Global Food Security Act of 2009 was:

To authorize appropriations for fiscal years 2010 through 2014 to provide assistance to foreign countries to promote food security, to stimulate rural economies, and to improve emergency response to food crises, to amend the Foreign Assistance Act of 1961, and for other purposes. 
After the World Food Price crisis, members of Congress wanted to act quickly and uniformly in response to the populations suffering from hunger and famine in the countries that were most impacted (Participant \#18). The Global Food Security Act of 2009's policy language centers around improving the "emergency response to food crises" and providing food assistance. As will become clearer in later subsections of the findings, the material needs of the people suffering after the World Food Price crisis were not persuasive enough to pass legislation. What changed between the bipartisan proposal of the Global Food Security Act of 2009 and 2016 was the language. The interorganizational stakeholders interested in global food security had to make a strategic case for continued food security development and assistance. Participants (ex., \#18, \#20, \#21) argued that the overall purpose was the same in the 2009 and 2016 pieces of legislation, including the spread of food security and economic stimulation. The key difference was that the 2009 bill was written to amend the Foreign Assistance Act (FAA) while the 2016 bill stood on its own as a piece of food security legislation separate from the FAA.

I found the 2009 bill particularly helpful for later examining the 2016 legislation because the language calls for the implementation of a "comprehensive food security strategy," a strategy that would create a whole-of-government approach to food insecurity (p. 5). The whole-of-government approach in the 2009 bill included the coordination of members across several Federal departments and agencies, including the USAID and USDA (p. 9). I was surprised by the discussion of a whole-of-government approach because I had been led to believe that this strategy was a new idea originating in the 2016 bill. Participants discussed how the new whole-of-government strategy was novel and 
advantageous for getting rid of redundant programs across government agencies. As I considered the similarities between the usage of food security language across the two bills and the broadly supported — all the way up to President Obama—objective to mitigate insecurity and improve nutrition, the following questions arose: What changes in language helped Congress pass the 2016 GFSA with bipartisan support while the 2009 version failed? Or, in other words, how did food security language get (re)structured by interorganizational stakeholders?

I address these questions by interpreting excerpts from the interviews where participants discussed changes in the language which were employed by food security professionals to pass the 2016 GFSA. First, I discuss how food security professionals shifted their discourse to make an argument for turning a temporary USAID-run program (Feed the Future) into a structured law, the GFSA. Second, I describe how USAID stakeholders communicated broad support for the GFSA as they drew upon little "d" discourses (from in-person conversations and text-in-action) and how they utilized big "D" Discourses in speaking to cultural narratives, including "morality" and "national security." Finally, I end the section by explaining how food security professionals retroactively made sense of constructing the GFSA by communicatively idealizing the process. These findings are explained below.

\section{Shifting the d/Discourse: Arguments for turning program into policy.}

In this section, I address the first question by examining the complicated behindthe-scenes communication between organizational actors who successfully transformed a temporary government program into a permanent food security law. I argue that the organizational d/Discourses (Alvesson \& Kärreman, 2000a; Jian et al., 2008; Kärreman 
\& Alvesson, 2008) slightly changed, or shifted, after the failure of the 2009 GFSA. I refer to little "d" and big "D" organizational discourses in this section. Little "d" discourse refers to "talk and text in situated organizational contexts... The processes in which organizational actors manage contradictions and work relationships" (p. 304). I think of little "d" discourses as the day-to-day conversations that make regular, ongoing organizing work possible for organizational members, and I refer to little " $d$ " discourses in this way. Conversely, big "D" discourses can include broader cultural narratives, with examples like "food is a human right." Although little "d" and big "D" discourses may seem separate from each other, they in fact inform each other. For example, I might utilize a little "d" discourse in saying to a friend, "My neighbor deservedly relies on government food assistance while she is unemployed." This "talk-in-action" still informs larger discourses of food as a human right. Individuals communicate with each other by moving between both little " $\mathrm{d}$ " and big " $\mathrm{D}$ " discourses.

Participants pointed out that there were key moments where language moved and changed. I argue that discursive shifting took place in these key moments, which thereby turned a temporary presidential initiative and USAID program into permanent legislation. Examining the discourses making this "shift" possible is important for scholars and policymakers because this process could be replicated for different issues: turning program $\rightarrow$ policy $\rightarrow$ legislation.

The importance of the 2009 precursor to the 2016 Global Food Security Act became clear during interviews with Participants \#18 and \#20. Participant \#18 worked on food security and policy issues at The Lugar Center and she had previously worked for two years on the Senate Foreign Relations Committee with another participant in this 
study, Participant \#20. Participant \#20 had originally authored a draft of the global food security legislation that eventually turned into the 2016 GFSA. Even though the Global Food Security Act failed to gain enough support on the Hill in 2009, Participant \#18 described behind-the-scenes discourses, little " $d$ " discourses shared between organizational actors. These moments, or what Jian et al. (2008) described as "talk-inaction," constituted older policy drafts that led to the construction of the 2016 version. Participant \#18 explained an organizational tension between congressional members and Obama's administrative members. The 2009 congressional members, who also worked with their various food security stakeholders, had written a draft of the Global Food Security Act. They expected this bill to address the global food security problems impacting countries affected by the World Food Price crisis. Congress members clashed with Obama's administrative members. They remained unconvinced that this bill was necessary. As a result, President Obama focused on a temporary food security solution, known as the Feed the Future program of USAID, that responded to the World Food Price crisis, but that would not require passage by the House and/or Senate. Participant \#18 described how this organizational tension between whether or not to try to send another Global Food Security Act through Congress kept building after the failure of the 2009 Global Food Security Act:

Participant \#18: I picked up the ball in 2011 and kept it kind of moving, even though the Feed the Future program had just been stood up [implemented] then, and frankly the [Obama] administration has no interest in seeing a piece of legislation become law. They [USAID] really didn't want Congress meddling in their business because they knew they had the authorities - there were general 
authorities under the Foreign Assistance Act - and they could do Feed the Future without Congress as long as the appropriations side of Congress continued to fund it at their [USAID's] request.

At this point in our interview, I did not recognize Participant \#18's sequencing of events since the construction of the GFSA had been explained quite differently by other interview participants. This person's version had not appeared in the literature I had read about the construction of food aid or food assistance policy. Participant \#18 described how President Obama's administrative staff and USAID members had turned down the opportunity to make food security action permanent. Considering how much the US has regularly funded foreign assistance and food security issues, this specific path towards a temporary solution to global hunger seemed surprising to me.

President Obama's foreign assistance experts and USAID's food security staff wanted to pursue an easier route to food security through the temporary Feed the Future program. Trying to pass legislation through Congress was much more difficult, especially at a time when there was great suffering and developing country populations needed immediate support. President Obama and USAID purposely shied away from policy change. Participant \#18 explained that asking Congress to change the FAA through an amendment that would permanently fund food security initiatives would be incredibly difficult. The Obama administration had the ability to implement a special program, Feed the Future, through USAID. Because Feed the Future was in place, an amendment to the FAA would have been redundant. But other organizational stakeholders, like Participant \#18 and certain members of Congress, saw food insecurity as an ongoing global challenge, not just a temporary setback brought on by events like the World Food Price 
crisis. I include a longer excerpt from Participant \#18 which explains how little "d" discourses, or every day talk-in-action, played a role in the discursive shift that eventually convinced members of the Obama administration that a permanent solution would be necessary to tackle food insecurity.

The interorganizational conversations between members of Obama's staff, USAID, and The Lugar Center would play a key role in the shift from turning a temporary program into a permanent bill, the GFSA. Participant \#18 argued that the 2009 GFSA did not pass because there was very little motivation to do so. In the excerpt below, from our interview, I included examples of little "d" talk-in-action discourses that Participant \#18 had recalled from regular organizational interactions. This intimate, discursive recollection brings an interorganizational interaction to life. Participant \#18's description gives audiences, who are unfamiliar with the communicative interactions that are part of policymaking, a glimpse into the ways administrative representatives discussed working around the typical legislative process. In other words, these extralegislative moments impacted what went on during Congressional meetings, including a shift from the failure of the 2009 GFSA to the success of the 2016 GFSA:

Participant \#18: Yeah. So, um, it's funny because I still remember, um, having a conversation with a Congressional Affairs representative of USAID and the State Department together in the early days of my staffing, on this this particular policy issue. And saying to them, "You know, I wanted to have a conversation with you - and sit down and talk with you about the next steps with regard to authorizing a [Global] Food Security Act under, you know, probably a lot of parameters from what you're doing on the agency side with Feed the Future." 
Interviewer: Yeah. Oh, yeah.

Participant \#18: They heard me out and then they said, "We have no, um, interest in legislation. And we don't intend to send any dropped [referring to failure of 2009 Global Food Security Act] legislation up to the Hill. And we have all the authority we need."

Interviewer: $\mathrm{Hm}$.

Participant \#18: And so, I said to them, "That is really interesting. And I

understand that you do have the authority under the [Foreign Assistance] Act. But because we don't have specific authority — and this is only a presidential initiative — at some point President Obama will not be in the White House." And then, again, this was in 2011. So, he was re-elected 2012.

Interviewer: Right.

Participant \#18: So, and 2012 was still a bit of an unknown at the time. And I said to them, "Either in one year or five years, he's leaving the White House. And so, for me, I really question the thinking about wanting to let this initiative die.

Interviewer: Yeah.

Participant \#18: And be an unknown under whoever the next president is after he leaves.

Interviewer: Sure.

Participant \#18: But if you institutionalize it in a law [volume goes quiet], it will live on regardless of who is in the White House." And you know what? We still had no interest [from USAID staff and members of the State Department]. 
During this recollection, Participant \#18 described a firm and repeated disinterest among USAID members and State Department representatives to create legislation related to food security. The little "d" discourses are the ongoing conversations between Participant \#18 and various representatives from the State Department and USAID. The fact that there was interest in creating long-term solutions to food insecurity never disappeared from Congress. Participant \#18 stayed in contact with members of Congress and kept reminding them about the ongoing struggles for global food security. That there was little interest in creating a long-term legislative solution seemed surprising based upon my conversations with participants from USAID who seemed on-board with the 2016 GFSA and the need for long-term solutions to food insecurity. Other participants who talked about the passage 2016 GFSA with me described the whole policymaking process as relatively uncontroversial, a theme which I cover later on in this section. And they described how the 2016 bill draft was fully supported by both houses of Congress and the Obama administration.

Participant \#18 presented the governmental options for addressing food security (i.e., through a short-term presidential initiative or permanent legislation) as organizational options in tension, or clashing, with one another. However, tensions can be generative for organizations and organizational actors (Cooren, Matte, Benoit-Barné, \& Brummans, 2013; Trethewey \& Ashcraft, 2004), particularly when those individuals, like Participant \#18 and colleagues, can resolve tensions through a constitutive process, such as policymaking (Canary, 2010a; 2010b; Cooren, 2004). Participant \#18 ends the excerpt by stating that there was still very little interest in 2011 in a government-wide global food security policy, yet these ongoing interorganizational conversations eventually shifted the 
broader discourse about the need for a global solution. A new draft of the Global Food Security Act did pass bipartisan scrutiny and institutionalized the short-term Feed the Future program into a longer-term legislative solution.

President Obama expressed interest in increasing funding for global food security initiatives, along with the other G8 leaders. But, he had not committed to supporting congressional legislation related to global food security, even though, according to Participant \#18, legislation would have been the next logical step to addressing the persistent nature of food insecurity. The G-8 funds promised during the L'Aquila Summit never came to full fruition. USAID instituted the presidential food security initiative, the Feed the Future program, and then decided to pursue more permanent policy change. Participant \#18 explained this shift that occurred during President Obama's second term. Several members of the administration acknowledged that transforming the Feed the Future program would create a more solid, long-term commitment to food security. A global food security policy would institutionalize the global food security and development work already being accomplished.

Participant \#18: Yeah. It wasn't until—yeah! As his second term was beginning to come to an end - and maaany people were pressing the administrationincluding, by then, Senator Lugar, who was on the outside because he had actually lost his primary in 2012. And he-I came with him to start this, still working on food security issues here [at The Lugar Center], which he began to make speeches when he went into the private sector if you will—-talking about the need for Congress and the administration to come together — and enact legislation to institutionalize global food security policy and US leadership of it. Um, and so 
it really was when the stars finally began to align and the administration sort of woke up and realized that was true-[ [that the government should work together on institutionalizing food security policy] and we didn't have an institutionalization with a law coming into enactment, that there was no guarantee it would continue.

Participant \#18 explained a process of aligning interests around the existing global food security programs and the possibility of passing legislation. President Obama and his administration "woke up" with a sense of urgency to pass a piece of legislation that would continue the work of USAID and the Feed the Future initiative. Participant \#18 retroactively made sense of this organizational decision — essentially a discursive shiftduring our interview. Participant \#18's explanation of the "stars finally beginning to align" and that "the administration woke up," could be interpreted as "a-ha" moments. In this excerpt, Participant \#18 revealed the effectiveness of the little " $\mathrm{d}$ " discourses, the interorganizational talk-in-action, that made passing a global food security act possible in retrospect. The interorganizational discourses between The Lugar Center staff and government staff strengthened interest in and support for a permanent global food security act. Participant \#18 described the communicative interactions happening behind the curtain of the public government stage. Most individuals can follow the introduction and passage of legislation within houses of Congress if they are interested in that process. What cannot be seen during the public process of congressional policymaking, or what typically happens on the Senate floor, is how the little "d" discourses unfold between food security stakeholders. The discourses shift and transform as they become institutionalized when legislative drafts become law. Participant \#18's description 
showed how the Obama administration's attitude shifted between 2011 and 2015-the beginning of more serious policy discussions about a new global food security act. Based on my interview with Participant \#18 and others, the overlapping and conflicting interests of the Senate and the President were known among members of USAID and the State Department. So, when Senator Lugar did not get elected to Congress, he could continue using his former contacts on the Hill and a new advocacy position to discursively organize global food security policy.

The prioritization and institutionalization of food security discourse happened as the USAID Feed the Future program and Bureau for Food Security members returned to Congress with progress reports of improved global food security outcomes between 2010 and 2015. These organizational artifacts provided members of Congress with programmatic success indicators including: number of households with formalized land; hectares under new or improved/rehabilitated irrigation; number of farmers who have applied new technologies or management practices as a result of US Government assistance; number of individuals who have received US Government supported shortterm agricultural sector productivity or food security training, among others. Other participants I spoke with described how university and lobbying stakeholders provided input to Congress leading up to the passage of the 2016 GFSA. These conversations supporting USAID's work on global food security constitutively layered upon each other, justifying the necessity of food security programming in the wake of the World Food Price Crisis, and adding evidence for a long-term policy solution. In the next section, I move from the perspective of an individual working for an advocacy organization to 
examining the discourses used by government employees and staffers that were central to the passage of the GFSA.

\section{Structuring d/Discursive support for the 2016 Global Food Security Act.}

In this section, I include examples of the little "d" and big "D" discourses that developed between interorganizational actors. The little "d" discourses include examples of the interorganizational talk-in-action that made a difference when the policy came under review by Congress. For example, the conversations that happened between congressional policy staffers and university administrators interested in food security. The big " $D$ " Discourses were those "culturally standardized interpretive frames historically rooted in systems of power/knowledge," such as the "moral argument" and "national security argument" for food security legislation (Jian et al., 2008, p. 305). The evidence from the interviews I conducted and the texts I examined suggest that the little "d" discourses and big "D" Discourses are in fact linked, as discussed in chapter 2. The discourses are explained in more detail below.

Specific examples and excerpts of these discourses come from congressional staff members, USAID staff, and BIFAD members working within or with the government. Knowledge and support of USAID's Feed the Future program, referred to from now on as FtF, became critical to government members trying to inform and persuade others to support the GFSA. One example of interorganizational and discursive support came from Participant \#23, a counselor to a member from the House of Representatives who helped write a draft of the 2016 GFSA. He described the small "d" discursive interactions that made a difference when the bill eventually appeared for debate on the Senate floor in 
2016. He explains how university administrators could make persuasive arguments for food security legislation:

Participant \#23: And you know, with the universities. And there's a lot of farmers that have been, that have really, you know, been very supportive and have made great contributions to the GFSA. So, it's more kind of like, lobbying groups within, within Washington, um, but then you get uh, and universities also are great. It, the, so legislatively, and I can speak more to the, sort of the legislative aspect of and the merits of the, you know, program, which you're probably more familiar with than I am. But having universities reach out, um, to um, Congressmen, Senators that were, were in uh, you know, and having them weigh in, in support of the Global Food Security Act made a difference when it came to, you know, counting votes and getting the attention of, of Congressmen. Interviewer: Wow.

Participant \#23: So that's, you know, definitely, um, you know, when, when (pause) uh, uh, you know, so it was Vanderbilt and University of Tennessee weighing in with the Foreign Affairs Committee Chairman from Tennessee. Or uh, Texas A\&M weighing in with uh, Chairman Conway in the Ag committee. You know, the, you know, that, I think, helped a lot.

Although I do not have excerpts or records of the exact face-to-face conversations that took place between farmers, university researchers/administrators, and congresspersons mentioned, Participant \#23's description nevertheless provides an inside-look at the "d"iscourses central to persuading members of Congress. What makes university researchers and administrators persuasive is the fact that they have been actively involved 
in government foreign assistance and development programs since the mid-20th century (Read, 1974). Participant \#23's description of these university actors who "helped a lot" also speaks to the discursively institutionalized foreign assistance goals written into the government Title XII legislation. The Title XII legislation had mandated more interaction between USAID and agricultural universities. Participant \#23's mentioning the university members who weighed in on the GFSA to congresspersons shows the connection between policy and action. Over the last thirty years since the mandate, USAID and Congress have in fact come to rely upon university leaders for insight regarding research that might helpfully inform food security policy. Managerial scholars Alvesson and Kärreman (2000a) refer to this kind of organizational-level discourse as mesodiscourse - situated somewhere between little "d" discourse and big " $D$ " Discourse (p. 1135). Additionally, Participant \#23's insistence that university actors were important assets in persuading Congress and passing the GFSA supports other participants' claims that through the linkage to universities BIFAD played a key role in promoting the benefits of a long-term legislative solution to food insecurity. University researchers and administrators have remained central to government development work and partnerships abroad: they act as persuasive advocates during the policymaking process. What Participant \#23 did not mention, but that I gathered from other members of BIFAD, the universities' discursive support and approval of the GFSA helped make this legislation become a priority during the 114th Congress.

Participant \#23's description of interorganizational collaboration highlighted the persuasive little "d" discourses at play leading up to the GFSA. Big "D" Discourses also helped persuade interorganizational actors in the months before GFSA's bipartisan 
passage. I read through many USAID and government documents mentioning food security, including the public BIFAD meeting minutes. Big D "D"iscourses inform historical contexts and (re)produce cultural and societal ideologies (Jian et al., 2008). Appeals to two specific Discourses are mentioned in BIFAD's meeting minutes during March 2016, only four months before the GFSA passed in the Senate. During a discussion about the Global Food Security Act between members of USAID's Bureau for Food Security and BIFAD, a government leader of the Feed the Future program and Bureau for Food Security, Beth Dunford, asked BIFAD members to use persuasive appeals that drew upon two particular " $\mathrm{D}$ "iscourses if and when they advocated for the GFSA:

Ms. Dunford responded that there is strong support for viewing food security as a global good and a national security issue from both sides of the aisle. She urged that we build upon this traction and keep the issue on the international stage, particularly by better articulating the work that we are doing, and rallying support from additional donors and alternative funding sources (p. 6).

This section from BIFAD's minutes connotes a, potentially, high level of agreement among legislators. Ms. Dunford's statement alleges that agreement already exists ("there is strong support for viewing food security as a global good and a national security issue from both sides of the aisle") and that BIFAD members should urge, "support from additional donors and alternative funding sources" for a food security bill. The content of the message given to BIFAD by Ms. Dunford advocates for the passage of the GFSA using these two persuasive discourses. 
The broader social " $\mathrm{D}$ "iscourses addressed in this section of the minutes simultaneously emphasize food security as a 1) "Global Good" and food insecurity as 2) a "National Security" issue. These two big " $D$ " discourses might be viewed as ideological tensions that build food security policy. The fluctuation of food security meaning is discussed in further detail in sections two and three of chapter 4. However, I interpret the "D"iscursive significance within this context as well. Larger social Discourses are concepts, ideas, or stories that hold a particular, shared meaning for large numbers of people (Smith \& Dougherty, 2012). Morality and the "greater good" are ideas that have been discussed, analyzed and written about for thousands of years. The "global good" related to food security would be, implicitly, the government working to ensure that no human suffers from hunger. The "national security" issue is the government assuring protection of its people and resources from food insecurity. In this excerpt from BIFAD's minutes, Ms. Dunford, and by extension USAID, insinuated that the US should take on global responsibilities as a prosperous nation. For example, the government should support passage of the 2016 GFSA for the "global good": our inherent responsibility to help solve global problems associated with food insecurity. The second larger Discourse addresses food insecurity as a "national security" issue. Other participants also discussed the links between national security and food security. And I discuss these two Discourses in greater detail under subsection three of the findings.

In another interview, Participant \#15, a congressional staffer said, "I mean, I think that the (pause) uh, big thing is that people know what Feed the Future is, and people know, you know, why there's a linkage between food security and, and national security." Larger societal Discourses are interrelated and feed into little "d"iscourses as can be seen 
in this example from Participant \#15 and others with whom I spoke. As a third example of national security Discourse in USAID's other communicative platforms, the organization explicitly explains its commitment to national and global security. This commitment can be viewed through the USAID's purpose statement on the History page of the organization's website:

Our objective is to support partners to become self-reliant and capable of leading their own development journeys. We make progress toward this by reducing the reach of conflict, preventing the spread of pandemic disease, and counteracting the drivers of violence, instability, transnational crime and other security threats. USAID referenced specific threats to "national security" such as conflict, disease, violence, crime and other security threats, presumably including food security as a security destabilizer. These Discourses are powerful and persuasive drivers for members of BIFAD and USAID because they, morality and security, speak to two essential human needs and values (Hoffman \& Ford, 2010). USAID asked its BIFAD members to draw upon the strength of these two Discourses when they advocated for support and funding. These Discourses became appealing for members of Congress from "both sides of the aisle." Relatedly, based upon the historical research I did for this study, I discovered that national security Discourse often appeared alongside national protectionist arguments which gained popularity among US leaders many times since the country's founding (Riley, 2017). The two social Discourses equipped bipartisan interorganizational actors and government legislators with shared language. Consistent with LC/MD, this shared language gave diverse stakeholders a chance to discuss the merits of the GFSA (Dougherty et al., 2009). 
Finding examples of advocacy and persuasion by an employee of the federal government urging non-government BIFAD members to speak with additional donors, appears both contradictory to and in line with USAID's eventual wishes to institutionalize the Feed the Future program in the GFSA. On one hand, government members of the State Department and other agencies are not supposed to influence the passage of legislation. On the other hand, reorganizing Feed the Future's activities from a temporary program into permanent legislation would benefit members of USAID working on Feed the Future initiatives, not to mention the developing countries where Feed the Future members have ongoing food security projects.

An interview with Participant \#11 shed light on the (dis)allowed communication practices available to USAID organizational members who might be interested in informing and persuading others to support the passage of food security legislation, as was the case with the GFSA:

Participant \#11:...Um, and now with that - uh so while we're on the subject, I guess - there are very, very fine lines that you have to walk when you work for a government agency...

Interviewer: Sure.

Participant \#11: Um, but essentially, we are [BEEP]— and when I say we, I mean the US Government — we are not allowed to [pause] influence anyone in a way that would uhhh [pause] make them inclined to support legislation. So, the word that they use is "coordinate." You cannot "coordinate" activities. So we, as a US agency, could not "coordinate" with the US advocacy community. We couldn't "coordinate" with folks on the Hill. We couldn't "coordinate" with folks like 
[NAME], and other BIFAD members, which seems coun-(pause) absolutely counterintuitive, but it's the law...

Interviewer: Yeah. There's a tension there, for sure.

Participant \#11: Yeah, you know there is. It it it, things that could be so simple, and such an easy conversation became this really awkward dance of you know calling someone and saying, "Heyyyyy, so I might have just heard someone say this. I don't know what you're going to do with that information, but if I was you, I might think about doing this. Ummm, but, you know, it's up to you." And then that person is like, "Oh! Well, what could I do? Or do you have talking points? Or X, Y, or Z." And then it becomes, "Well, I can't tell you what to say, but if you send me an information request, a formal information request about the status of the legislation, and you ask for talking points about Feed the Future, I am obligated to respond to your email." But you can—like in no way can you-and I'm I'm saying this as me. I could not in any way, in any written communication, insinuate that someone should, could, or might support the piece of legislation. Interviewer: Mhm.

Participant \#11: And even phone conversations, you have to be really, really careful because it's it is a violation of the law, and I could go to jail.

The discursive process necessary to change the temporary Feed the Future initiative from a program into a policy both constrained and enabled government members, particularly those from USAID. From Participant \#11's explanation of their involvement with this process, the policymaking rules in place constrain informed members of the US government from informing and persuading others, unless the inquirer knows how to 
appropriately seek out information without breaking the law. The rules and regulations of the US Government around communicative "coordination" are in place to protect members of Congress from outside, biased influencers. And yet, coordination could still happen by means of hidden persuasion as long as communicators shared a discursive understanding about how to ask for or receive information. Discourse is structured to be contradictory in this process. Government agencies are not allowed to inform the government's policymaking process.

Ideally, members of Congress should be able to write, debate, and vote upon new laws transparently without obscuring persuasive parties. Similarly, the mechanisms in place for funding for new laws should be separate from the advocacy community. However, the discursive reality of policymaking is much messier. The advocacy community (like lobbyists, NGOs, etc.), congresspersons, and other stakeholders (universities, corporations, different branches of government) communicatively intersect all the time! But, my interview with Participant \#11 showed the nuances of engaging in this complicated kind of discourse around the creation of a new piece of legislation.

Participant \#11's hesitancy around the topic with slowed down speech, longer pauses, and repetition of certain words show her using cautionary language throughout her explanation. Also, she engaged in warning discourse to emphasize the risk or danger of sharing this information: “...I don't want to be quoted as saying something that will get me into trouble" and "you have to be really, really careful because it's it is a violation of the law and I could go to jail." Therefore, policymaking processes become constraining for members of the US Government and for legislators. For other stakeholders, (such as advocacy groups) policy discourses can enable communicative 
interactions: for example, providing new opportunities for educating others about the subject matter of legislation through new interpersonal connections. Participant \#11 explained the obfuscated discursive dance that takes place between government members and stakeholders who have mutual interest in food security legislation. She reveals a coded way of communicating about policy: “...but if you send me an information request, a formal information request about the status of the legislation, and you ask for talking points about Feed the Future, I am obligated to respond to your email.” This particular way of communicating about the Global Food Security Act contributes to scholars' understanding of an unspoken, but internally well-known, organizational code around how successful policymaking works in Washington. Participant \#11's explanation of the awkward dance around the creation of policy also reveals underlying discursive messiness between interorganizational actors.

In this section, I unpacked some of the challenges legislators and interorganizational members ran into when they negotiated the GFSA's construction and passage. There were also counterexamples where participants recalled and discussed the GFSA's policymaking process as relatively easy-going and smooth at the interorganizational level. I called this sensemaking process of recollection, "communicative idealizing" because the participants described the years leading up to GFSA's passage through a lens of logical, and idealized, extensions of government and university interactions and research. For example, participants told similar stories of widespread agreement among interorganizational actors. Below, I interpret this story of agreement by using the resources of sensemaking theory (Weick, 1995). 


\section{Communicative idealizing: Making sense of policymaking recollections.}

Idealizing the policymaking process means looking retrospectively upon interactions from a more positive perspective. Positivity permeates the story of GFSA's passage according to some of the participants I interviewed. One way to examine retrospective organizational processes is through a sensemaking framework (Weick, 1995). Sensemaking situates organizing/organizational relationships as both constructing and constructed by the cognitive and social processes that unfold when individuals collectively make sense of an event (Deetz \& Eger, 2014). Individuals engage in sensemaking collectively even when they may all develop different meanings about an event, such as the construction of the GFSA. Basically, Weick (1995) described seven distinguishing characteristics that define the sensemaking process. These seven characteristics can explain the sensemaking process as 1) grounded in identity construction, 2) retrospective 3) enactive of sensible environments, 4) social, 5) ongoing, 6) focused on and by extracted cues, and 7) driven by plausibility rather than accuracy. For the scope of this study, I focused in on the identity, retrospective, and plausibility characteristics of the framework. My participants described their GFSA policymaking experiences especially through these properties.

Scholars have noted that the process of making sense about an event can potentially be identity threatening (Tracy, Myers, \& Scott, 2006) and so putting a positive spin on a past event may buffer one's identity and keep social bonds strong. Participants also shared an idealized story of policymaking as an uncomplicated process. By uncomplicated, I mean that participants described a communicatively one-sided perspective of interorganizational collaboration; the story leaves out challenges like 
disagreements, negotiations, and tensions. Sensemaking discusses how individuals will create meaning retroactively, and the story must be plausible. In their stories, participants offer evidence as to why the GFSA received bipartisan support and passed so quickly. As one example, I unpack an excerpt from an interview with Participant \#1. Participant \#1 had impressive knowledge and experience related to global food security and the GFSA. At the time of the interview, Participant \#1 was active on the BIFAD advisory board to USAID. The story explaining the passage of the GFSA provided by Participant \#1 reveals communicative idealizing while making sense of a series of events. Participant \#1 explained his role in the passage of GFSA:

Participant \#1: Well and let me say BIFAD was very involved in the developing and getting that bill passed... So, we were involved in all phases, so uh the legislation was drawn up to try to get Congress (pause) rather than being a product of the agency and what the agency was doing, they said, "Let's basically, let's try to get the Amer-expresses the will of the American people." So, the global, a Global Food Security Act, that is what it does; it's a very well-crafted, I think, piece of legislation it really expresses the best of the best hopes of our country and how to deal with these issues because we have been very successful in addressing global food security uh and reducing extreme poverty with the programs that have been there under Feed the Future.

Interviewer: Right.

Participant \#1: And, likewise, with the Global Food Security Act, it was the logical continuity of what we've been trying to do for the last 20, 30 years and that uh those policies have been drawn out of bipartisan support in Congress... 
Interviewer: Right.

Participant \#1: You know Democrats and Republicans, uh have both supported these approaches and so we thought that the Global Food Security Act, [pause] real strategy here was to get support on both sides of the aisle. So, we all worked closely you know and briefed various members of Congress and you know there were many, many groups involved in this, the uh Public America uhh the APLU - the Association for Public and Land Grant Universities with whom we also worked closely. There was a real coalition of uh nongovernmental agencies, private sector, and the agency itself - USAID, we try to uh get that passed. And fortunately, it did pass with the uh, with you know bipartisan support on both sides of the aisle.

Interviewer: Right! That's what I found so fascinating.

Participant \#1: (at same time) It was an excellent, yeah, an (pause) excellent expression of of what we have been doing the past many years.

Participant \#1's story of how the GFSA bill came to pass begins with BIFAD's central role in helping move the GFSA to a vote in Congress. He also claimed that the GFSA sprouted from "the will of the American people" rather than any single government agency. This claim taps into a Big "D" Discourse of "democracy." What I mean here is that Participant \#1 is playing with the notion that legislation springs from the common American person, rather than motivated organizations or other kinds of sources. Then, he discussed how the GFSA was simply the next logical step for interorganizational actors addressing global food insecurity. He bypasses any discussion of disagreement or contentious negotiating, even when I prodded by asking about the challenges surrounding 
passage of the GFSA. His recollection of the details around communicatively constructing the GFSA, that it was "drawn up by Congress rather than a product of the Agency [USAID]," leaves out the discursive complexities other participants discussed around the policymaking process.

One of the most interesting parts of Participant \#1's storying of the GFSA's construction is the assertion that the appearance of GFSA in Congress was an expression of the will of the American people. As part of the social process of sensemaking, Participant \#1 includes the fact that the GFSA was appealing to both chambers of Congress, the President of the US, and other interorganizational stakeholders. He describes the constructive collaboration as an expression of "what we have been doing for many years" ("we" including university researchers, BIFAD, and USAID). However, the GFSA was debated like any other bill, with some Congresspersons upset with the outcome of its passage. In this counterexample, the persuasive conflicts and tensions that were, at so many points along the way, integral to gaining bipartisan and national support are hidden.

During another interview with a member of BIFAD, I asked Participant \#4 an open-ended question about working with USAID on the passage of the GFSA. Participant \#4 described the contradictory role, in a similar way to how Participant \#11 discussed earlier, that BIFAD played in policymaking. As in, BIFAD members were not allowed to lobby on behalf of USAID, but they could talk as ambassadors about the passage of GFSA. Like Participant \#1, Participant \#4 communicatively idealized how the GFSA passed the Senate, possibly because they were not directly involved in drafting the bill or privy to the challenging debates related to the bill: 
Interviewer: Mhm. Mhm. Yeah. I- yeah- I definitely can see that. Uh So I want to ask you a little bit more about the Global Food Security Act. And you mentioned working with BIFAD since the fall of 2015. And I I believe that's kind of when the GFSA kind of started gaining some traction. Um, there were two congressional members, if I'm not mistaken, who started working together. And then what-I guess how does the story continue from there, working with USAID?

Participant \#4: So that bit I really can't inform you on because I was not—and we are not part of AID. And I was not party to any of those conversations at all. Um, and, and so really AID is not allowed to ask BIFAD to lobby. Some of what we do is visits to Capitol Hill. But it's simply to talk to people almost as ambassadors and advocates about how the work is going, what the investments are producing. Um, so I have no idea. This question that you have is, what was the biggest controversy around the act? I have no idea. I have no idea what they were-I uh I (pause). One of the things that everyone celebrated when it finally passed was that there was such um rotund, bipartisan support at a moment when they couldn't agree on anything else, the one thing that they could actually agree on was food security. And so everyone, including Congress, was actually happy that um that they could agree on this. But what it took to get there, I have no idea what the inner conversations, the machinations, were around that at all.

Participant \#4 recalled speaking about the GFSA as an ambassador and advocate for permanent food security legislation. However, she mentioned the organizational distance between BIFAD and USAID. This discursive distance separated the members of the two 
organizations from each other and limited Participant \#4's involvement in giving input on the bill or being able to participate in the policymaking process.

Nevertheless, Participant \#4 engaged in communicative idealizing when she made sense of how the GFSA passed through the Senate in 2016. She considered the controversies that might have come up during policymaking and stopped talking to pause. Participant \#4 then recalls that "everyone celebrated when it was passed" and that because of the bipartisan nature of the bill, everyone was "happy that they could actually agree" on the GFSA. Participant \#4 uses wholly positive language around the passage of the GFSA. Her communicative idealizing strips away organizational challenges and tensions that might have also informed the bill's passage. Rethinking how organizational actors make sense of a complicated process through communicative idealizing adds a new facet to the sensemaking literature (Weick et al., 2005). For example, determining how and when individuals describe positive memories associated with a difficult organizational incident might help organizational managers shift the language they use to accomplish particularly challenging tasks. Even a USAID Bureau for Food Security officer who was closer to the policymaking process than BIFAD members explained that “all of Congress celebrated” GFSA's passage in 2016 (Participant \#7, personal communication, 2017). Participant \#7 described how Congress "took over the [policymaking] process on its own and the Act continues the keep AID in the driver's seat" of the, now-permanent, Feed the Future programming. The process of communicative idealizing is important for organizational communication scholars because it identifies an imaginative linguistic side to sensemaking. This finding might be applied to organizations as managers look for new ways to build member camaraderie 
and agreement in the midst of increasingly diverse and mobile organizational actors. Also, communicative idealizing may create unrealistic expectations around how agreement happens in the policy building process.

In this section, I laid out "the case" of the 2016 Global Food Security Act by providing historical context. Then, I showed how little " $d$ " and big " $D$ " discourses provided a lens through which to view a discursive shift—one which turned the presidential initiative Feed the Future program into a permanent congressionallysupported policy and strategy overseen by USAID. Finally, I provided a counterexample to the discursively messy policymaking process by describing communicative idealizing, a sensemaking resource participants used to recollect challenging organizational processes with optimism and agreement. In the following section, I include a second vignette: this vignette delves into the data collection challenges that I ran into while trying to interview suspicious government participants. In the second subsection, I discuss the complex convergent and divergent policy meanings around food security. 


\section{Chapter 5: Managing Meanings}

\section{Vignette \#2: Project Paranoia}

April 2017 - Participant \#2, from AID, proved to be great at introducing me to new connections at the organization. I'm feeling confident about getting participants for the project. Participant \#2 and I have spent hours talking about food security: a communicative lens could help us develop better policymaking and implementation practices for changing the way development programs unfolded abroad. My project will be useful and interesting! She introduced me via email to two of her colleagues who worked in similar circles related to policy/development: Colleague \#1 and Colleague \#2. I spoke on the phone with each of them for an hour or more and followed up with the requisite thank you's. In the weeks after our phone conversations, Participant \#2, Colleague \#1, and Colleague \#2 sent me relevant research articles, forwarded internal emails, and informed me about upcoming food security and development conferences. July 2017 - I reach out to Colleague \#1 via email about participating in an on-the-record interview now that I had IRB approval.

Hi Colleague \#1,

I hope you're doing well since we last talked in April - I can't believe how quickly the summer is passing.

I wanted to follow up to let you know l've narrowed in on my research topic (thanks to our conversation and talks with others). I'm interviewing members of BIFAD and the USAID Bureau for Food Security about the development/construction of the Global Food Security Act and wanted to ask if you'd be willing to do a phone interview with me. I'm doing the phone interviews between now and the end of September. I recognize you are quite busy at this time, and would be happy to find a time that would be most convenient for you. If you would like to see more information about the project, please just let me know and I can send you more materials. 
Please let me know if you'd be available. Thank you very much!

Best,

Megan

No response.

I call the cell phone number I have for her and leave several voicemails.

No response.

August 2017 - I reach out again, hopeful she'll get in touch this time because we had such good phone rapport when we spoke in April.

Hi Colleague \#1,

I'm following up on my email to you from a couple weeks ago regarding participation in my dissertation on food security policy and the Global Food Security Act. I have engaged in interviews with a few of the BIFAD advisors, USAID staff from the Center for Resilience, and others about the Global Food Security Act. And I believe your experience as a policy analyst for the Bureau of Food Security would contribute additional insight to this project. Would you be willing to engage in a phone interview with me sometime in the next couple of weeks?

I would be willing to send you my research questions ahead of the interview in order to make sure our time on the phone can be used productively.

I look forward to hearing from you. Thank you.

Best regards,

Megan

No response.

[Internal monologue - August 2017] 
Maybe Colleague \#1 is out of the office, or on a field mission abroad doing research or programming for USAID? No, but she'd have an "away” message on, just like other USAID staffers I've emailed and who mentioned they were traveling frequently. What if I pissed her off during our email interactions or sounded like an idiot when talking about my dissertation project ideas on the phone call? Perhaps she doesn't think my project is worthwhile... Pshhh, why worry and who cares? I don't need her. Wait, what am I saying? Yes, I totally need her, or want to talk to her again, at the very least. She had such clear insight into the policymaking practices and relationships on Capitol Hill... And I only have two interviews so far, AND classes start up again in a few weeks. I mean, I have talked with her before and we had good rapport over the phone, so she knows I'm a legitimate researcher and not some random person (or god forbid, a journalist!). I don't know anyone at USAID. She's one of the only three or four people I do know at USAID. Gosh dang it. Why did I have to choose such a precarious project? How does this snowball sampling thing work again? Will I be able to gather enough data to write up chapters four and five by next spring?

All right. Interviews should be rolling soon. I spend so much time justifying my project over email to USAID staffers and congresspersons, I could have written chapter four in the time it's taken to send these messages back and forth, trying to secure my first couple of interviews. I follow up with thanks to Colleague \#3 from Food for Peace at USAID after she spoke on the phone with me and helped me think about narrowing my research questions in April. I promised to email her about future directions of the project after passing my prospectus defense. After getting approval from IRB, I reach out to her again 
in June - she had previously agreed to e-introduce me to several of her colleagues at

USAID.

June 2017 - A response!

Hi Megan,

Thanks for the reminder - can you please send me an email briefly describing your research in your own words? Please include the purpose for conducting interviews. That way I can simply forward that when I make the introduction.

Thanks!

Colleague \#3

Apparently, my brief research summary response isn't quite good enough though...

Hi Megan,

I actually meant can you provide a short snapshot of your dissertation? I thought I remembered something policy related - a broader significance to the research you are doing. Why is the research important and how will this interview feed into that?

I think as worded, it would be very hard to convince an extremely busy person that it is important it be them that addresses this issue for you. I think many people could discuss the multiple meanings of the term food insecurity.

I found this in the thread. Something like this - updated as necessary:

Megan is a doctoral candidate in organizational communication at the University of Missouri in Columbia. She is developing a research program that broadly encompasses how people communicate and organize around food policy. For her dissertation, Megan is narrowing in on organizational policy-making processes related to food security. In particular, she is interested in community relationships and how policy knowledge gets communicated to different groups. She is interested in focusing on the connections between organizations and food because food insecurity continues to plague populations around the world in spite of the collaborative work happening between international, non-profit, corporate, and government organizations to alleviate hunger and food insecurity. 
I rewrite the email and send Colleague \#3 a new description of my project and research agenda with more in-depth description. She emails me again. Still, there are things she'd like me to tweak...

Also, one of the people you asked to speak to, Colleague \#4, is involved in resilience measurement - can you relate that to what you are doing please? It might be easiest if you send a separate email intended for forwarding to her as I link the two of you. Also, Colleague \#5, who you asked for an introduction to, is with USDA. Do you want to send a separate email for that purpose as well?

One out of the three connections Colleague \#3 made turns into a viable interview for the project. All of this to get access to one participant? Yeesh. Feeling concerned about the prospect of garnering more participants.

Fact: It's several months into data collection and analysis that I begin to take notice of the persistent "beeps." But when I go back through my notes, I notice they had started even during that first interview. They sound gentle, unobtrusive.

Interpretation: It was probably just a call waiting on Participant \#1's cell phone.

Sometimes you can hear when a person has an incoming call on the other line.

Fact: The beeps that I notice (and write into the transcripts) continue through about half of the interviews.

Interpretation: Something strange is happening; why would these sporadic beeps continue throughout so many of the recordings? Perhaps something is wrong with my computer and the application I've been using to record the interviews. But the computer's less than a year old! And, I haven't had trouble with my voice recorder before. I notice the beeps don't appear in the recordings of the interviews I've done faceto-face (four interviews). So, it can't be a problem with my phone, because I've recorded 
interviews on there, too. Perhaps the other interviewees have had calls waiting or calls coming into their cell phones during our conversations. These are busy people after allworking for the government and running such well-connected organizations. But... What if someone or something is checking up on me? Listening in?

Fact: Interview 16 is with another member of USAID. I have made all my phone call appointments via email. During the first 15 interviews, I had the WiFi activated on my phone and computer as I recorded the phone calls with the participants. Our interview appears to go smoothly. No strange beeps, errors or issues with the recording device, as far as I can tell once we finish. I send the audio file off to a service for transcription, just as I've done with the other interview recordings. When the service sends back a notice of the finished transcription, I listen through the recording and double check the transcript. I apply the same listening and coding procedures that I've completed for all the other interviews. No beeps to be heard.

Now, there's something new and strange. The final three minutes of the interview, the volume sounds as if it was turned WAY down. The voice of my participant slowly becomes inaudible during several of her answers. I don't remember this audio trouble while doing the phone interview... Plus, I took notes during our discussion, and wrote down her responses which are now missing from the audio.

Interpretation: The sections missing from my recording include information about Participant \#16's personal background, her work at USAID and information regarding other staff members working for the organization (she had recommended the names and titles of other USAID and NGO folks to reach out to). The audio is gone from the recording. 
Interpretation: Why? Could someone or something (a program?) have tampered with my recordings in real time? Did I accidentally turn up/down the volume on my phone during the end of the interview? I hold the phone very still over my computer's microphone during the entirety of each conversation. What happened to the audio from Participant \#16? Who could access my computer recording? Or the participant's phone call? My voice still comes through loud and clear, which sounds strange next to the silence on the recording where the voice of the participant SHOULD be. Mechanical error?

Interference?

Fact: Interview 17 is also missing several large chunks of audio. Nine sections have been marked [INAUDIBLE] by the transcribers. Another nine sections have been marked with [AUDIO OUT]. I've never seen this caption before.

\section{Excerpt from beginning of transcript:}

MEGAN: Yeah. Yeah. And if you have other names, of course, you know, people I should reach out to, speak with? You know, please, you know, throw those names out. Because that's how it's been so helpful over the last couple months.

Participant \#17: Yeah, okay 3:56-4:02 [AUDIO OUT]

MEGAN: Great. That would be excellent. So, I'll just jump in and ask you first, you know, what is-what's your involvement been with food security at USAID?

\section{Excerpt from end of transcript:}

MEGAN: It was. And I will go through those quick demographic questions. Um, there's just a couple of them.

Participant \#17: Yeah, for sure. 
MEGAN: What is your age?

Participant \#17: My age is 30.

MEGAN: And your race or ethnicity?

Participant \#17: My race is, Caucasian um, white Caucasian.

MEGAN: And where are you from, or grow up?

Participant \#17: [AUDIO OUT] um

MEGAN: And where do you currently live?

Participant \#17: I currently live [AUDIO OUT]

MEGAN: And your job title?

Participant \#17: My job title is Communications Director.

MEGAN: And your highest level of education, and major?

Participant \#17: [AUDIO OUT] degree, Masters [AUDIO OUT], um, and the degree [AUDIO OUT] is in International and Intercultural Communications.

Interpretation: Again, I had remembered hearing everything with clarity during the phone call interview. Now, I'm just perplexed AND irritated. I took notes during Interview \#17 as well, but they were not detailed notes around the beginning/end of our conversation, where the audio appears most fragmented.

Interpretation: In a similar pattern to Interview \#16, the audio in Interview \#17 sounds as if an outside source is quickly turning down the volume and then turning it back up. My voice remains stable and audible through each interview. The [AUDIO OUT] sections are qualitatively different than the [INAUDIBLE] sections. [AUDIO OUT] sections have no sound whatsoever. It is as if the audio has disappeared from those moments in the interview. The [AUDIO OUT] sections appear again when Participant 
\#17 described her background, her specific work details at USAID, and sensitive information about US senators.

Fact: I reach out to a former graduate school colleague via text for technical advice. She says that she has never run into this kind of problem with computer recorders or recording applications before. However, she suggests running a test with another interview to see if the problem continues: by purchasing a backup digital recorder and running it at the same time as the computer. I go into my Amazon account and choose a digital recorder - speedy delivery.

Interpretation: Someone is definitely tampering with my data! What the hell? Why would anyone care about this project? I'm (essentially) a nobody! Yes, several participants have asked to remain nameless; yes, several participants have also asked that certain portions of our interview be kept "off the record." But most of the information I have recorded and read through does not appear to be particularly threatening or confidential. I'm now considering turning off my phone and computer WiFi each time I do another interview...

Fact: The disappearance of audio continues during Interview \#18. At the time of the interview, this participant worked for a non-governmental organization on food security and development issues, but she had also worked for the government before this current job. Several minutes' worth of discussion about the participant's status, job, and background have disappeared from the first few minutes of our phone conversation. Additionally, I have received an increase in notifications from my Academia.edu account recently. I see on the "Analytics" section of the website that the same person (or device?) has read through my (two) publications ten times over a couple weeks in 
November and December. They also viewed my information while traveling between Montana, Virginia, Maryland, San Juan, Puerto Rico, California, and China.

Interpretation: Well, it seems pretty clear that someone is checking up on me. Who would go to San Juan (except maybe a government official) right after the hurricane? Perhaps once they read through my publications, they'll realize my research is clearly not threatening to the government? But, then again, could it in fact be threatening? How? What am I missing? Maybe this person is just someone I've already interviewed and they are checking into my records and the research I've posted online.

Fact: I turn off the WiFi on my phone and computer for Interview \#19. The digital recorder has arrived. I record with both my computer and the new digital recorder. Before sending off the recording for transcription, I listen to excerpts of the audioespecially the conversation at the beginning and end of our time on the phone. From the digital recorder, the content is all there!

Interpretation: Perhaps I was just running into some odd technological fluke that has made my recordings quiet/loud over the past few weeks. Maybe turning off WiFi helped minimize some sort of equipment interference. Or, perhaps because Participant \#19 was a civilian participant (formerly USAID), but now a food security consultant, no one had a good reason for tampering with this recording?

Fact: I record the last five phone interviews (participants \#20-\#24) on the new digital recorder. I stopped using the computer recorder and turned off the WiFi on my phone and computer during each of the final interviews. The audio from these interviews is clear and easy to hear; the voices remain uninterrupted on all five recordings. In other words, no audio is missing. However, one moment stands out during Interview \#21. She 
was not a government employee at the time of the interview, but she had worked for a congresswoman on the Hill before her current role as an advocacy organization on food security issues. I notice a six-second interruption where the digital recorder picks up a [BEEP] and other background noise.

Interpretation: The noise sounds like someone hanging up a phone in the middle of our conversation, but the interviewee remained on the line and kept talking over the background noise.

Fact: I come into my office at 7:30am on March 1st to drop off my bags and coat before I head to my weekly yoga class across campus. The door is locked, like usual, when I arrive in the mornings. But, as soon as I step into the office, I notice several objects are not in their usual place around the room. In fact, many items have been shifted, moved, and placed into new locations. I don't touch anything as I try to make sense of what has happened, and I take pictures of different sections of the office, just in case anything has been taken or stolen. For example, the bean bag chair (over 50lbs and awkward to maneuver) has been flipped over and pushed across the office several feet. The trashcan has been turned around 180 degrees. My corner chair has been moved to the other side of the room and is now under my colleague's desk. All of the papers, folders, (including some handwritten interview notes for the dissertation) and books have been moved from the corner chair to my desk. Data binders from other qualitative projects have moved from the floor to my desk. Everything has been stacked in a different order. Nothing immediately appears to be missing or taken: the campus-provided computer is still on the 
desk, a sweater is still on the coat rack, a 20 Euro note even remains undisturbed in plain sight on top of my desk.

First, I visit our office administrator and ask if anyone had been scheduled to come in and clean the offices. She tells me no; students are responsible for cleaning their own offices. I also inquire about exterminators; perhaps someone had been scheduled to spray for bugs last night? She replies in the negative about this possible scenario as well. I have to leave to get to my morning yoga class on time. In my head, I try put a positive spin on the incident. I text my officemate:

Something weird happened in our office last night. Someone came in and moved stuff all around! I locked the door when i [sic] left around 6:15pm because it was still locked when i got in this morning. Just wanted to give you a heads up it is all different. I asked [NAME] but she said no one was scheduled to come in. I thought someone might have come in to clean or put mousetraps in But it looks the same cleanliness wise haha
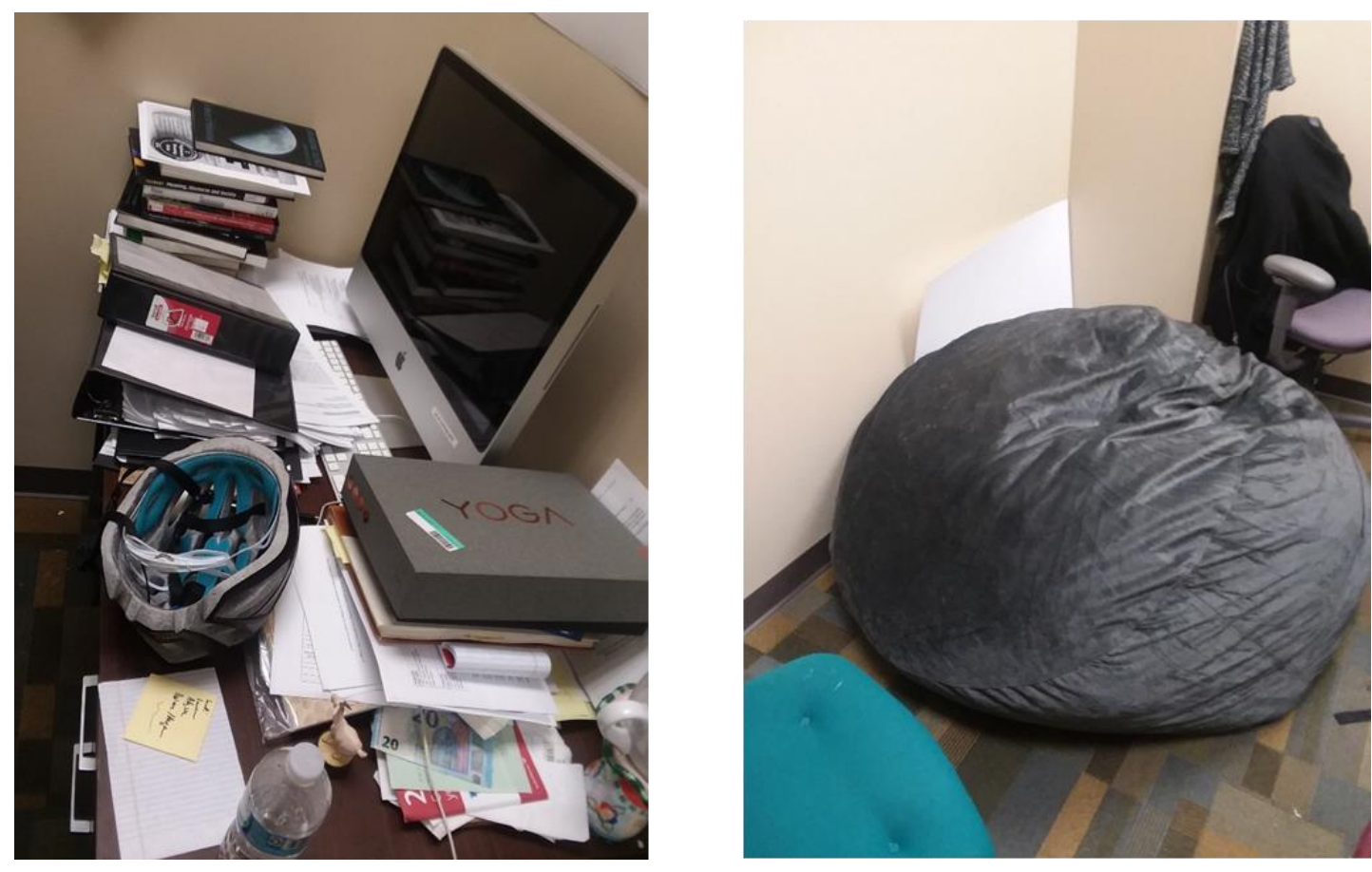

Interpretation: Huh! Maybe it looks like someone perhaps wanted to clean our carpet but there are still crumbs, hole-punch paper holes, and strands of hair across the floor. If no 
one vacuumed or cleaned, maybe they were looking to put down mouse/bug traps around the edge of the room since the chairs and posters against the wall have been agitated. Still, I find no mouse or roach traps. I briefly consider that perhaps my officemate moved items around for some reason, but wouldn't he have texted to let me know he would do this? Maybe he'll be able to give an explanation for the unusual disarray when he gets into the office.

Fact: I return to the office and my officemate is there. He insists that he remembers fully closing and locking the door the previous night after a night class ended around 8:30pm. While I was at yoga, he informed our department chair that the office was broken into and that some almonds that had been on his desk were taken. The campus police are called by our office administrator. I text my advisor. Two officers arrive. They listen to my story and take notes about the break-in while the office administrator is present. She tries to explain that there is sensitive information related to the academic journal my officemate and I work on. The officers appear confused. I try to clarify that this explanation would not make sense. I tell the officers and administrator that we don't keep anything physical related to the journal in our office. The journal is an online presence only.

The officers keep touching the door handle and lock. They explain that if the door was in fact locked the night before, it would have been ("nearly," according to them) impossible for a student or another person to get into the office, based upon the type of lock we have. They ask about who else had a key to the office. Only me and my officemate have keys, plus the master lock in the main office. The officers ask if there was anyone 
who might want something in the office. Based upon the strange incidents of missing audio, I answer "yes."

Interpretation: I feel incredibly silly and paranoid when I tell the officers that members of the government might want access to my research data. I look down quickly at my yoga/workout clothing and feel even less credible. They ask, "Who from the government might want this data?" I hesitate before answering, but then throw out acronyms like: CIA or FBI, and then add that members of the State Department might also want access to my data. I don't even know if this is true or plausible - and, reasoning while talking to them, I know it's probably not likely. The two officers raise their eyebrows and take note. I remember one officer smiling a bit as he says, "It doesn't give me a whole lotta faith if our top security doesn't know how to put things back." I feel my face turning red while I chuckle and nod. I get it - it all seems ridiculous. The younger officer gives me his card and tells me to call if I notice anything else missing.

My advisor emails the department chair, explaining that there might be some reason to believe individual(s) would want to break into the office and view my project data. Later in the morning, my officemate and I ask other graduate students and a colleague in the office next door if objects in their offices had been agitated. The graduate students I talk to in the offices downstairs do not know of anything being moved around. The woman next door to our office explains that she did notice a few objects displaced from the previous day.

I can't help thinking that someone looking for data would do exactly this kind of manipulation: make the break-in look sloppy so if I told anyone it might be someone from the government, I would not be believed, or the proposition would seem absurd and 
therefore, forgettable. This break-in shakes me. Could this incident somehow be related to the data audio disappearing or the person who kept visiting my academia.edu webpage? I mean, probably it's a student who broke in, right? I just... why would a student come in and rustle through books and papers, and turn over the bean bag chair? Grades are password protected on my computer and attendance files are locked in desk drawer. A couple months earlier, I remember students pulled a prank in the upstairs, unlocked faculty lounge. They painted the carpet yellow. This event feels different than a student prank. The whole building would have been locked after 7:30pm. The way things are turned over, moved, and rearranged makes me think the person who came into the office was looking. Nothing was taken, and all of the transcribed data the government might want access to is on my personal laptop. I keep trying to think of different scenarios and reasons for the break-in. When I think back to the moment I walked in the office that morning, I felt icky, violated. I spend a few days working from home, away from my office. I buy an external hard-drive and transfer copies of all my files to there. I carry the hard-drive around with me for a few days whenever I leave my computer at home.

A few weeks go by. No updates from the police. I start to convince myself it was likely a building engineer or bug exterminator who had to get at the edges of the room for whatever reason.

I stop thinking about the break-in. 


\section{Subsection 2: Converging/Diverging Meanings around Food Security Policy}

In this section, I show how individuals used shared language to construct multiple food security meanings since the passage of the Global Food Security Act (2016). Language Convergence/Meaning Divergence (LC/MD) provides a useful lens through which to analyze these findings. In particular, I examined how organizational actors who worked for or with USAID managed multiple food security meanings. LC/MD posits that humans communicate through the use of symbols and that individuals are constantly striving to create shared meaning (Dougherty et al., 2010). Using the explanatory power of LC/MD, individuals may share (or converge around) common language, using the same words or language to describe certain phenomena. Yet, individuals also tend to ascribe varied and divergent meanings to shared words and language. Sharing a common language should enable humans to communicate more clearly about simple and complex ideas. After examining the data, I found evidence to support LC/MD: interorganizational participants converged around the use of "food security" language when discussing the GFSA and diverged when ascribing meaning(s) to "food security."

To show examples of convergent language, I include excerpts from the interviews where participants converged around an institutional definition of "food security." Individuals working for the US government, consultants, advocates, and advisors all spoke about food (in)security using a similar shared language. A formal version of this shared language can be seen in the World Bank (1986) publication entitled, Poverty and hunger: Issues and options for food security in developing countries:

The term "food security," although interpreted in many ways, is defined here as access by all people at all times to enough food for an active and healthy life. Its 
essential elements are the availability of food and the ability to acquire it. Food insecurity, in turn, is the lack of access to enough food. There are two kinds of food insecurity: chronic and transitory. Chronic food insecurity is a continuously inadequate diet caused by the inability to acquire food. It affects households that persistently lack the ability either to buy enough food or to produce their own. Transitory food insecurity is a temporary decline in a household's access to enough food. It results from instability in food prices, food production, or household incomes — and in its worst form it produces famine.

World Bank members created the discursive foundations for the now familiar "four pillars of food security" (access, availability, utilization, and stability) definition. The US government and other global development institutions use the four pillars as a shorthand for explaining the key factors that lead to food insecurity. However, the four pillars emerged ten years after the World Bank definition at the 1996 World Food Summit, a meeting to recognize the food security work accomplished by the United Nations and the Food and Agriculture Organization. Additionally, in the more recent Global Food Security Act S.B. 1252, the meso-level (i.e., organizational) policy language describes food security using nearly identical language: "The term 'food and nutrition security' means access to, and availability, utilization, and stability of, sufficient food to meet caloric and nutritional needs for an active and healthy life" in the "Definitions," Section 3, clause 4 (p. 5). The four pillars of food security made their way into the GFSA policy. Many of the participants I interviewed shared a common language: they drew upon these meso-level and definitional discourses as the basis for their own understanding of food security. I asked all 24 participants the same question: "What does 
food security mean to you?" Many of the participants began their answer to this question by (consciously or unconsciously) referring back to parts of the institutional food security definition or by acknowledging aspects of the four pillars of food security. For example, Participant \#16, a USAID member from the Bureau for Food security explained:

Participant \#16: Mhm, well, so I think we try to be consistent with kinda the internationally recognized definition around food security, which is about access, availability, utilization, and stability of sufficient food to meet um caloric and nutritional needs for an- [trails off]

I: Mhm, yeah, sure!

Participant \#16: Yeah, we tend to stick to that definition.

In responding to my question about the definition and meaning of food security, Participant \#16 almost casually describes the consistency with which all USAID organizational members define concepts like food security. As evidence of LC/MD, Participant \#16 draws upon shared food security language by listing the four pillars framework: access, availability, utilization and stability. She also describes the nutritional and caloric dimensions of food security, harkening back to the "nutrition security" component within the meso-level discourse of the Global Food Security Act (2016).

During another phone interview, I spoke with a participant member of the Board for International Food and Agricultural Development (BIFAD) about food security and the GFSA. This individual had worked for non-profit and government-affiliated food security organizations before her current role as an advisor and consultant to USAID Bureau for Food Security through BIFAD. I asked Participant \#4 what food security 
meant to her as someone who had worked in development and food security for many years:

Participant \#4: I am, I I love strategy. I love paradigms. But I am also very pragmatic because I think the whole point of conceptual frameworks is really so that you have something that you can use to organize and operationalize. And I actually stick absolutely to the FAO definition. And so, I I know there have been literally hundreds of you know definitions of "food security." But I use the World Food Summit, FAO 1996 definition of food security. And that is the basis of all of my thinking and my writing, because I really think um (pause) it's very robust. Interviewer: Yeah.

Participant \#4: And what people love to do-- and you saw this, again, in post2008 - the first thing that scholars and academics do is they come in, and they start arguing about terms. And and and (pause) I don't understand why, when we had a very good definition and a very good framework. And I didn't find anything in any of those conversations that I found added (pause) added insight or structure to what we were doing.

Participant \#4 had worked on global food security issues and consulted with global foundations. Now in retirement, Participant \#4's knowledge about the causes and consequences of food insecurity on an international scale, guides interorganizational conversations about the challenges surrounding the tools used to measure and evaluate food security and hunger. Also, in her role as a BIFAD member, her historical experience with leading food security projects allowed her to explain the links connecting NGO work on food security issues happening in the field to the technological research being 
done at universities - the same research that informed international food security programs implemented by USAID members.

The shared language that Participant \#4 used in her discussion with me overlapped with the 1996 World Food Summit and FAO definitions. Despite sharing food security language, she acknowledged the robustness of the "food security" concept: Participant \#4 implied the existence of complex and divergent food security meanings when she mentioned the many definitions of food security. For example, Participant \#4 explained that there are "literally hundreds of definitions of food security." This acknowledgement of divergent food security meanings can be supported by Shaw's (2007) book on the history of world food security and Riley's (2017) comprehensive overview of food aid and security. When Participant \#4 said the construction of "conceptual frameworks is really so that you have something that you can use to organize and operationalize," she was speaking to the functional communicative power that individuals have when they share a language to address the challenges of food security. Sharing food security language allows individuals to build a sense of cultural security as their language converges around specific organizational definitions and concepts. Cultural security is one's sense of (dis)comfort with their culture and surroundings. After taking inspiration from Bourdieu (1991) and Dougherty et al. (2010), cultural security can also be built around how individuals share overlapping language and/or meaning with others.

Participant \#4's tone of voice shifted when she recalled discussing the development of food security definitions in meetings with other academics, although she herself had never worked in academe. She spoke in an upbeat tone to describe the 
widespread usage of FAO frameworks and definitions and then pivoted to a frustrated and disparaging tone. Under an LC/MD framework, this type of communicative association — creating positive connotations with other food security professionals, like members of FAO, and negative connotations with academics — can be described as a process of 'othering.' Othering occurs when "people with different meaning systems are socially constructed as abnormal in some way" (Dougherty et al., 2010, p. 175). Participant \#4 became impatient with conversations about food security meaning. Consequently, she lumped scholars and academics together, viewing them as unnecessarily argumentative: "The first thing that scholars and academics do is they come in, and they start arguing about terms. And and and (pause) I don't understand why, when we had a very good definition and a very good framework." In other words, academics' meaning systems were abnormal in the development/policy world. Participant \#4 communicatively positions academics as outsiders to the food security and development world. Even though she acknowledges the existence of multiple and divergent definitions of food security, she preferred to use the World Food Summit (institutional) language, "And I actually stick absolutely to the FAO definition." Participant \#4's comprehension of the complexity of food security (the material problem), and the need for a simplified, practical definition of food security (the constituted concept) speaks to what Dougherty et al. (2010) have described as an “illusion of agreement." While participants, including Participant \#4, continued sharing the same food security language, they did not share the same meanings. Shared language but divergent meanings keep an illusion of agreement alive across organizations. By othering those who could aid in the search for food security solutions, Participant \#4 
created a barrier to communicating about the importance of overlapping and multiple food security meanings.

While Participant \#4 spoke to me about the difficulties she faced when discussing definitional issues with academics and scholars, I conducted a dyadic interview with two academics (Participant \#12 and Participant \#13) who described why it was important to carefully articulate food security definitions. They had both worked with USAID and BIFAD food security professionals over the years. For example, Participant \#13 was a professor who had received government-funded research grants in partnership with USAID and Participant \#12 had worked on tackling the differences between national (US) food security issues and global food insecurity (e.g., Africa). When discussing how they defined food security, Participants \#12 and \#13 co-constructed a mosaiced definition that shared overlapping language in line with the four pillars. While using shared language to describe food security, Participant \#12 also hinted at multiple and overlapping food security meanings, acknowledging that "food security" can be misunderstood. She explained:

Participant \#12: And so, we have uh been involved in more of an educational, um, effort to help people to understand food security, um, because we find um now that we focus so much on food security, um, on a global level, that it's right here at home that we have people who don't have access to healthy foods. Interviewer: Right.

Participant \#12: And even on campuses, we have students who don't have access um to foods-period. They spend their money on just basic living um expenses, housing, and whatnot that they don't have funds for food! And so that has also 
become kind of a push on campuses nationwide to, um, have food pantries available to students so that, um, they don't suffer from insecurity as far as um nutrition is concerned. Um, [turning to Participant \#13], did you have some [thing to add]?

In Participant \#12's definition and description of food security meaning, she explains how being part of the solution to food insecurity in the US includes providing "access to healthy foods." Researching food access as part of food security was an integral part of her mission as a university leader. She explained:

At the university, um [pause] NIFA is our major funding agency, the National Institute of Food and Agriculture under USDA. They have um for the past few years identified that [food security] as one of the priority areas that in which we should focus our research. So, we um encourage our faculty to support um those initiatives by designing research projects.

She added that the geographic availability of food was key, especially when researchers examined food security at the domestic level ("right here at home"). Participant \#12 highlighted the fact that food access and availability challenges are present globally and nationally. By mentioning "healthy foods" and "nutrition," Participant \#12 discursively draws upon the "utilization" food security pillar. This pillar addresses the human body's ability to metabolize (utilize) food resources, turning food into energy and nutrients. Participant \#12 brought her colleague, Participant \#13, into the discussion of food security by asking if he would like to contribute an answer related to my question. Participant \#13 diverged from Participant \#12's answer, but still used shared food security language to describe the availability of food: 
Participant \#13: [crosstalk - No, um] certainly and usually [that that] and basically the "availability" which is quantity and quality, Participant \#12: Mhm.

Participant \#13: and also, affordability. So, if a student can't have access to food. And most of the time, people look at just the "availability" issue. If you are in the ground - on the ground - in most of these countries, the food may be there, but they don't have the income to buy it.

Interviewer: Mmm. Right.

Participant \#13: So, people sometimes misunderstood, and they only look at the "availability" issue instead of the availability. So, yeah, instead of the the Participant \#12: Affordability. [Correcting Participant \#13's wording] Interviewer: Mmm.

Participant \#13's correction of Participant \#12's response gives a clue to how these two academics define food security and share food security meanings as well as language. The participants converge in their language and understanding of the food security pillars as evidenced by Participant \#12 filling in the correct wording during Participant \#13's response. Participant \#13 also reiterates Participant \#12's point about misunderstanding or multiple meanings of food security when he said people tend to "only look at the availability issue." The participants' responses also show evidence of divergent meanings. Participant \#13 shifted Participant \#12's discussion of domestic food insecurity back to a focus on global food insecurity: "If you are on the ground in most of these countries..." By mentioning multiple meanings associated with food security (e.g., “quality," "quantity," “availability," “affordability”), Participant \#13 paints a more 
complicated picture of the ways in which individuals might define or describe global food security affiliated challenges.

From these interview excerpts, I showed how shared food security language allows interorganizational members to speak broadly, and in similar ways, about the complicated causes of food insecurity. Without a shared language, the Global Food Security Act would not have held any special meaning to USAID members, academics, or congresspersons. However, even with shared definitions and food security language, these individuals acknowledged or mentioned the multiple meanings of food security. Multiple and divergent meanings attributed to the same language can lead to othering within and across organizations. When othering occurs in organizations, communication about global challenges, like food security, can become strained or silenced. In the next section, I show the more complicated discursive movement that leads to meaning divergence. Different food security meanings develop and become reinforced through interorganizational collaborations and institutionalization in policy text. I outline the ways in which individuals engaged in what I have termed as "discourse maneuvering" processes to reconcile the multiple and divergent food security meanings. Participants diverged in two key ways: equivocation and differentiation.

\section{Discursive maneuvering: Multiple and divergent food security meanings.}

The process I have called "discursive maneuvering" describes how participants used two specific communication processes related to meaning divergence. I have termed these two processes "equivocation" and "differentiation." Overall, discursive maneuvering largely refers to the communicative movement that occurs when meaning divergence happens during human interaction. Discursive maneuvering extends LC/MD 
by providing options for scholars and practitioners to examine the ways meaning diverges and/or when there are multiple meanings in play. In the past, scholars have carefully examined organizational communication and meaning-making, showing how organizations' communicative meanings can be shut down through discursive closures (Deetz, 1992; Bullis, 1993; Leonardi \& Jackson, 2004; Koch \& Compton, 2015) and made accessible through discursive openings (Angman, 2013; Christensen, Morsing, \& Thyssen, 2015; Thackaberry, 2004). Additionally, Mortensen (1997) has examined the ways (mis)communication can happen in interpersonal scenarios through processes like distortion, disruption, confusion, and transformation. Finally, Bakhtin in his essay, Discourse in the Novel (1934), utilized the terms "centrifugal" and "centripetal" from physics to describe the forces of language. He argued that social centripetal forces act to pull all aspects of language towards one central point, or in other words, to create one common (hegemonic) language. Conversely, centrifugal forces decentralize language, or allow for the multiplicity of meanings. Language is varied with infinite meanings for individuals and groups. Bourdieu (1991), in his essays on language and symbolic power, wrote similarly about hegemonic language and how the use of a centralized language may marginalize those without political power or economic capital. My explication of discursive maneuvering extends the discursive options available for scholars to explain how language morphs depending on the possible meanings that exist.

In the current version of LC/MD, scholars have suggested that meaning diverges in two key ways. First, when different words are used to express different meanings and second, when the same word is used to express different meanings (Dougherty et al., 2009, p. 27). These two approaches are still central to LC/MD but, scholars have not yet 
shown how different meanings develop, which should be critical to understanding how interorganizational actors communicate across cultural and organizational boundaries. The meaning of food security diverges when different and shared words are used to articulate different meanings. For example, because I have been involved and invested in researching everything about "food security," I have succeeded in being able to converse with individuals who work for or with USAID. We, the participants and myself, share enough overlapping language to have a conversation about the intricacies of food security meanings. However, because I have not had the same organizational training and framing, life experiences, travels, and cultural exposure as the participants-meaning, I have not been exposed to all of the same USAID government documents, emails, reports, measurements, etc.-_internal organizational members and external organizational audiences miss out on constructing shared understandings around food security meaning.

Part of the reason different meanings develop around shared language can be attributed to the breadth of individual experience. Individuals who have different experiences will use language to make meanings about those experiences (Rivkin \& Ryan, 2017; Teubert, 2010). An individual's language may converge and overlap with the language of those who have shared similar experiences, like hunger, or diverge based on the words chosen to communicate about an experience (Hauser, Chomsky, \& Fitch, 2002; Clair, 1998). Taylor (2008) has noted that the bridge between communication and discourse is language, which has led me to the explanatory power of LC/MD. LC/MD aids scholars in bridging this gap through a framework that I argue for termed, “discursive maneuvering." 
Participants discursively maneuvered between discussions about their food security work and their relationship to food security through their own diverse experiences (e.g., living in poverty on a small farm; struggling with an eating disorder; viewing videos in elementary school of impoverished children abroad; researching plant genetics; participating in food security policymaking, etc.). Typically, at some point during the middle of an interview with a participant, they would reveal stories about their familial, cultural, or organizational background and how these stories connected them to their current food security work. These stories opened up opportunities for discussion about food security meaning misunderstandings. In each interview, I asked the participants to tell me about a time when they had used the term "food security" and were misunderstood. After pausing to reflect, participants responded with a story. These stories would either affirm or negate a recollection about a situation leading to food security misunderstanding. This question elicited participant responses that showed how divergent meanings developed around food security language. I analyzed both the content of the participants' responses as well as how they were told, or the response structure. As outlined above, meaning divergence and discursive maneuvering happened through communication processes, called equivocation and differentiation. First, I explain discursive equivocation by including instances when participants used two different words and multiple meanings in an effort to bridge gaps in understanding. These understanding gaps around the meaning of food security existed between the multilateral organizations working on food security issues, between USAID organizational members, and between food security organizations' internal and external audiences. 


\section{Discursive equivocation: Conflating hunger and food security.}

In this study, participants equivocated by using the term "hunger" when they meant "food security" which they described leading to miscommunication and misunderstandings. Equivocation has several meanings. First, equivocation can refer to the use of equivocal or ambiguous expressions, especially in order to mislead someone. Second, equivocation may refer to an ambiguous expression. Third, in studies of logic, equivocation refers to a fallacy caused by the double meaning of a word or speaking on both sides of an issue at the same time (Merriam-Webster, 2018). In this case, discursive equivocation emphasizes the interplay between ambiguous language and double meanings. Participants engaged in discursive equivocation when they used the term "hunger" as a direct synonym for food security. The participants in this study equivocated by using ambiguous expressions or drawing upon multiple meanings at the same time. One way that USAID staff and affiliated organizational members would talk about food security was by employing "hunger" with non-development workers in the same way that they would talk about food security with their colleagues. Again, participants acknowledged that food security contained multiple meanings and that these multiple meanings could cause miscommunication or confusion. Equivocation could also be useful for organizational members trying to connect with different types of audiences (i.e., lay members of the public, congresspersons, USAID staff). By using ambiguous language and multiple meanings, the participants could create emotive connections with others. In other words, the precise meaning of their language became less important than the emotive content of their discourse. I show an example of equivocation used by a member of BIFAD, the university and research advisory board for USAID, and then 
explain how emotion played a role in forming more meaningful understanding about food security:

Interviewer: Um, could you tell me about a time when you may have used the term food security and were misunderstood?

Participant \#10: It happens all the time! [LAUGHS]

Interviewer: [LAUGHS]

Participant \#10: Whether it is in a classroom, or um I'm talking to a community of people,

Interviewer: $\mathrm{Mmm}$.

Participant \#10: or people at a higher level, (clears throat) I think the connection people make is that palpable connection. And that is that, uh, you know, you're talking about hunger. And that's important in that, in the way that it is. If it meets a professional definition or not, it's very important. And so that's what people um uh refer to when they're talking about food-food security. Or times when people are, um you know, associating it with political decision-making, when the people are talking about food sovereignty and, and so on. But this is important.

Participant \#10's response created a moment of shared laughter. I felt genuine surprise after his response because I had not expected such a direct acknowledgement of misunderstanding around food security. My surprise at his directness also derived from the fact that this participant had been especially difficult to get in touch with and persuade to have a phone conversation. For thirty minutes of phone contact with him, I had done the following: Asked mutual contacts and project participants to reach out on my behalf; rescheduled our conversation several times due to timing conflicts; emailed 
back and forth a few times, then he transferred all communication to his administrative assistant without explanation; and he questioned several methodological aspects of my project after reading through my IRB approval form. But, once he began to talk about his experiences researching food security and working with USAID professionals, Participant \#10 answered my interview questions candidly and his responses contributed a great deal of insight into discursive maneuvering processes for this research project.

By explaining that misunderstandings happen all the time, Participant \#10 was one of the few people I interviewed who quickly identified food security misunderstandings and why misunderstandings actually helped create connection. He said that misunderstandings about food security happened, "all the time!" and with varying groups of individuals, "Whether it is in a classroom, or um I'm talking to a community of people, or people at a higher level." He went on to state that he managed the multiple meanings of food security by persuasively engaging in (e.g., making a "palpable connection" to other people) equivocation, substituting "hunger" for food security. Hunger is a primal feeling that nearly everyone has experienced, and the word carries a complexity of emotions with the ways it is used. The palpable, emotional connection that stirs individuals to relate to "food security" through hunger has an organizing power (Fineman, 2000). In other words, organizational actors discuss complex topics, like food insecurity, with others who might not immediately comprehend the multiple and overlapping meanings embedded in the concept. Therefore, creating emotional cues through their language forges new connections-even if that language becomes ambiguous or misleading. In organizing, Sieben and Wettergren (2010) argue that emotions, or feelings, can "serve as internal guides, and they help us communicate 
signals that can also guide others" (p. 3). By conflating "hunger" with food insecurity, Participant \#10 guides others towards a palpable connection and therefore understanding that organizes individuals and allows them to act.

Even though Participant \#10 emphasized the connections organizational members might build around "hunger," the complexities of food security remained absent from his discursive equivocation. From the tone and context of this section of the interview, Participant \#10's equivocation could be interpreted as resignation when he says, "And that is that, and that's important in the way that it is." He seems to be suggesting that food security professionals, like those individuals at BIFAD and USAID, cannot describe the key differences between food security and hunger with any greater clarity or complexity to others. From Participant \#10's description of these misunderstandings, he does not seem to be using "hunger" to purposefully confuse others but instead to communicate the palpability, the severity, of global food insecurity challenges. By making this discursive equivocation with hunger, Participant \#10 reveals the multiple and divergent meanings of food security, especially for individuals who may not be as fluent with the four pillars of food security or the "professional definition" used by development professionals.

At the end of this section in the interview, Participant \#10 mentions two additional meanings associated with food security: food sovereignty and political decision-making. Both food sovereignty and political decision-making (when related back to food security and food system issues) are complicated concepts in and of themselves, with meanings and definitions separate from the professional definition of food security. I interpreted Participant \#10's mention of these concepts at the end of his response as an effort to provide more examples of the multiple meanings of food security. 
He argues that the connections people make to food security are important, even if those meanings do not meet a professional definition: in other words, a definition that USAID professionals might use to describe the central facets of food security. The importance of distinguishing the multiple meanings of food security and how it is related to other concepts, like food sovereignty and political decision-making, becomes important for those implementing internationally agreed-upon outcomes (i.e., regular and known access to, availability of, stability, and utilization of food) compared to other development goals (such as, economic stability, crisis resilience, childhood education, gender equality, etc.).

Another example of a participant using discursive equivocation by substituting "hunger" for food security came up during an interview with Participant \#9, a USAID Bureau for Food Security coordinator. She also had previously worked on food insecurity issues in Africa. I asked her a question about the misunderstandings she encountered when using the term "food security." She responded by affirming that misunderstandings happen and then explained the broader complications food security professionals faced when trying to communicate both food insecurity challenges and solutions with members of the public:

Interviewer: And so, I was wondering if you had any experience, or times when you used that word, either abroad or here in the US, when you used 'food security' and were misunderstood?

Participant \#9: Yeah, I wouldn't use food security, generally, with the lay public. I would just say "hunger," or that kind of thing. Because you're right, it isn't something the person on the street might use. I think you're correct there. Um, I got a kind of wake-up call at a point in time. I was at a conference, and it was 
even a business kind of conference. We were all talking about the jobs we did, and, and part of our assignment was to learn about work streams and other people's work places to try to be able to describe your job in terms of work flow. And what was so fascinating to me, I took for granted that people even knew what AID did...

Participant \#9 acknowledged using food security could create miscommunication, "Yeah, I wouldn't use food security, generally, with the lay public.” Like Participant \#10, Participant \#9 describes the experience of being misunderstood when using "food security" with non-development audiences: the "lay public." Participants \#9 and \#10 presumed that lay audiences would understand "hunger" more vividly than "food security." For both Participants \#9 and \#10, misunderstandings about food security were not unusual. Participant \#9 escapes the complexities of explaining the four pillars of food security and "just says hunger, or that kind of thing." In other words, she offered lay audiences one ambiguous term, "hunger," to escape the ambiguity of another term, "food security." Lay audiences are left with two ambiguous terms and multiple possible interpretations of both. Not addressing ambiguous language about food security may become problematic for lay audiences who will need to understand how insecurity impacts their own communities, especially as more and more people begin recognizing the breadth of problems associated with food insecurity (Alvis \& Demment, 2017; Wolters Kluwer Health, 2017). Teasing out the meaningfulness of the language used by organizational members who regularly communicate about hunger and food insecurity may help clarify various problems that resonate with extra-organizational audiences. 
In the second half of the response Participant \#9 tells a story which, I argue, lays a foundation for why such misunderstandings exist around ambiguous terms. Participant \#9 described experiencing a moment of awakening at a business conference where she saw misunderstandings unfold. In a space (a business conference) where she expected to share the same language about her work and experience in food security, she found that other conference attendees did not "even know what AID did." Because others did not know USAID's mission, Participant \#9 discovered that she could not share food security meanings with these individuals. Participant \#9's experience at the conference offers readers the opportunity to also experience a disruption in constructing meaning around AID's work and Participant \#9's expertise in food security. My interpretation of Participant \#9's story is that lay audiences do not understand food security, in part, because they do not know the goals, mission, and work of USAID - an organization specifically devoted to solving food insecurity challenges. Instead of explaining the complexities of food security, engaging repeatedly in interactions that might prove cumbersome, Participant \#9 relied on connecting with others through "hunger." Participant \#9 specifically avoided using "food security" ("I wouldn’t use food security, generally, with the lay public. I would just say 'hunger'...”). Identifying these points of connection, perhaps through hunger, between food security organizational members and the public could offer new paths towards mutual understanding about USAID's work in the US and abroad. I provide a final example of discursive equivocation with an excerpt from Participant \#19, a former USAID staff member and current independent consultant on international development issues. 
While interviewing Participant \#19, I learned more about the subtle changes in food security language that could impact organizational communication outcomes. Participant \#19 also described the multiple meanings people associated with "food security." While she did not use "hunger" instead of food insecurity, she acknowledged that others used different language to address the complexities of food security. During our conversation, Participant \#19 spoke several times about using clarifying terms for both development and non-development audiences. She argued that communication and "changing the language" could persuade public audiences to invest in their food systems:

Participant \#19: So, I'm kind of changing the language, trying not to use [government] "subsidy" because I think, like, "public investment” [instead of government subsidy] in the food environment is critical to getting the kind of both of results at the individual level and at the societal level that a country wants, right?

Interviewer: Yeah.

Participant \#19: And so, I (pause) I just so strongly believe right now (laughs), I know I've just been digging in this web for the last like eight years, that we need to, we need to change the, the language and the way we discuss these things. Interviewer: Yeah.

Participant \#19: Because just saying “ending hunger," that is, like, not the right thing [pause].

Interviewer: Right.

Participant \#19: Um, "self-sufficiency" and "staple grains," not the right thing (pause). Vibrant global trade, uh, in the food industry, not the right thing. We 
aren't going to get where we want to be if we don't pay attention [to the language]. In the first part of Participant \#19's response, she explains that "changing the language" around food security issues is important. Her argument is that public audiences do not respond well to hearing the old and formal political language that refers to "government subsidy" recipients (i.e., those who receive financial aid for food), and therefore, the language around food security creates division. Participant \#19 wants to change the language around food security as well as food systems by democratizing the problem, making food security about “public investment.” From Participant \#19's extensive experience tackling global food security issues through her work with USAID, she has gained insight into the importance of convergent language and divergent meanings: "And so, I just so strongly believe right now, I know I've just been digging in this web... we need to change the language and the way we discuss these things." Participant 19 gives examples of how substituting certain words for "food security" has, in the past, not persuaded people to change their minds or behaviors. She explains that, "Because just saying 'ending hunger,' that is like, not the right thing... We aren't going to get where we want to be if we don't pay attention" to the language. She understands the complex and multi-faceted nature of food security. She argues that if we do not pay attention to the ways our language can persuade, then food security will elude nations around the world.

Participants \#9 and \#10 used equivocation to simplify the concept of food security for external audiences. Still, at the same time, they recognized the multiple meanings individuals might attribute to food security. In Participant \#19's case, she concurs that equivocating food security and hunger had been used in the past as a clarification strategy. Members of the development community have equivocated by "just saying 
'ending hunger"” when they mean food insecurity. Participant \#19's statement adds an interesting contradiction to this scenario. She argued that when individuals used different terms, it did not solve the material problems related to food insecurity, nor did different language always persuade individuals why food insecurity mattered. Nevertheless, she too discussed wanting to change the language and use different language to more precisely identify the multiple meanings implied when one uses "food insecurity." This contradiction shows just how difficult it is for organizational members to speak clearly about the complexities of food insecurity. The problems of food insecurity are both local and global. Organizational members, like those from USAID, must keep finding new ways to change the language around food insecurity in order to maintain high interest and investment in the related issues.

Participant \#19's insistence on paying attention to the language led me to the theoretical usefulness of LC/MD. Examining meaning divergence through discursive maneuvering and specifically, discursive equivocation, helps scholars and food security practitioners more deeply understand how multiple meanings develop around shared language. Participant \#19's emphasis that, "We aren't going to get where we want to be if we don't pay attention" reiterates why creating a precise language around food security could help USAID development staff coordinate on food security policy and programs like the GFSA. And yet, creating a precise language can also constrain organizational members. Apparently, using precise, technical language, like the four pillars definition that USAID relies upon, does not make for clearer communication about the issue. For the organizational members working with and for USAID, the implications surrounding their ability to draw on multiple meanings are still unknown. However, organizational 
members can and do move between food security meanings. Some meanings, like hunger, can create emotive connections between individuals, while others, like food aid which is discussed below, can become more fraught over time.

Divergent meanings can be constructed through equivocation as shown by the ways participants conflated "hunger" and "food security", and other meanings can be created through "differentiation" discourses as well. Differentiation is another way that discursive maneuvering happens when individuals construct divergent meanings as part of language convergence/meaning divergence. For communication scholars, the divergent meanings are important to identity because these examples show how discourses exist within $\mathrm{d} /$ Discourse and how divergent meanings continue to propagate from divergence. The next section explains differentiation in more depth through extended examples from participant interviews.

\section{Differentiation: Separating discourses of aid and security.}

Differentiation creates meaning divergence when individuals construct firmer boundaries between one concept and another to discursively separate the concepts, ideas, etc. To show how these firmer boundaries are created and how differentiation operates through communication, I include excerpts of participants separating discourses of "food aid" out from "food security." In the previous section, I gave examples of how the case study participants drew strong similarities between discourses of "hunger" and "food insecurity," especially for lay audiences. Sometimes, participants would use hunger/food insecurity interchangeably. However, unlike the equivocating processes they used to speak about hunger and food insecurity, participants instead described "food aid" as one of many routes to food security. Yet, "food aid" could not, and should not, be mistaken as 
the same thing as food security. Graphically, the discourses might look something like this:

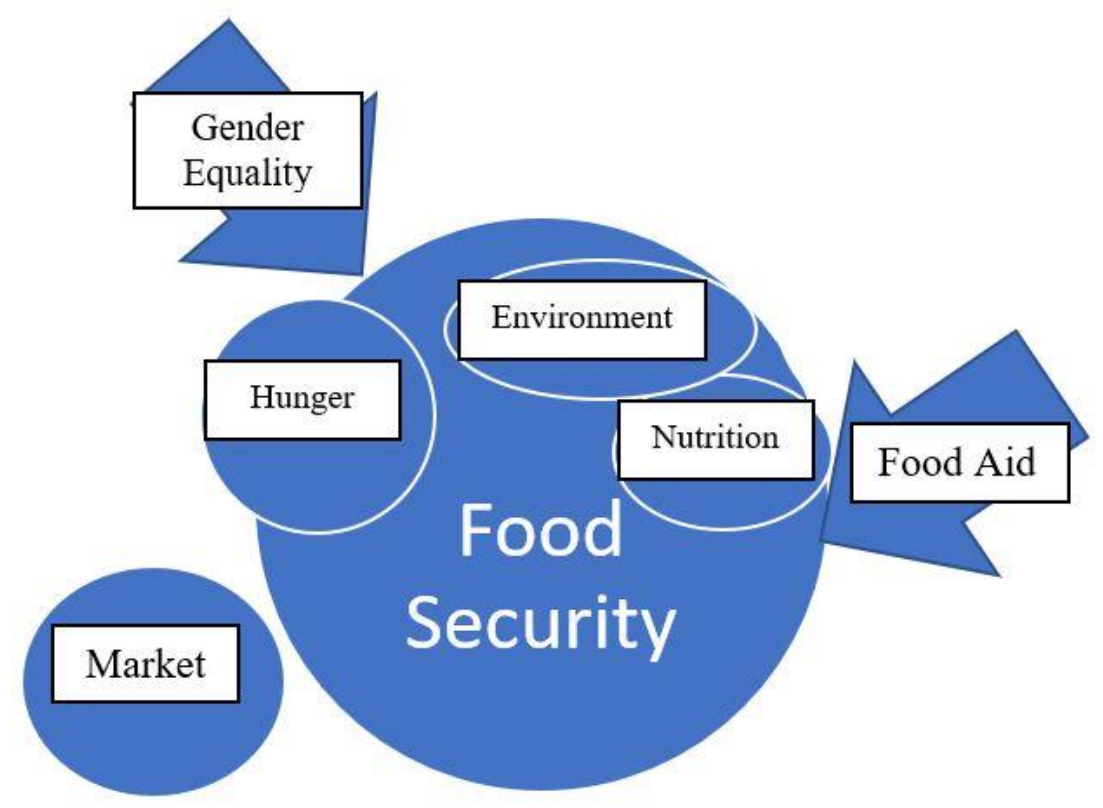

Figure 3. Overlapping discourses of hunger and food security.

Participants pulled certain discourses, like "food aid," away, separating them from "food security." And yet, food aid was still seen as one of many paths towards a community's struggle for food security. The other concepts participants recognized as integral to and part of food security, such as "the environment" or "nutrition."

Food security becomes the primary Discourse and challenge for USAID's Bureau for Food Security — a challenge that could be addressed in entirety by the Global Food Security Act. The GFSA is the US's first food security-specific piece of legislation. In figure 3, related discourses overlap with the broader "food security" Discourse. As discussed in the previous section, equivocation creates overlapping meanings between food security and "hunger." Participants sometimes purposely conflated hunger and food security, dependent on their audience. Therefore, "hunger" and "food security" are shown as overlapping in the model. 
Additionally, those who worked for and with USAID discursively differentiated, or separated out, "food aid" from "food security." Subsequently, food aid is shown further away (separate) from the centralized food security Discourse in the model. Even though the participants spoke of food aid as a separate "thing" from food security, the literature on food security still concedes that "food aid" is an important part of any government's food security plan (Riley, 2017). Because food aid still offered one of many pathways to food security, the model shows "food aid" within an arrow, signaling a pathway towards food security. Readers will notice that I included an arrow on "gender equality" outside the central food security Discourse. Although in this study, I do not discuss how "gender equality" can be a pathway towards food security, like food aid, readers can follow up by taking a look at the Committee on World Food Security's "Gender, Food Security and Nutrition policy recommendations" report (FAO, 2011). The other circles with text represent additional overlapping, competing, and divergent discourses that are a part of food security (e.g., nutrition, the environment, sustainability, etc.). Below, I give some historical context for USAID differentiating food aid from food security, and then I incorporate examples from participants.

The US's involvement in global food aid and assistance has provided many decades of contentious fodder (Riley, 2017). Justifications for/against the US providing international food aid have swung between two extremes, including 1) The moral argument, or embracing the human responsibility to help others who are suffering and 2) The political argument (lack of a constitutional US mandate necessitating foreign assistance). Both scholastically and professionally, food aid has been defined separately from food security as 1) the international sourcing 2) of concessional resources 3) in the 
form of the provision of food (Barrett \& Maxwell, 2007, p. 5). The US has provided food aid through international assistance programs since the country's founding in the late 18th century, but most scholars refer to and study the challenges surrounding food aid occurring over the last 60 years. Lay persons tend to think of food aid as the provision of cash crops (ex., soy, corn, wheat, rice grown in the US) to developing countries in the Global South (Participant \#1, personal communication, 2017). This type of food aid does still happen through the approval of US Congress. However, provisioning countries in the Global South who face acute and chronic disasters with food aid is actually more complicated now. For example, development agencies, like USAID and others, have more recently had success giving out cash rather than foodstuffs (Gelan, 2006). Conceptualizing food aid as separate from food security limits scholars and practitioners from recognizing the potential of aid as one route to food security. Differentiating food aid from food security makes the two concepts appear to be a "one or the other" solution to hunger in the eyes of congresspersons. Instead, food security is the larger umbrella concept where food aid plays a small role.

The first example showing evidence of how participants differentiated food aid from food security comes from Participant \#3, a member of BIFAD. Participant \#3 consulted members of USAID's Bureau for Food Security team on the development of the Global Food Security Act. He differentiated food aid from food security, seeing food aid as only a temporary solution to the longer-term goal of food security:

Participant \#3: But what about next year, and the next year, and the next year? If we just address the current hunger, we're not going to be able to address this [food security] on a sustainable basis. So, so what you see in the [Global] Food Security 
Act, and the one-government initiative [i.e., whole-of-government] and all that, there's a real underlying sense there of not doing away with but getting away from the concept of emergency food aid. But all emergency food aid does isobviously, it helps the person who's hungry right then, which is critical, right? But it doesn't do anything tomorrow. [Chuckles] It doesn't do anything for next year. Now, it's critical for someone who's in hunger. But, it's for too long, it's been the answer people have fallen back on.

In this example, Participant \#3 differentiated food aid from food security. The key part of Participant \#3's excerpt is this idea of "not doing away with but getting away from the concept of emergency food aid." Participant \#3's discursive maneuvering pulls food aid away from the umbrella of food security Discourse. Food aid is characterized by time. Aid is seen as temporary strategy that has failed in the long-term (“... it helps the person who's hungry right then... but it doesn't do anything tomorrow"). Food security is characterized as "sustainable," a long-term, and thereby, worthy endeavor. The US has participated in international food aid since its founding ("But, it's for too long, it's been the answer people have fallen back on") and, likely, will continue to participate in food aid in the foreseeable future. A holistic approach to food security is what gets addressed by the Global Food Security Act and USAID, but still, food security professionals and government members see aid/security as tightly associated. The Global Food Security Act minimizes the role of food aid by including it as one among many other food security initiatives.

Participant \#20, a food security professional and GFSA stakeholder from The Lugar Center, also noticed key differences that separated food aid out from food security. 
She argued, "In the beginning [of the GFSA policymaking process], there was [sic] a lot of people who did not understand the difference between food aid and food security and felt that what we were talking about was food aid." Conversations around the purpose of the Global Food Security Act required advocates to engage in differentiation to make food security fresh and interesting for policymakers. Participant \#20 explained that, chiefly, The Lugar Center educated Capitol Hill congresspersons and senators about international food security policy and development issues. Participant \#20 used differentiation discourse to separate food aid from food security saying, "Well, food aid is just, um, that's just an immediate response to a crisis... Or at least that's the way it was [laughs] developed to be..." Participant \#20 then clarified the acute nature of food aid, and the long-term nature of food security that would be addressed by the GFSA: "Where, whereas, um, you know, agricultural development is the long-term: how do you develop, you know, any country's ag sector? Which is, you know, much larger than just what happens on the farm." Participant \#20's differentiation comments speak to some of the major tensions legislators had to confront when constructing the GFSA. The passed version of GFSA still touched upon food aid-related issues, but USAID members and GFSA advocates, like Participant \#20, had to maneuver around the contentious food aid issues (shipping agricultural products abroad) that allowed them to instead highlight unique components of food security (improving a developing nation's agricultural sector). Despite the temporal dimensions, food aid has also been long-term. Other scholars (e.g., Riley, 2017) have explained that food aid legislation passed with intentions of a limited duration, but international assistance often proved more complicated since they could extend indefinitely. 
In a third example of food aid/food security differentiation, Participant \#4, a member of BIFAD, described the historical context surrounding the Global Food Security Act. Participant \#4's historical knowledge provided more insight into the complicated connotations around international food aid. Unlike previous food policies, Participant \#4 saw the GFSA as the first and only specifically food security legislation. All previous US foreign assistance legislation addressed food aid. Previous legislation, prior to the GFSA, created outlets for the agricultural overproduction of grains in the US — grains that were sent to countries bordering on famine during and after World War I and World War II:

Participant \#4: And so, what you had was this overproduction in the US. And you had this food crisis going on in Europe because of the war. So, the, the first legislation that I'm aware of, or at least the one that we talk about the most, is PL480 [Public Law 480].

Interviewer: Right.

Participant \#4: And that was not food security. That was food aid. And there is a huge difference between food aid and food security. So, it was developed as humanitarian food aid, with the real [emphasis] objective of finding a market for all of this American surplus [agricultural] production. And so, a lot of our history with legislation has not been on food security. It has been on food aid. And the development professionals - we started to see this. People started to see the problems that this was causing, because you would get all of the surplus... In the US, they started moving towards monitorizing — monetizing, excuse me — aid as opposed to just sending food. 
Participant \#4 differentiates between food aid and food security by referencing previous US food policies. Food aid, according to Participant \#4, refered to the physical transfer of agricultural overproduction, and now cash, from the US to other global locations in need of assistance. Early food aid legislation created reliable international markets for US farmers who needed to get rid of agricultural surplus. The US government, the shipping industry, and farmers all stood to make a profit when food was transported on ships to struggling regions (“...they started moving towards monetizing aid...”). This transfer of agricultural surpluses became institutionalized in US policy (PL-480) and in international development programs (USAID). According to Participant \#4 and others, food aid policy has been built upon contradictory foundations of humanitarian sentiment and profitseeking markets. Participant \#4 emphasizes that food aid is different from food security, especially in the Global Food Security Act. However, food aid still makes it into the GFSA. For example, in section 6, subsection 7 of the GFSA, the policy text reads: "Describe [in report to Congress] how the Global Food Security Strategy leverages other United States food security and development assistance programs on the continuum from emergency food aid through sustainable, agriculture-led economic growth..." While participants discursively separated food aid from food security, the language surrounding aid still gets brought into the Global Food Security Strategy - a cooperative whole-ofgovernment approach to ending food insecurity. USAID members had to differentiate food aid from food security to appeal to the congresspersons that would vote on the GFSA. Congress members did not want to see another bill like the 2009 GFSA that would change the Foreign Assistance Act. USAID framed the GFSA as different from an 
"aid" bill because it would holistically address multiple factors contributing to food insecurity and not just the consequences of hunger.

While the participants from USAID, BIFAD, and NGOs differentiated between food aid and food security, other participants from USAID and Congress revealed more intricate points of contention in constructing GFSA. The writers of the GFSA draft could have taken one of two directions. In one option, government staff members could word the GFSA to primarily be an avenue for food aid reform. But this choice would have reconstructed a policy that would have been too similar to the failed 2009 GFSA. As a second option, legislators could separately include food aid or international assistance into the GFSA as one of many routes to global food security—a small piece in the comprehensive food security puzzle. Participant \#6, a USAID member from the Bureau for Food Security, shed light on contextual issues with the Global Food Security Act and these two options for policymakers as they wrote the original bill and prepared for GFSA's re-authorization, or an appeal to Congress for continued funding.

Participant \#6: But it'll be an interesting year [2018] because there is—not only is the Global Food Security Act up for reauthorization, but also, the Farm Bill is being reauthorized. So, kinda, how we navigate those two will be interesting. I know food aid continues to be a big issue... And uh because I know that that was one of the stumbling blocks in the passage of the [Global] Food Security Act. And [a higher-up member of USAID] could tell you more about that. I think he knows more of the details, um because that, at one point, was one of the constraints, sort of the things that were roadblocks in the process, as I understand it. Interviewer: Food aid? 
Participant \#6: I mean, it's not a very deep understanding-yeah. Some of the food aid issues were contentious during the passage of that act. You may, if you go back to 2009, there was other legislation that didn't pass. This was, there was sort of an early version that did not actually pass in 2009 . You might be interested to also go back and look at that legislation, um which didn't pass, and think about what changed and what is different about the new legislation.

Food aid issues became a "stumbling block" to the passage of the GFSA. According to Participant \#6, food aid "continues to be a big issue," differentiating the discourses of assistance apart from the more popular food security Discourse. In fact, tensions around how to determine funding for food in the Foreign Assistance Act (FAA) and the first GFSA bill (2009) stood in the way of its passage nearly ten years ago. Participant \#6 hinted that foreign assistance, and food aid, reform sat at the top of legislators' wish lists. Reorganizing food aid spending was a budget priority for many US congresspersons. Tensions were strong around food aid funding because assistance had to be approved and authorized across several government departments (ex., State Department, United States Department of Agriculture, Department of Commerce). The conversations that happened around the construction of the Global Food Security Act revealed underlying points of contention related to food aid reform, even though many the participants praised the act for its speedy passage and bipartisan agreement. The points of contention around food aid reform included conversations about international grain trade and prices, disagreements with the USDA about who would oversee and manage food aid and donations, discussions about military and defense protections for aid workers, among other issues. 
Broadly, the Global Food Security Act exists to continue funding development programs, primarily under the guidance of USAID. The GFSA creates collaborations with other agencies and organizations; this is called the Global Food Security Strategy (GFSS). The GFSS has implemented and institutionalized a "whole-of-government" sharing of information and research across agency boundaries. The GFSS is meant to reduce food security program duplication while allowing individuals to work on programs connecting food security to larger social problems (poverty, gender inequality, public health, etc.). Even though the GFSA and GFSS were institutionalized two years ago and are currently in-progress, the legislation continues to appeal to bipartisan audiences in Congress according to my participants. The GFSA continues to be supported by several members of Congress because 1) senators and representatives have actively supported Feed the Future (the Obama initiative that became GFSA); 2) the GFSS coordinates activities across the government, reducing redundancies; 3) USAID and Feed the Future members have been able to provide consistent evidence to Congress that US food security programs are working, and therefore, deserve continued funding. One reason the GFSA passed in the Senate at all was because the bill did not introduce food aid funding reform. Instead, the GFSA mentioned food assistance as only a small part of a government-wide food security strategy. The GFSA and GFSS together strategically differentiate food aid as a small aspect constituent of a larger food security goal. These documents de-emphasize food aid while at the same time prioritizing several other facets of food security.

The previous excerpts show the strategic differentiation that separates food aid from global food security funding and programming. Food aid remains situated more in 
the territory of the Farm Bill. Participant \#15 discursively delineated food aid from food security, but how overlap between these two areas may happen as the two bills (Farm Bill and GFSA reauthorization) go up for renewal on Capitol Hill.

In sum, food aid can be one of many solutions to the challenges of global food insecurity, yet food security professionals used differentiating strategies to separate and distinguish food aid from food security. In terms of language convergence/meaning divergence theory, differentiation can extend our understanding of how meaning divergence occurs around specific concepts. Pinstrup-Anderson, former World Food Prize laureate and professor of food policy, described food aid as one of many multifaceted prongs in the global fight for food security: "Using food aid as an integral part of a food security policy is likely to be more beneficial to recipient countries than simply using food aid as a disposal mechanism for rich countries' surpluses" (Barrett \& Maxwell, 2007, p. xi). Pinstrup-Anderson argued that food aid strategies could be incorporated into food security policy and international development programming, like USAID's Feed the Future program, which ended up becoming institutionalized through the Global Food Security Act. Because food aid typically sparks controversy when it appears in Congress as evidenced by the fact that the GFSA of 2009 did not pass either chamber, this partly explains why USAID staff members, legislators, and others differentiate food aid from food security. There may be other reasons why interorganizational members now differentiate food aid from food security which gives me room to continue investigating this issue in future studies.

For this reason, the language in US government policies, strategies, frameworks, and program descriptions has shifted away from referring to international food assistance 
as "aid." Instead, the participant and organizational document data support that food aid becomes discursively differentiated from food security. Participants who used differentiation to connote divergent food security meanings ended up creating a more palatable path to food security, and therefore, a more widely acceptable global food security bill. By differentiating food aid from food security, participants created a path of acceptability for food security with their language. Differentiation helps create positive connotations around food security which appealed to stakeholders across the political spectrum — from senators to food security stakeholders. Participants insisted upon distinct differences that separated food aid from food security, even if they did not provide professional definitions of either concept.

This section of chapter four explains how individuals in the government and development sectors converged their language and meaning when asked to define food security. Several institutional definitions have converged around the four pillars of food security: access, availability, utilization, and stability. These components of food security re-emerge in conference proceedings, research studies, organizational minutes, and food security program strategies. Many of the participants spoke under the assumption that food security was cut-and-dry, "So, there's not a question of what they mean by the language. They've put that on paper. It is black and white” (Participant \#4). Even though the participants' language and organizational texts converged around the four pillars, I also found evidence for the presence of divergent food security meanings.

Participants and organizational texts showed examples of meaning divergence. I called this communicative movement, "discursive maneuvering." Discursive maneuvering happened in two key ways: equivocation and differentiation. First, 
participants would equivocate "hunger" and "food security." Equivocation led to ambiguity around the possible meanings of food security. Additionally, when participants equivocated about "hunger," their responses suggested the existence of an emotive component to hunger. This emotive component could create deeper connections between individuals who do not share food security language or meanings. More ambiguity might be undesirable if congresspersons and USAID members are trying to gain the support of the American public or even global support for development projects. But, ambiguity can also be useful for food security professionals if they must coordinate on food security projects and quickly act in times of need or disaster. In other words, describing food security as "hunger" might allow for faster programmatic action, agreement around policy objectives, or justification for continued government funding. Second, participants created divergent meanings by differentiating between "food aid" and "food security." Differentiating food aid from food security let policymakers and government members broaden their global development objectives while steering clear of the debates around aid. These strategies add to our understanding of LC/MD and how it functions in the space of food security policy. The theoretical and practical applications of these findings will be expanded upon in chapter 5 .

In the third section of chapter four, I include a third vignette that recounts the emotive challenges of completing the case study while searching for a job in academia. Then, in subsection 3, I unpack the discursive ways in which participants connected food security with larger US security issues, including conflict and defense. 


\section{Vignette \#3: Reaching the Mountaintop}

The phone vibrated: a bright green screen

Beckoning swift response

On my desk.

Color and sound together condition a less-and-less sweet endorphin release.

Our bodies cruelly tricked

Into desiring relief through cabled connection.

Bad news travels like a jolt

From my head to stomach, stinging the spine

One.

Painful.

Vertebrae. At a time.

An anticipation once filling my body with a forward buzzing life

is gone.

Now, a numbed shell of uncertain flesh turns the hot water faucet

Even hotter

And hotter

Until this shield that should be vulnerable feels SOME thing. 
I've never sat in this tub before, taking the time to stretch my legs.

Letting scalding pellets from above

Push away private tears while

Salt and soap form a cleansing scum

That remains.

But sad news never settles. A seedling

Of hope bursts forth

We have been called to imagine new journeys.

Anticipation rises once again

Like the resilient goat

Hopping playfully over craggy boulders

Reaching the sweetest grass

On the mountaintop. 


\section{Subsection 3: Global Food Security through National Security: Making the Case for Food Security as Defense}

When viewers visit the homepage of USAID's website, a photograph of a nameless brown-skinned woman who smiles with teeth bared and eyes focused, greets all online visitors. She wears a bright purple and turquoise-colored wrap around her head and shoulders; the saturation of the garment stands out against a blurred gray and green field behind her. The text just underneath this woman's photograph reads, "What we do: USAID is the world's premier international development agency and a catalytic actor driving development results. USAID's work advances US national security and economic prosperity, demonstrates American generosity, and promotes a path to recipient self-reliance and resilience" (What We Do, 2018). This opening statement on USAID's website encompasses the key missions of each agency bureau, including the Bureau for Food Security. In this section of chapter four, I home in on the national security connections to food security in the Global Food Security Act and how strategic ambiguity becomes a discursive resource for interorganizational members (Taylor, Bean, O'Gorman, \& Rice, 2017; Jarzabkowski, Sillince, \& Shaw, 2010). National securityrelated discourses emerged out of interviews with the participants, policy documents, and USAID organizational texts.

Part of the complexity surrounding interorganizational food security d/Discourses had to do with how individuals used ambiguous language to discuss conflict and defense and the ways in which conflict and defense connected back to global food insecurity. These connections are strategic because the linkages seemed to come up frequently and served the policymaking process. Organizational members I spoke with could have 
chosen to use language other than national security discourse about food security, such as talking about quality of the food, the impacts of climate change, or otherwise. But particularly in my conversations with USAID organizational members, their talk about how conflict and defense fit into food security policy language became strategically ambiguous. I discuss how the process was strategically ambiguous in two ways. Before I address the ways in which strategic ambiguity was used by interorganizational members to engage multiple, competing interests, I unpack "conflict" and "defense" as these terms were used in the organizational documents reviewed for this case.

"Conflict" in food insecurity contexts, often also written about as "violent conflict," in government documents refers to a serious clash of interests (ex., originating in war or disaster) (Simmons, 2017). "Defense," in food security and development contexts, refers to the government utilizing specific means (military resources or otherwise) for protecting US interests. When starting this project, I did not fully recognize the US government's expansive involvement in global conflicts or interest in using food security as a means to national self-defense. After speaking with a few participants, I quickly picked up that USAID, an agency of the US government, and other interorganizational members working on food security issues discussed "conflict" and “defense" regularly.

Hearing about conflict and defense surprised me during the interviews. Since beginning the case study project and examining drafts of the GFSA, I had only rarely seen references to either conflict or defense in the legislative language. But, related to conflict and defense is the term "security," as in "national security" and "food security." "National security" gets mentioned only once in the House of Representatives draft of the 
GFSA under Section 2a, in the Statement of Policy Objectives: "It is in the national security interest of the United States to promote global food security, resilience, and nutrition, consistent with the national food security investment plans, which is reinforced through programs, activities, and initiatives..." (2016, p. 2). In the version of the GFSA bill passed by the Senate, National Security appears five times. National security is one of the main goals of the USAID to be achieved, partly, through agriculture and food security development programming and policy. For example, under section (2), subsection 2a, the bill cites the January 2014 "Worldwide Threat Assessment of the US Intelligence Community" which states, "the lack of adequate food will be a destabilizing factor in countries important to US national security that do not have the financial and technical abilities to solve their internal food security problems" (Clapper, p. 1). National security objectives also appear under the bill's mandate for USAID to create a Global Food Security Strategy where the whole-of-government initiative shall “...demonstrably support the United States national security and economic interest in the countries where assistance is being provided" (p. 5). Even though the bill's language demonstrates the importance of food security to national security, the bill does not clearly specify how U.S. national security can be achieved through food security. The only sections of the bill that discuss how national security ties to food security are near the end of the bill where the text specifically mentions the Syrian crisis and how it is the U.S.'s duty to respond to the food security needs of displaced Syrian refugee communities (p. 7).

Even though food security seemed to be an important part to the U.S.'s national security and defense strategy, I did not know how to reconcile what I heard about "conflict and defense" in my interviews with what I already knew about the government 
achieving food security. I had been more comfortable making the discursive connections between concepts such as agriculture, gender equality, technology advancements, management of natural resources, etc. and the success or failure of global food security government development programs. The vivid stories participants had relayed to me about crisis, localized violence, and famine and the repetitive imagery of "soldiers guarding grain piles with machine guns" felt inconsistent with the more sterile and ambiguous "national security" language I had read in the GFSA and other government documents.

For instance, mentions of conflict and defense in relation to food security kept emerging during the participant interviews, but nothing I read regarding discussions of food insecurity definitions (e.g., the four food security pillars) or measurement (i.e., the Food Insecurity Experience Scale, FIES) uncovered how or why these discourses might be left out of the GFSA. Additionally, I examined other USAID organizational artifacts, looking for discussions of how conflict and defense connected to food security. Participant \#5 pointed me towards the Household Food Insecurity Access Scale (HFIAS), a scale used by USAID members to capture the experience of food insecurity at the household level (Coates, Swindale, \& Bilinsky, 2007). USAID members viewed HFIAS as a progressive way to survey and capture data on food insecure families' reactions and responses to their cultural/livelihood circumstances. While the scale integrated the four pillars of food security (access, availability, utilization, and stability) into the questionnaire, addressing many dimensions of food insecurity, hunger and nutrition, HFIAS did not address the cultural and livelihood circumstances of conflict or defense. USAID participants discussed conflict as a key cultural barrier to food security and 
national defense as central to involvement in global food security and development projects.

The ambiguous language around conflict and defense in the GFSA hints at interorganizational inconsistencies (i.e., between USAID and their collaborators) and limits broader social conversations about the important linkages among conflict, defense, and food security. Organizational communication scholars can address this limitation in three ways: 1) By describing how USAID and other governmental agencies use strategic ambiguity creatively to accomplish multiple food security goals and 2) By explaining the conflict/defense connections to food security and 3) By putting these connections, and offering a contextual, material landscape of food insecurity, back into the widely-used scales and measurements of household food insecurity or community experiences of related problems, like poverty or gender inequality.

This section relies upon theorizing about strategic ambiguity (Eisenberg, 1984) and miscommunication (Mortensen, 1997) to uncover how food security professionals used unclear language and communication strategies to accomplish policy objectives, like the GFSA. For example, international development organizations like USAID engage in strategic discourse about conflict and defense to advocate for the continued funding of long-term food security programs (e.g., Feed the Future). First, I argue that members of the government must "make the case" for food security as a national security issue. The participants I interviewed "make the case" by using strategically ambiguous language which helps them justify food security policy and funding to their stakeholders. Second, I explain how organizational members ambiguously positioned food security as a defense strategy. 


\section{Making the case for food security as a national security issue: Strategically ambiguous discourse}

Governmental members had to "make the case" for food security as a national security issue in order to pass the GFSA. The government's collaboration toward collective, interorganizational goals meant that ambiguity both spurred and obscured strategic action. Eisenberg (1984) was the first scholar to introduce strategic ambiguity in the context of organizational communication. According to Eisenberg (1984) and others who have examined communication in organizing, strategic ambiguity means "the deliberate use of ambiguity in strategic communication in order to create a 'space' in which multiple interpretations by stakeholders are enabled and to which multiple stakeholder responses are possible" (Davenport \& Leitch, 2005, p. 2). Strategic ambiguity is essential to internal organizing processes because this kind of communication: 1) promotes unified diversity, 2) facilitates organizational change, and 3) preserves privileged positions (Eisenberg, 1984, p. 227). Jarzabkowski et al. (2010) have shown that ambiguity "enables partial and multiple meanings and interests to proliferate" which partly explains why the case study participants both revealed and concealed the connections between food security and conflict/defense (p. 221). After spending time with the interview data and putting these into conversation with other organizational texts, policies, and previous research, I discuss how participants used strategic ambiguity to discuss food security as a national security issue.

\section{Making the case.}

Participants explained the links between national security and food security by telling long stories that digressed into multiple new topics. These strategically ambiguous 
stories, or explanations, put participants in control of the discourse that linked national security to food security. Taking control of the discourse gave an advantage to those who were members of the government and had to make an argument for food security as national security in interorganizational policymaking discussions. In the first excerpt below, I asked Participant \#22 about the relationship between food security and national security:

I've been hearing a lot of really interesting connections between, um, food security and, um, conflict and defense and national security, ... and, um, I was wondering if you could speak a little bit to some of those connections or how you talk about that, um, with the, with congresspersons?

I wanted, and had expected, the participant to wrestle with how food security and national security became linked together during policymaking conversations about the GFSA. I had hoped Participant \#22, a staff member in the US House of Representatives, would provide more insight into the multiple meanings of food security that specifically tied to national security. What happened was that although we shared language about food security, I did not have the same type of national security knowledge as Participant \#22. This miscommunication led to me feeling like his language was perhaps more strategically ambiguous than he meant to be. Nevertheless, this interaction led to a peripheral understanding about how these concepts became intertwined leading up to the passage of the GFSA. Participant \#22 discussed how food security and national security became linked:

Right, and so I think that that is, one of the things that we always have to deal with is, you know, when we are using funds, um, federal funds for a program, 
especially like an international program, you always have to make the case because there is among a number of people, a very strong feeling that we're spending too much on foreign assistance and I think people have a, a distorted view on how much we are spending. A lot of people think we're spending $20 \%$ of our budget on foreign affairs- or on foreign assistance, you know, which is clearly not the case. And I think, you know, there are a lot of people that say, let's just, you know, get rid of all of it and let's, let's spend the money on our own people, and I think that's where you have to make the case that it, A) is the right thing to do, B) it's in our own interest-

Here, Participant \#22 discussed why international assistance and food security needed to be strategically justified as a national security issue. He argues that the House of Representatives has to "make the case" for even a small amount of federal spending on food security. Participant \#22 draws upon the big "D" Discourses of "morality," as in national security is "the right thing to do," and that spending funds on food security is inherently a national security issue: "it's in our own interest." When Participant \#22 spoke of "our own interest," which according to my interpretation, signaled that national security interests are tied to global food security, he never gave more detail about how and why these become linked together. But through strategic ambiguity, Participant \#22 is able keep the US's global interests at the center of the conversation by being vague about the US government's involvement in food security/national security. The ambiguous talk about national security and food security allows Participant \#22 to connect these concepts and a variety of audiences with varying levels of policy 
knowledge. During our conversation Participant \#22 tells a strategically ambiguous story about the linkages between national security and development (including, food security): Participant \#22: That if we just completely block ourselves off from providing any assistance, uh, it is going to come back, you know, it's, it's, it's going to affect us in, in a different way-And, I, I know I was at a, um, dinner earlier, uh, last month, I guess it was, but, uh, you know, kind of this link between security and, and development-And, eh, there was, you know, there was a good group of military leaders and a, you know, people from sort of the State Department arena and those, but just making that strong case: that the more development you have, the less need you have for the military...

Participant \#22's story is strategically ambiguous because while he lets me see that these two realms are connected, State Department members (diplomacy and development) and the military leaders (national security and defense), he uses "making the strong case" to infer that there are important linkages without clarifying how or why. I perceived Participant \#22's story to mean that these government institutions (military and State Department) are primarily responsible for managing global conflict and food security. Additionally, Participant \#22's story argues that the US government prefers to manage global instability through development rather than military presence. He finished answering my question by providing justification for the continued funding of global development (including food security) programs.

Participant \#22: Um, uh, option, so I think the, uh, it's something that is always useful to explain to people when they say well let's just zero out any kind of foreign assistance. Because if you can make the case, look, we spend a cer- you 
know, the appropriated amount of money, and you have proper oversight, you have, uh, accountability, but if you do that and you can get people more reliant, they are going to be less likely to, uh, cause, you know, have instability in the nation, um, you know, having to, uh, you know, topple governments or whatever, you know, because you see what's happened in these countries when so many of those, uh, issues where you have instability in countries, it's caused by, you know, not having access to food-

Interviewer: Mm-hmm (affirmative).

Participant \#22: Or a food crisis, you know, just basic, the price of bread, you know, could go up significantly and all the sudden you have riot, right? Because people don't have food and so that's ... if, if you can have something where the countries have that kind of access, uh, you know, the, the citizens have the access to food, you're not going to have those kinds of security issues. And, and, and then, you know, the, the US government doesn't have to get involved later, you know, it's a preventative measure. In, instead of having to de- deal with things, um, potentially militarily later.

Finally, Participant \#22 arrived at the topic of food security by bringing up a situational story where the description revolved around a specific kind of national security issue: crisis. At the same time, he loosely links global food prices (food insecurity) to riots to national security issues. He made strategically ambiguous ties between state instability and widespread food insecurity by saying, "They [the nations] are less likely to have... instability... and topple governments." State instability could of course include other types of insecurity or conflict. The strategic ambiguities around making the case for 
involvement in global food security as a national security issue become elevated by Participant \#22's shift in the structure of his language. While responding, he moved from a few colloquial "you know's" in every other sentence to increasing the use of "uh's," "eh's," and the repetition of words within each phrase. This change in the structure of his language occurred as he spoke about making a case for the links between food insecurity and national security.

In the following subsection, I argue that participants spoke about food security as defense by using strategic ambiguity as a way to protect sensitive knowledge about food security/defense and their organizational connections to USAID. I discuss the examples as a correlative discursive strategy employed by the participants.

\section{Correlating food security and defense.}

Participants easily identified global regions that were struggling with food insecurity and regions that were embroiled in conflict (e.g., war, natural disaster, border disputes, etc.). In these instances, participants would insinuate that global food security was one of many US defense strategies. One of the participants' discursive tactics was to strategically refer to the connections between food security and defense as "correlation, not causation." In between interviews, I read through material that explained the background between food security as a defense strategy but did not find much besides the ambiguous link that essentially stated, "If all the world's regions have food security, then the U.S. will also be safe and secure." After expressing interest in these connections to my participants, some of them recommended I read other government publications, including the Quadrennial Diplomacy and Development Review (2015), a Department of State and USAID report on the global trends that constituted threats and opportunities. 
Additionally, an outside development consultant I met at the World Food Prize conference in the fall of 2017 suggested research sources as follow-up on the issue of food security as defense. Several studies definitively made claims for connecting food security and defense, while other studies debated how to connect these global issues.

For example, Verwimp (2012), commissioned by the United Nations Development Programme to examine food insecurity in Africa, found that households had difficulty acquiring income during violent conflicts, which interfered with their food intake levels. In another case, Simmons (2017), a former USAID staff member and consultant for the Center for Strategic \& International Studies, published a fifty-page report titled, "Recurring storms: Food insecurity, political instability, and conflict." This report detailed the threats continuously disrupting local and global food systems through war, climate change, market volatility, etc. Finally, the most recent Food and Agriculture State of Food Insecurity and Nutrition in the World report (2017) argued that the number of global conflicts is rising, exacerbating food insecurity and related food crises. These reports suggested that global food security was one route to successful self-defense. But, researchers have not linked how food security works as non-violent defense, except to state that places with higher level of food security also correlate with more peace. I discussed these connections with my participants. I expected that conversations with the participants about these connections would help me gain more insight into the "how," the ways individuals organized and managed global food security as defense.

During interviews, participants argued that a strong correlation existed between food security, conflict, and national security. They described the links in general terms and related the connections back to the GFSA. These conversations happened when I 
spoke with participants from USAID and with food security professionals from other stakeholder organizations. In this first example, Participant \#21, a food security policy and advocacy member from InterAction, an alliance of international NGOs who educated congresspersons and advocated for development issues, spoke about the intersection of food security and defense. The discussion of these connections remained ambiguous because of the content of her response and the halting and meandering structure of her language.

Participant \#21: Um, I think the always - the challenge with the food security, um, [long pause]. There's always a challenge with the national security argument, um, in the parts don't fully connect, um, causality with uh, just correlation. But, I think the evidence of correlation between, uh, food prices and people's access to food and, um, their, and personal security and their — and political happiness with their administration is strong. Um, and if you are healthy and uh, not hungry[laughs] and your children have access to food and you have access to food, and you're invested, and you feel that you're making money off of your local farm and you feel that you have a future, um, which is agriculture is still, one of the larger, largest employers in the developing world. Uh, if you see you have a path for a future of economic security through agriculture, um, and that your family and your friends have um, food in their bellies, and uh, a pathway to education and healthy uh, that, that promotes political stability. And when those things start to not happen and when those aren't there, um, communities are, can become unstable or can, instability can arise, and conflict can arise. Um, again as, it's hard to say - food insecurity, lack of food, is what directly caused political upheaval, 
um, but it definitely can be a correlative factor. Um, that has been seen.

Structurally, Participant \#21 changed the structure of her language during this exchange more than at any other point during the interview. She frequently paused to search for words and careful phrasing; she used "um's" and "uh's" as filler between her clauses. She stated that correlation "has been seen" but left the exact nature of the connections between food insecurity as a defense strategy ambiguous.

"Causality," a specific relationship between cause and effect, is more precise than “correlation,” or a mutual relationship between interdependent variables. Participant \#21 utilizes the broader and more ambiguous discourse of "correlation" to draw connections between food insecurity, conflict, and national security. She begins by stating that the US government (and NGOs, like InterAction) has difficulty connecting the national security argument to food security. She argues that "causality" may not link issues like political upheaval, food access, economic security and food security, even though she provides a thorough progression of how these issues become correlated. By choosing to frame this explanation in terms of correlation, instead of causality, Participant \#21 has strategically provided organizational outsiders with a more encompassing and ambiguous set of meanings. Previous scholars have argued that strategically ambiguous communication can take on negative connotations (Leitch \& Davenport, 2007). Participant \#21 actually revealed a great deal about the relationship between conflict and food insecurity, even stating that the "evidence... is strong." However, she created a strategically general description of the factors leading to food security. The ambiguous language here is not necessarily negative or positive. Because of the sensitive nature of these interviews, she might have been trying to back away from revealing too much detail, or she may not have 
had specific research on hand to back up her statements. Participant \#21 continued describing InterAction's advocacy strategy using strategic ambiguity for food security related issues.

Participant \#21: Um, and then in NGO world, it is sometimes challenging for us to make the national security argument. Um, and so we're hesitant to make the national security argument and we understand it's important to do, we do see where it comes from. But um, there's also a, not the reason why the NGO community is there and why um, I believe that they, we should be divesting in, investing in development if it's security development. Um, whether or not it's in the U.S. national security side.

She finishes this part of the interview by describing a hesitance around making a national security argument for getting involved in food insecurity development. This hesitance can be interpreted in several different ways, showing again her use of strategically ambiguous language. Participant \#21 goes back-and-forth between 1) saying her NGO finds it challenging to make a national security argument, but 2) they should be making a case for the national security argument to their audiences and 3) that national security is not the focus of her organization - they are focused on addressing the moral argument for global involvement. The overall back-and-forth language leaves the connections between food insecurity, conflict, and national security ambiguous. In other words, Participant \#21 was able to speak more precisely about the direct connections between economic security and food security, while she could only hesitantly correlate food insecurity, conflict, and national security. 
Like Participant \#21, Participant \#11 also spoke of the correlation between food insecurity, conflict and national security. Participant \#11 worked in USAID's Bureau for Food Security and described how vague references to "national security" helped congresspersons collaboratively construct national policy. These congressional collaborations ultimately helped fund global food security and development. I asked Participant \#11 to speak about the connections between food insecurity, conflict, and defense:

Interviewer: I've been talking with, um, a lot of individuals about, maybe, the more military, or defense side of food security, and wondered if you, um, had come across this component of food security, or talk about it with any of your colleagues?

Participant \#11: Yep. Definitely. Yes, so that uh is a critical piece of this. It is, frankly the argument that, uhh, helps get funding for food security. Because, the moral argument doesn't really stand anymore. Um, because every sector, whether it's injured leave [referencing Department of Labor], or education, or whatever. People argue the moral imperative. There is a moral imperative, but it's not enough. So, the link to security, um and the correlation between food insecurity and instability is both strong, and a very important message to tell, because it resonates, right?

Participant \#11 argued that the correlation between food insecurity and instability helps pass legislation for funding food security programs. Participant \#11 referenced a deliberate use of strategic ambiguity by using the "defense" argument to achieve a moral end. While the description tied these concepts together, the exact nature of that 
connection was never revealed because its function is persuasive. Participant \#11 assumed I knew what she meant by "moral imperative" and "security." I had a clearer grasp on the moral imperative (to feed hungry people around the world), but I may not have completely shared her understanding of "security" and its link to global instability (conflicts). I had interpreted "security" in relation to my question, that food security was, at least partly, a military or defense strategy to maintain US security. Participant \#11's description of the links to security remains strategically ambiguous.

Participant \#11: So, if you think about the food price spike and a lot of the unrest we all saw around the world in 2008, 2009. Well, researchers are very hesitant to uh make too strong of a linkage between the food price spike and the insecurity. Anecdotally, it's very clear. And you have food riots that then lead to instability within the government, which then weakens the government, which then allows insurgents to come in and take over territory. And I'm thinking specifically of Mali, and the Sudan. Um, so, as the demand for food grows, there's a greater risk that this will happen. So, um we have countries that have made a lot of progress on all fronts. In terms of development and policy reform. But, if they're not able to feed their people - um hungry people are angry people. And, so there will be problems ... So, you can have a country that's currently stable, backslide, and backslide very, very quickly on account of a lack of food.

Again, I found Participant \#11's discourse of “correlation,” instead of causality, fascinating. The multiple possible interpretations of whether the food price spike caused or correlated with global food insecurity shows Participant \#11 using strategic ambiguity to talk about these linkages. I could see why it may have been necessary for Participant 
\#11 to simplify and extrapolate generalized scenarios where riots and political instability lead to food insecurity. Her description of these correlations demanded that I, an American living in comparative comfort and safety, imagine an unstable world with state fragility, violent conflict, and food insecurity. Her statement about how correlation "resonates" with audiences suggests global food insecurity and conflict together create a powerful emotional appeal: an appeal that generated stakeholder interest and action.

Participant \#11's use of correlative language left me with unclear understandings about food security as defense. Strategic ambiguity through talk of correlation over causation gives USAID organizational members room to conceal or protect information about the U.S.'s defense strategy. Another way of explaining my understanding of the food security as defense argument is through a Venn diagram associated with LC/MD, where our language overlapped around the usage "food security" and "defense," yet our understandings of the interrelatedness of these concepts did not completely match.

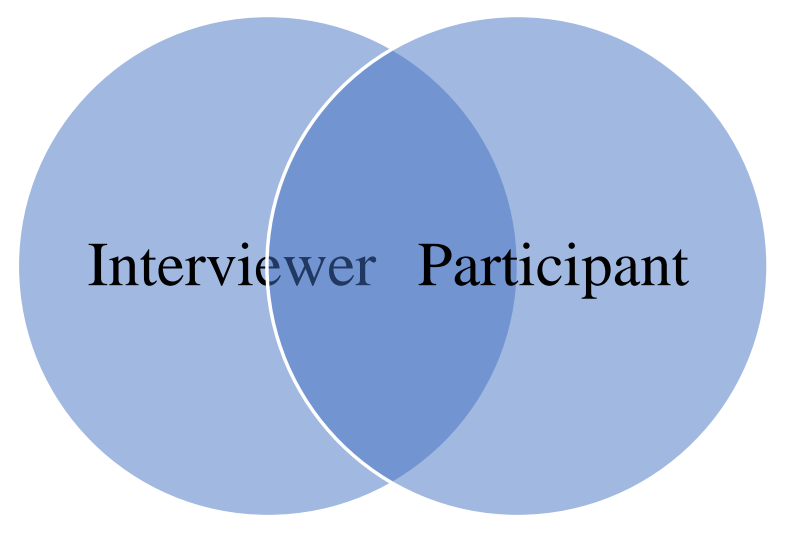

Figure 4. Overlapping and divergent understandings of "food security as defense."

When Participant \#11 and the other USAID members use strategic ambiguity to talk about food security as defense, they are furthering organizational initiatives by using intentional goal-oriented message dissemination. Essentially, the participants from the 
government needed language convergence/meaning divergence for strategic ambiguity to happen. The participants' messaging about food security as defense appeals to multiple, bi-partisan audiences and has proved more effective, according to Participant \#11, in getting legislation passed than past appeals to the "moral argument" of food security and foreign assistance.

The ways in which participants "made the case" and used correlation to argue for food security as defense helped USAID and policymakers maintain strategic ambiguity. Together, the strategies helped ensure members of the government and their interorganizational collaborators did not reveal too much information around sensitive topics, like terrorism or U.S. national security interests in relation to food security. In addition, these strategies of ambiguity allowed interorganizational professionals to work collaboratively toward broader goals of food security through policy action. In the chapter 5, I discuss how these findings will contribute to areas of the literature, including food security scholarship. Next, I discuss how the findings have implications for LC/MD theory, strategic ambiguity, sensemaking, and interorganizational research. Then, I argue that these findings will contribute significant to the practice of policymaking in the realm of food security. Finally, I cover the limitations, strengths, and future research directions for this study. 


\section{Chapter 6: Discussion and Conclusion}

In this dissertation, I introduced and explored the structure of discourses and communicative meanings created by interorganizational members who contributed to the constitution of the US Global Food Security Act (2016). I examined converging and diverging processes of the multiple and competing food security meanings used by individuals who worked for or with members of the United States Agency for International Development, or USAID. By examining these communication processes across organizational stakeholders who worked together on the construction of broader US policy, I uncovered contradictions in the ways individuals use food security discourses to secure the bipartisan passage of legislation and continued funding for international programs meant to end world hunger. This case study contributes to a larger social conversation about how to construct persuasive discourse (Dougherty et al., 2010) and expands scholarly understanding about interorganizational policy construction in the context of security studies (Canary et al., 2015; Taylor et al., 2017). First, I summarize my findings in terms of my research questions. Then, the rest of the discussion focuses on the implications of the case study analysis. I consider implications for 1) food security scholarship, 2) for LC/MD theory (Dougherty et al., 2010), strategic ambiguity (Sillince, Jarzabkowski, \& Shaw, 2012), and sensemaking in policy construction (Canary \& McPhee, 2009; Maitlis \& Christianson, 2014), 3) implications for organizational practice, and 4) I invite further analysis of the GFSA and Global Food Security Strategy through future research. I discuss the implications in further detail below.

In order to determine how interorganizational food security professionals attributed similar and divergent meanings to "food security," my first research question 
had two parts and asked, "How do the meanings people attribute to food security converge?" and "How do the meanings people attribute to food security diverge?" To address the "how" part to these questions, I closely examined the content of the participants' answers and the ways in which they structured their discourse during conversations. Participants discussed how they define food security and/or what they thought "food security" meant. Broadly, participants argued that there was widespread agreement on the meaning of "food security," especially across organizations run by or associated with food security professionals. I discussed this agreement by drawing upon excerpts from historical and policy texts referring to this agreed-upon definition as "the four pillars of food security": access, availability, stability, and utilization. I analyzed this definitional agreement as a type of language convergence. Many of the participants and organizational texts shared overlapping language related to food security and food insecurity challenges. Shared language and convergent meanings allow individuals who are part of large-scale social institutions, like the US government, to collaborate on legislation. Passed legislation can lead to more funding for significant global problems like food insecurity.

Even though significant interorganizational agreement on issues like food security can move institutions towards progress, language convergence has an equally strong counterpoint in meaning divergence. While food security professionals shared definitions and food security language, they also acknowledged or mentioned multiple and conflicting food security meanings. The participants' acknowledgment of meaning divergence brings me to the second part of RQ1: "How do the meanings people attribute to food security diverge?" I found that participants engaged in complicated discursive 
movement, or what I described as "maneuvering," where the participants' talk showed clear evidence of divergent meanings. The two ways participants engaged in discursive maneuvering happened through equivocation and differentiation. First, I argued that participants engaged in discursive equivocation by using ambiguous expressions and by drawing upon multiple food security meanings at the same time. Food security meanings tended to shift and change for food security professionals depending on their audience (ex., laypersons, family members, colleagues). As I described in the findings, participants working for or with USAID would describe the problems associated with food security in the same ways that they might talk about "hunger," especially when speaking with lay audiences. The multiple meanings and connotations with food security created moments of misunderstanding. Misunderstandings and multiple meanings can slow down the already cumbersome policymaking process.

Second, I showed how multiple food security meanings formed through differentiation. Differentiation created meaning divergence when food security professionals constructed firmer boundaries between two concepts, such as aid and security, with their language. Through exemplars, I provided differentiation examples where the participants separated discourses of "food aid" out from "food security." By differentiating these concepts for legislators and other policy stakeholders, USAID created a distinct "food security" bill, the Global Food Security Act. The Global Food Security Act, importantly, did not try to reform food aid policy which is complicated in its own right and covered under the Foreign Assistance Act, overseen by the USDA. Participants in this study pulled food aid discourses away from food security, yet still talked about aid as one of many possible paths towards food security. While drawing 
upon divergent meaning systems seems to help persuade legislators to pass food security policies, there are still concepts, like food aid, that spark controversy in Congress. Participants differentiated "aid" from "security" to create a more palatable food security bill. The language used in discussions about the GFSA and in the text of the bill itself organized those with divergent meaning systems under one food security act.

In RQ2, I asked, "What food security meanings shape the USAID and international food security agenda?" This question helped me uncover some of the most interesting findings from the case study. These findings became more and more interesting over time because I did not expect them when I began data collection or the analysis phases of research. Discovering the unexpected, or unanticipated, is one benefit of completing a qualitative project. I had expected to hear my interorganizational participants discuss food security meanings that might fit within categories associated with one of the four pillars: food accessibility, availability, stability, and utilization. But the participants instead discussed broader social constructs that they considered closely tied to food security meanings. Two food security meanings helped shape USAID's international programming and policy agenda.

The first meaning can be referred to as "the Global Good" argument. Stopping food insecurity was considered necessary by food security and development professionals for improving the "Global Good." Participants would talk about the meaning of the "Global Good" as a moral argument for fighting food insecurity and persuasively appealing to the logic and emotion of legislators, congresspersons, and food policy stakeholders. Drawing upon the "Global Good" Discourse harkens to a perspective that the US has long been seen as a beacon for democratic decision-making, and 
synonymously "hope," for people living under other, often oppressive, government systems. The US is viewed both domestically and globally as a wealthy and prosperous leader that can and should provide development guidance for other nations (Who We Are, 2018). By working collaboratively to end international food insecurity, the US is living up to a perceived social responsibility that we can solve the world's problems. This responsibility came up in organizational documents and in interviews as participants actually used the term, "Global Good" and spoke of the "moral argument" for creating food security policy. The moral argument is appealing for lawmakers because it effectively makes legislators the "good guys" when they speak to constituents and stakeholders in the US and abroad.

The second food security meaning participants drew upon to shape an international food security agenda is referred to as the "National Security" argument throughout the findings. During informal conversations with government professionals, I heard about the 3Ds of "national security." According to the USAID's 3D Planning Guide, these three "D's" include 1) defense 2) diplomacy and 3) development, which together, "provide the foundation for promoting and protecting U.S. national security interests abroad" (2012, p. 4). The interconnectedness of these three pillars is much more complex than I can manage to fully unpack in this dissertation. But suffice to say that food "security" also links to these 3Ds of national security, especially the development and defense pillars.

One of USAID's stated missions is to advance US national security interests and economic prosperity by attending to global food insecurity and agriculture through policy and programs. National security-related language appeared in legislation and in 
interviews through discussions of "conflict" and "defense." International conflicts are more likely to exacerbate food insecurity in developing regions and countries as evidenced in recent research reports (Simmons, 2017; Verwimp, 2012). Several participants who had worked for or with USAID told stories of working in locations where political conflicts coincided with occasional and chronic food insecurity (see World Food Price Crisis). Other participants who worked for NGOs and advocacy organizations had trouble drawing upon discourses of "national security" as a strong argument for implementing international food security programs. And still another participant argued that national security tied directly to US military intervention. He argued that national security actually could refer to military involvement in the sense that the US government has a vested interest in food "security." Food security in this case meant protecting international agricultural products and trade to the benefit of US citizens over international populations.

I explored the dominant meanings around food security as a "National Security" issue in more depth through RQ2a: "How do food security meanings shape the USAID international food security agenda?" I answered this research question by examining the ways in which participants talked "made the case" for food security as a national security issue and the communicative structure of how participants constituted food security as defense. In order to fund the GFSA and enact USAID development programs, the participants described how important it was for the government to "make a case" for international involvement. USAID works in collaboration with many stakeholders from a wide variety of organizations: non-profits, corporations, advocacy and lobbying centers, universities, international governments, and more. USAID and government actors use the 
multiple and divergent meanings of "national security" to make a case for leading food security programs in other countries. Additionally, participants used discursive strategies to construct an argument for food security as defense, which provided congresspersons with strong justification for passing the Global Food Security Act. When participants used strategic ambiguity, they appealed to multiple audiences. Their linguistic choices also prevented them from having to create specific meaning(s) around food security and allowed them to maintain strategic ambiguity in persuasive efforts. USAID benefitted from strategic ambiguity because it allowed legislators to retain a bipartisan position. These strategies helped organizational members avoid conversations about how international food security programs serve to protect US citizens. Another benefit to organizational members using these strategies is that they can use strategic ambiguity through language convergence/meaning divergence. In other words, food security professionals can speak to the interests and concerns of multiple audiences by engaging in this type of discourse.

There are several important and meaningful implications of this case study analysis. First, I present the implications for food security scholarship. Next, I discuss implications for theory, focusing particularly on LC/MD theory, strategic ambiguity, and sensemaking in policy construction. I also touch upon this study's contributions to the interorganizational literature. Third, I describe implications for organizational practice. Finally, I address the limitations and strengths of this qualitative case study and conclude with suggestions for future research exploring meaning-making in policy construction, particularly in relation to the Global Food Security Act. The GFSA is a piece of legislation that will be important for future international development projects. 
Additionally, the policy language will continue to come up for reauthorization every few years with successive meetings of Congress.

\section{Implications for Food Security Scholarship}

Food (in)security is a condition that organizes human beings, and humans will continue to organize around their food status. Food security provides a powerful lens through which to view communicative processes like language convergence/meaning divergence, (mis)understanding, the strategic use of ambiguous language, and sensemaking. Food security has become central to domestic and international conversations about humanity's capability to collectively survive diminishing and unevenly distributed natural resources (FAO, IFAD, UNICEF, WFP, \& WHO, 2017). The overlapping language and competing meanings discussed in this study contribute to a larger conversation about the social and material causes and consequences of food security. This conversation will only become louder as humans confront new difficulties in accessing and utilizing food resources.

I have identified three primary implications for food security scholarship in this dissertation. The first implication relates to the definition and symbolic meaning of "food security." The second implication contends with the cross-cultural aspects of food security policymaking, especially as US leaders move the country towards nationalist ideals. The third implication explores how food security can continue to guide interorganizational collaborations. I discuss these implications below.

\section{Defining food security.}

Throughout this dissertation, I have referred to the four pillars of food security: access, availability, utilization, and stability. These four pillars have long guided scholars 
and practitioners who have been interested in measuring, recording, and ameliorating food insecurity as well as its related challenges including poverty, gender inequality, health care, etc. However, both scholars and practitioners have also acknowledged that the definition of "food security" can be varied and contentious (Jarosz, 2014; Maxwell, 1996). Although the professional definition of food security has not changed significantly in the past thirty years, the use of food security language and its meanings have shifted based upon evolving historical and contextual circumstances.

As Participant \#24 mentioned during his interview, the problem with using food security language does not reside in being able to define or agree upon the definition of "food," but in determining the meaning(s) of "security." From the interviews I conducted, the conversations I had, and the policies I analyzed over the past year, the data and experiences all confirmed overlapping and competing "security" meanings. In this dissertation, I focused on the multiple and competing food security meanings that led to misunderstandings. The findings showed how interorganizational professionals discussed, with contention, the meanings of hunger, food aid, and security/defense.

Food aid connotes helping those who cannot help themselves. The US government and agricultural system has come to the rescue of other nations many times over the past three centuries (Riley, 2017). Because of this cyclical history of the US spending and sending food aid to help others, food aid currently has negative connotations among many government members and lay persons alike (Participants \#19 and \#23, personal communication, 2017). Food security professionals have told me that it is crucial for the government to distinguish food security from food aid in order to successfully implement the Global Food Security Act through the interagency Global 
Food Security Strategy. Distinguishing "aid" from "security" entails changing the language and educating others about the holistic approach uniting policy and practice. Universities have become an essential communication resource for both changing the language and for food security education.

Through this case study, I have described how the US government draws upon the resources of the university system to pass food security policy and implement food security programs. As one example, BIFAD has provided a link between university food security researchers and USAID international development programming. The Association of Public and Land Grant Universities (APLU) is another essential organization that has linked government—including USAID—and universities systems. The APLU organization recently published a report called the Challenge of Change (Alvis \& Demment, 2017) which carefully distinguishes multiple facets of food (in)security. The report offers scholars and practitioners a more nuanced approach to separating food security, and its multiple meanings, from food aid and hunger. For example, the report breaks down the food security "pillars" into seven specific "challenges" discussing the ways universities can collaboratively address global food insecurity. I have included a summary of the challenges below.

Under the food security "availability" pillar, the Challenge of Change report proposes the following: 1) Increase yields, profitability, and environmental sustainability simultaneously, 2) Develop the varieties and breeds needed for sustainable food systems, and 3) Decrease food loss and waste through more efficient distribution systems. Under the "access" pillar, the report proposes that interorganizational actors can: 4) Create and share resources that serve all populations, and 5) Ensure inclusive and equitable food 
systems, and finally under the "utilization" pillar: 6) Address the dual burdens of undernutrition and obesity to ensure full human potential, and 7) Ensure a safe and secure food supply that protects and improves public health. The language used in this report begins to distinguish what is and is not included in food security strategies. Yet, the conversations happening between interorganizational actors at the levels of policymaking, advocacy, and international programming still show communicative gaps. In my findings, I exposed a communicative gap by arguing that some of the ways participants were using "security" did not fit within any of the existing four food security pillars, especially when "security" meant protection from conflict, or defense. What makes "filling the communication gap" tricky is that food security professionals were still unclear in explaining how a community's food security status defends the US population. The closest participants came to describing the connection between food security and defense was when they would make the link between an individual farmers' access to the global marketplace, for their agricultural products, which would provide a path for economic security and secure enough life satisfaction to ensure overall political stability (see Participant \#21).

A communicative gap exists between the following: 1) assumptions behind the meaning of "security," particularly if there are multiple meanings used in discussions by food security professionals and 2) the meaning of "security" that gets written into policy language and/or organizational texts, like the Global Food Security Act. Many of the participants defined food security using the professional definition when they referred to one or more of the four pillars. In contrast, other participants in this study associated food security with other concepts like gender equality, agriculture, trade and free markets, 
transportation systems, land rights, etc. As a third and new meaning, food "security" communicated a strategy that protected US citizens and defended their personal safety and economic/political interests. This third strategy was described by three participants (\#5, \#7, and \#8). It is this third version of "security," related to food, that has recently become further integrated in the government's organizational texts and communications, such as the Intelligence Community Assessment (2015) of global food security and the Global Food Security Strategy implementation report (2017). As the connections between food security and conflict/defense become more widely acknowledged, new discourses of "security" will likely shift the definition and indicative measurements of food (in)security.

However, at the time of this study, food security professionals were still hesitant to discuss and make connections between global conflict, food insecurity, and the defense of US national interests. I surmise these individuals may have been uncomfortable discussing the ties between food insecurity and conflict for several reasons. First, food security professionals are required to describe cases where food security programs have been successful when they report back to Congress. Successful cases provide good evidence for more or continued funding. If food security programs become interrupted or fail due to situations of conflict or violence, then US government members may not want to highlight these kinds of incidents. Second, several participants spoke of correlations between food insecure regions and communities plagued by conflict. These participants were careful to state that these connections were not necessarily causal, as in conflict causes food insecurity or food insecurity causes conflict, but that local conflicts could be correlated with exacerbated food insecurity in certain communities. Finally, participants 
may have felt uncomfortable speaking with me about conflict and food insecurity. They might have felt uncomfortable for several reasons. One reason might have been that many of the participants did not know me well enough to trust me with sensitive government information. A second reason might have been that the participants just felt uncomfortable speaking on a topic where they were not the expert with enough information or background. I fully acknowledge that I am an outsider to the complicated world of government global development projects and policymaking practices. It is possible that the participants were actually comfortable discussing conflict's role in food insecurity, or that they are more comfortable speaking on this topic with other food security experts.

All of the insights discussed in this section will contribute to the growing body of research that brings together "security" studies and communication (Taylor et al., 2017). For example, Taylor et al. (2017) have called for researchers to explicitly conceptualize and theorize the relationship between communication and security. This entire study examines discourses of food security, effectively linking communication and security. Additionally, Taylor et al. have recommended that communication scholars engage with security institutions, which I have done by interviewing participants from USAID, a US government institution devoted to security through international development programs. Finally, this study extends scholarly understanding about the distinctive structures of meaning that organize the experiences of food security professionals (Jensen, 2013). I uncovered how organizational members' multiple and competing food security meanings constituted the GFSA. This study will be useful to food security stakeholders and policymakers in the future. The findings I have uncovered about the linkages between 
food security as defense could help USAID members justify food security policy to congresspersons as well as lay audiences.

Above, I argued for expanding and (re)defining food security based on my case study findings. Insights into the communicative boundaries separating and linking food aid, hunger, and conflict should reinvigorate scholars' interest in development and security language. In the next section, I describe implications for the central theoretical perspectives I engaged in my analysis of the data, including Language Convergence/Meaning Divergence, Strategic Ambiguity, and sensemaking.

\section{Implications for Theory}

\section{Language convergence/Meaning divergence.}

As discussed in the literature review, there are three key elements to understanding LC/MD theory (Dougherty et al., 2009). First, language convergence means that common labels or words can be used to facilitate meaning-making between individuals and groups. Second, meaning divergence can happen when people use the same words or labels to identify different meanings. Third, combining language convergence and meaning divergence can function as an illusion or barrier to actual shared meaning. I examined evidence that appears to support these three LC/MD tenets. LC/MD functioned as a useful lens for examining the data, especially as I interrogated participants' shared labelling of food security.

Most of the participants took for granted that food security could be viewed as a contentious topic. I know this because I had a hard time persuading some of the participants and other food security experts I reached out to but who turned down an interview because they did not believe that a deeper investigation into the multiple 
meanings of food security was a worthwhile endeavor for a dissertation project. For the food security professionals who agreed to speak with me, I asked them, "What does food security mean to you?" The participants' responses supported LC/MD, particularly when they drew upon the "four pillars" language of the widely-accepted professional food security definition. Participants would even say things like, "So there's not a question of what they mean by the language. They've put that on paper. It is black and white," (Participant \#4) or "I feel like at this point in the game, it's very widespread alignment in how people are conceptualizing food security. I haven't run into ambiguity or debate on that front” (Participant \#5). Participants often responded to my question by reciting a definition of "food security." While definitions and conceptual meanings can certainly overlap, I also argue concepts' meanings are more complex, which brings me to the divergent meanings participants constructed throughout the interviews. For example, participants used the same words and labels (i.e., food security) to create new and divergent food security meanings. The convergence/divergence of meanings becomes cyclical. Participants used divergent language in order to converge around similar meanings, and yet, the participants also constructed divergent meanings while converging their use of language. This communicative process is an underdeveloped piece of the LC/MD framework.

Previous scholarship has argued that meaning diverges in two primary ways. First, meaning diverges when different words are used to express different meanings. Second, meaning diverges when the same word is used to express different meanings (Dixon \& Dougherty, 2014; Dougherty et al., 2009; Dougherty et al., 2010). Through my analysis, I have shown how divergent meanings develop across interorganizational 
boundaries. Explaining how meaning divergence occurs is a new extension to LC/MD theory. I described two different strategies, explicating how meaning divergence happens: equivocation and differentiation. First, I discussed equivocation and meaning divergence, and then I discussed differentiation. Discursive equivocation and meaning divergence occurred when organizational actors would use ambiguous expressions which led to participants describing food security through the use of double meanings. I provided examples of equivocation when I explained excerpts that described how government members and food security professionals would talk about "food security" with their stakeholders and audience, yet the government members would actually use the term "hunger" to emotionally connect with their audiences. Meanings include both the emotive content of language and the dictionary definition. These linguistic aspects are both tightly and loosely woven, dependent on who constructs the communicative meanings. One question that remains after analyzing language convergence and meaning divergence is, "How does food security through national security drive emotive connection and fit into a consistent definition?" Emotion might become just one fragment of an individual, or an organization's meaning system. For some, emotion becomes an incredibly persuasive and powerful tool used to manipulate peoples' meaning systems, while for others, the emotion behind language meaning might be only peripheral.

From this study, it seems clear that different kinds of challenges exist that revolve around food. These challenges could include everything from transportation to food waste, to high commodity food prices, to poor soil drainage, to new pests, and uneven demand for crops, and on and on. Equivocation and meaning divergence had a purpose for interorganizational actors. The communicative purpose of equivocation for 
development and government workers was to connect the diverse food-related challenges of faraway communities to policymakers (who are not suffering from those same food challenges) in Washington, D.C. and influential advocates at other organizations. Participants who had spent their lives working on food security issues (ex., Participant \#19 and Participant \#24) argued that using multiple meanings and "changing the language" was necessary to reach different audiences, especially if organizations wanted to tackle food insecurity. When organizational members use "food security" language and meanings, the organizations must consider how different meanings might resonate with their different audiences. For example, is the organization trying to communicate a food security solution through the implementation of a government program? Or is an organization using policy language to accomplish change? These questions will be important for food security organizational members, from organizations like USAID, to reflect upon and ask throughout interactions with food insecure communities. Additionally, USAID should consider the implications of communication with those who might have the power to lead change, such as country governments, international food security organizations, and others. Often in communication studies, we talk about the consequences of communicative actions, or in other words, communication effects. Here, I am arguing that the intentionality behind those communicative actions, the use of multiple meanings, matters based on how interorganizational members communicatively collaborate and use discursive maneuvering processes like equivocation to solve food insecurity problems.

Another way participants created multiple meanings was through differentiation. Differentiation created meaning divergence when participants communicatively created 
firmer boundaries to discursively separate concepts from one another. I showed how participants used differentiation to separate concepts like "food security" from "food aid," which many might argue are concepts that have significant meaning overlap or could be considered the same (Riley, 2017). Participants argued that food aid could not, and should not, be mistaken for food security. In the analysis, I gave examples of participants arguing "food aid" was a temporary, short-term strategy meant to save communities from a crisis. But, what policymakers and other governmental actors found was that food aid could not be successful in the short-term. These participants needed a new way, a new discourse, for addressing the complex food challenges facing developing nations. "Food security," a concept these organizational members could use to differentiate "food aid" from long-term involvement and programming, fit the bill. Structurally, participants would still use "food security" to encompass food aid actions, but they would communicatively use "food security" to squeeze other agenda items under the same policy language. For example, the Global Food Security Act discusses building "resilience to food shocks among vulnerable populations and households..." This is a policy objective that shares overlapping meanings with food aid, yet the objective becomes differentiated enough to fit underneath a "food security" umbrella. Food security as a concept becomes favored in the policy language, and persuasive enough to appeal to congresspersons, food security advocates, and development professionals.

Both equivocation and differentiation strategies add to Dougherty et al.'s (2010) call for theory development involving "a concerted exploration of the ways in which meanings evolve" (p. 183). Additionally, LC/MD helps uncover persuasive strategies for policymakers who might use meaning divergence to appeal to intercultural audiences and 
food security advocates. Equivocation and differentiation also speak to the creation of an illusion of shared meaning for food security professionals. The illusion of shared meaning is also very much tied to organizational strategic ambiguity. From the findings based upon LC/MD that were outlined in this study, I argue that language convergence/meaning divergence could be viewed as a precursor to strategic ambiguity. Shared language and the construction of multiple meanings happened in this case around the use of "food security" in the GFSA, but these communicative principles could also apply in other situations. From my findings, I bring forward a new proposal that individuals use divergent language to construct the same or similar meanings around food security. The use of divergent language to create similar meanings can also create confusion that might look like strategic ambiguity. In the future, I would like to explore how LC/MD makes strategic ambiguity possible. Organizational members will benefit from these findings as they continue to develop strategic communication plans for their internal/external audiences. I have shed new light on the ways LC/MD provides a foundation for strategically ambiguous discourse. I discuss other limitations and future directions in the final section of this chapter.

While LC/MD informed much of my analysis and communicative theorizing, I also found strategic ambiguity and organizational sensemaking useful for disentangling the complexities of the data. Next, I discuss discourse and strategic ambiguity in the context of food security meanings.

\section{Strategic ambiguity and discourse.}

Organizations use strategically ambiguous communication with both internal and external stakeholders for many reasons. Strategic ambiguity can promote unified 
diversity in organizations; it can facilitate organizational change; and it can preserve privileged positions. Eisenberg (1984) and Davenport and Leitch (2005) have argued that strategically ambiguous communication allows organizations to create space for multiple interpretations by multiple stakeholders. Jarzabkowski et al. (2010) have added to the literature by theorizing about the co-existence of seemingly incompatible strategically ambiguous discourses (p. 240). Essentially, they point towards two perspectives on strategic ambiguity: 1) ambiguity as problematic for organizations and 2) ambiguity as generative for organizational managers and goals. They have argued that these two perspectives might both be valid and present simultaneously where strategic ambiguity becomes an organizational discursive resource. Ambiguity-as-resource allows for the constant shifting of stakeholder positions and complex organizational commitments. This characterization of strategic ambiguity-as-resource matches the communicative practices happening at USAID, between their stakeholders, and through their work on food security issues. Those participants who worked for or with USAID on global food security programs and policy navigated complex organizational commitments. They were expected to educate food security stakeholders about USAID programs, yet also hold back from advocating for those same programs/policies.

In conducting this study, I also found that USAID used strategic ambiguity in the creation of multiple and competing food security discourses, particularly policy discourses. From participant interviews, field notes, and document analysis, I took note of the times when strategic ambiguity seemed useful for food security professionals and government institutions, as in discussions of the moral argument vs. the national security argument for food security policy. Furthermore, I noticed when strategic ambiguity 
seemed to create even more complications and confusion, for example during discussions about food security and conflict or national defense. I argue that the linguistic strategies used by the participants maintained ambiguous linkages for organizational members between food security, defense, and conflict. These strategies both help and hinder food security professionals and organizations. For example, drawing upon ambiguity-asresource allows interorganizational professionals with different types of food security knowledge to work collaboratively toward broader goals of policy creation and passage, such as in the case of the Global Food Security Act. I argue that this communicative process of using ambiguity-as-resource actually takes a new approach to Eisenberg's perspective on preserving privileged positions of power in organizations. If interorganizational members use strategic ambiguity to construct and advocate for new food security policies, they may disrupt traditional organizational hierarchies. For example, international organizations are asking for more help and input on food security programs from the community leaders within countries where USAID has implemented programming. USAID, and other organizational structures like the United Nations, are beginning to shift what power looks like, at least in the realm of food security research and programming. This usage of strategic ambiguity could soften the rigidity of privileged positions of power in organizations.

Aside from acknowledging the benefits of strategic ambiguity to interorganizational members, the discursive correlations I identified created new places for misinterpretation and misunderstanding. Communicative misunderstandings become magnified when they happen at the juncture of intercultural settings and interactions (Dougherty et al., 2010). Because intercultural organizations operate in a fast-paced and 
globalized era, they must be prepared to deal with ambiguity, misunderstandings, and discursive closures. USAID takes cues from the US government on how to engage in development and diplomacy, but this organization also operates within the decisionmaking spheres of larger international institutions, like the United Nations. There exist overlapping meanings and fundamental miscommunications about food security, especially regarding how to achieve a stable food status for all (Participant \#19 and Participant \#24, personal communication, 2017). As one example of how ambiguity-asresource could be investigated in the future, the United Nations Sustainable Development Goals narrow in on specific topics, like "No poverty" and "Zero Hunger" as global agenda-setting priorities (The Sustainable Development Agenda, 2017). Many nations, including the US, have signed on to tackle these goals in collaboration with other global governments. However, the UN has chosen to address food security through a "hunger" lens on its online knowledge platform rather than food insecurity. Scholars could apply strategic ambiguity strategies to examine how "hunger" discursively operates as an organizational resource for ending global food insecurity through interorganizational collaboration. In the final theoretical section, I summarize contributions related to the sensemaking perspective and directions for future communicative theorizing.

\section{Sensemaking and policy.}

Some of the participants from this study recollected and discussed the policymaking process of the GFSA with enthusiastic optimism. They made sense of the bipartisan passage of legislation by communicatively idealizing the years leading up to GFSA's passage. Participants made sense of this process by describing interorganizational collaboration stripped of the difficulties inherent in organizational 
decision-making: disagreements, negotiations, and tensions. In a summary of the sensemaking literature, Maitlis and Christianson (2014) have described sensemaking as the "process through which people work to understand issues or events that are novel, ambiguous, confusing, or in some other way violate expectations" (2014, p. 57). This study shows participants doing sensemaking retroactively and in relation to the GFSA's passage. Sensemaking that framed the idealizing processes in the data were similar to intercultural sensemaking, "the process involving the selection of scripts that reflect individuals' cultural values and cultural history" (Fisher \& Hutchings, 2013, p. 796) and political sensemaking, "how powerful social actors construct the relationship between multinational enterprises and their multiple local contexts" (Clark \& Geppert, 2011, p. 395). Idealizing involved both sensemaking processes where the individuals who became involved in policymaking reimagined a collaborative endeavor between intercultural actors who had constructed legislation and addressed multiple contexts. However, idealizing is different from these, too, in that conflicts and tensions became hidden through recollected discourse.

As Weick (1995) discussed in his groundbreaking work on sensemaking, there are at least seven distinguishing characteristics that set sensemaking apart from other explanatory organizational processes. Briefly, these seven properties show how sensemaking is a process that is 1) grounded in identity construction, 2) retrospective, 3 ) enactive of sensible environments, 4) social, 5) ongoing, 6) focused on and by extracted cues, and 7) driven by plausibility rather than accuracy. This study offers an extension to the seventh characteristic that states sensemaking is driven by plausibility rather than accuracy and which emphasizes that organizational discourse is laden with opportunities 
for misperceptions and irrationalities. The communicative idealizing process I discussed in subsection 1 of the findings shows that discussions about interorganizational policymaking are not necessarily a reflection of the real actions taken by congresspersons, government aids, lobbyists, etc. Organizational members moved beyond the plausible and towards the idealistic when making sense of the difficult realities of policymaking. When organizational members retrospectively engaged in sensemaking that is driven by idealism, this type of sensemaking could become problematic if the organization wants to create and pass new food security legislation. I suspect that when organizational members collectively idealize policymaking, they will not adequately take into account the complexities of the process. Future research should examine how idealizing might impact policymaking and negotiation during legislative debates.

More recent studies of sensemaking have taken up the issues of discourse/language and sensemaking (Cornelissen, 2012; O'Leary \& Chia, 2007; Taylor \& Robichaud, 2004) as well as the role of power and emotions (Weick, Sutcliffe, \& Obstfeld, 2005). I see my findings as having an impact on how scholars examine sensemaking and language in the future. Communicative idealizing still leaves open questions around how individuals' language use may influence collective organizational sensemaking around the implementation of food security policy. By communicating the idealistic, or imaginative, side of policy sensemaking, organizations may also be able to build stronger agreement around contentious issues and challenges, even those that have diverse and intercultural stakeholders. 


\section{Interorganizational contributions.}

Interorganizational communication is an area of study that has gained popularity in the field, especially in the last fifteen years (Carlson, Poole, Lambert, \& Lammers, 2017; Chisholm, 2017; Doerfel \& Taylor, 2017). When I began researching the case of GFSA and USAID's involvement in contributing to the passage of this recent legislation, I did not anticipate the highly complicated interorganizational structures that I confronted and that regularly make policymaking possible in the US. During the interviews I conducted for this study, I heard many participants talk about conversations between interorganizational actors including, congresspersons and farmers; congresspersons and lobbyists; USAID staff members and university administrators; USAID members and nonprofits; and several other combinations. The communicative networks connecting USAID to other organizations run broad and deep (Monge, Contractor, \& Contractor, 2003). Interorganizational communication scholars have examined these complexities, including organizational tensions collaborations, and relationships (Doerfel \& Taylor, 2004; Hardy, Phillips, \& Lawrence, 2003; Lewis, Isbell, \& Koschmann, 2010). After conducting this study, I saw contradictions in how the participants would talk about interorganizational collaboration as both constraining and enabling in the process of drafting policy language. For example, interorganizational collaborations proved helpful to the process of confronting food insecurity when President Obama decided to set up the Feed the Future Program. However, interorganizational collaborations also seemed to slow down the GFSA's path to becoming a bill because of the number and diversity of stakeholders invested in a global food security strategy. I can imagine taking an interorganizational perspective to the sections of the data where participants assume a 
collective "US Government" identity in order to communicatively construct and pass global food security legislation (Koschmann, 2013).

Alternatively, USAID participants and their interorganizational collaborators regularly discussed the intricacies involved in communicatively building interpersonal trust and credibility over time (ex., Participants \#7, \#16, \#19, \#21). I labeled certain sections of my data with codes like, "Constructive collaboration" and "Connection has prestige," which I was not able to fully include or explore in this case study. However, by reexamining these codes with an interorganizational lens, I will be able to tease out how little "d" and big "D" discourses travel across organizational boundaries. As organizations' goals and values overlap and as interorganizational actors continue collaborating around food security challenges, I think an investigation into migrating discourses would be valuable to organizational researchers. The findings might shed light on how to keep challenges, like food insecurity, at the top of policymakers' minds. I have only just started to consider the possibilities within this line of research related to my findings.

Since I have addressed theoretical contributions and opportunities, next I explain the implications for practice resulting from this study.

\section{Language, Organizing, and Food Security: Implications for Practice}

Food insecurity is a global challenge that is not going away anytime soon. In fact, food insecurity will continue to plague both developing and developed parts of the world, according to the most recent State of Food Insecurity in the World report (SOFI, 2017) put out jointly by the Food and Agriculture Organization of the United Nations (FAO), the International Fund for Agricultural Development (IFAD), and the World Food 
Programme (WFP). The food insecurity challenges of the future will evolve based on changing human and animal migration patterns, natural disasters, fluctuating food prices, changing climate, and other factors. This dissertation provides both theoretical and practical information about how language functions as a meaning-making process in interorganizational interactions, especially around food security and policy issues. There are four primary implications of this dissertation for food security organizations and food insecure populations. These implications will impact how interorganizational collaborators will engage in policymaking practices. In other words, organizational members must examine their linguistic and meaning-construction practices which may impact both internal and external audiences. Participant discussions and organizational documents point to overlapping and competing meanings in interorganizational understandings of food security and the construction of food security policy.

First, the US government is only at the beginning of gaining experience with the passage of food security legislation and policy. US government organizations have been responsible, in many ways, for international development through the material and discursive management of poverty and hunger for some time (Riley, 2017). But now, government organizations are collaborating more than ever in multilateral partnerships (i.e., interorganizationally) to solve complex global challenges like food insecurity. Even within the US government, the whole-of-government coordination towards these efforts is unprecedented. The Global Food Security Act defines "relevant Federal departments and agencies" as inclusive of the United States Agency for International Development, the Department of Agriculture, the Department of Commerce, the Department of State, the Department of the Treasury, the Millennium Challenge Corporation, the Overseas 
Private Investment Corporation, the Peace Corps, the Office of the United States Trade Representative, the United States African Development Foundation, and the United States Geological Survey (Global Food Security Strategy, 2016, p. 38). Even if the federal government distributes the same policies and communication materials about food insecurity to the eleven collaborating agencies, individuals working for these agencies will have come into their respective organizations with widely varying backgrounds, cultures, experiences, biases, goals, and values. Analyzing and reporting on the ways in which food security language converges and meanings diverge will become increasingly important for government members and their stakeholders as complex interactions take place across organizational boundaries (Dougherty et al., 2010). By taking a communication perspective of organizational meaning-making and policy language, government members will be able to explore how food security legislation becomes persuasive for a variety of audiences. USAID could benefit from this study by using more accessible food security language in regular social media posts (Facebook, Instagram, SnapChat) by defining terms with links in the text. For example, they already post about ongoing work in target countries, and in the future, they could include links to definitions and historical context about the following concepts: "food security," "hunger," and "food aid."

Second, the US government, and the country more broadly, has entered a phase where economic, political, and social divisions, misunderstandings, and inequalities have created material and discursive gaps in individuals' ability to secure comfortable and stable lives (Hochschild, 2016; Piketty, 2013). What I mean here is that the economic and social divisions in the US have become wider (Hochschild, 2016). The economic, 
political, and social gaps created by these divisions have exacerbated recurring crises (ex., the World Food Price crisis) along with global food insecurity, according to the US government's most recent Quadrennial Diplomacy and Development Review (2015). Despite the social and material challenges of food insecurity, organizational communication studies could help government members break down these divisions at both the individual and organizational levels, thereby helping to mitigate the spread of food insecurity. Analyses of stakeholder discourses around food insecurity issues can inform government members, company managers and employees, non-profit staff, scholars and others about how messaging influences policy creation and how "changing the language" can secure bipartisan support and/or contribute to divisive, polarizing criticism. The US government could approach "changing the language" by addressing why language matters at all in their reports, BIFAD meeting minutes, conference panels, and other venues. I imagine food security organizations addressing language by adding a fifth pillar which would incorporate "communication and culture." Alternatively, I think food security organizations would benefit from adding a "communication and culture" foundation: a base that holds up the other four food security pillars.

Third, after analyzing the data for this dissertation, I would advise government members and their food security stakeholders to continue educating members of the public about "what" food security is, how food security can be accomplished dependent on the context, and the programmatic steps government members are taking to tackle food insecurity abroad and in the US. As one example, Participant \#9 argued that USAID could do a better job of informing the public about the Bureau for Food Security's actions and involvement in programming via social media. She explained that the government's 
communications often feel forced or too formal, limiting the spread of valuable information about the successes and failures of food security programs, like Feed the Future. In another instance, I noted that USAID participants (i.e., Participant \#2 and Participant \#7) would ask me to keep certain information confidential, including the food insecure countries where USAID would be working during the coming year. One step USAID could take to shift their communicative practices and build connections with multiple audiences (direct and indirect stakeholders alike) would be more explicit and open discussions of these countries once they have been selected. In addition, sharing more specific stories about the on-going food insecurity programming in these countries via Instagram, Facebook, podcasts, Twitter, etc. might help unify the whole-ofgovernment global food security strategy and develop emotional, social, and financial investment from the public related to these important projects. These mediated stories should include first person accounts from those being helped by USAID, including these individuals' names and information about their food security struggles, rather than just pictures of smiling brown bodies sharing the triumphs of US-led programs.

Fourth, the USAID and other food security stakeholder organizations should create and post interorganizational charts that clarify key linkages and programmatic collaboration. No such charts or holistic explanations yet exist on these organizations' websites. Perhaps this lack of clarity is purposeful on the part of these organizations. However, I think it is rather more likely that the organizational members of USAID and their partners have become enmeshed in the complicated connectedness of their food security activities, policies, programs, hierarchies, etc. Therefore, the history and connections may already seem obvious to these individuals. But to an external observer 
interested in food insecurity, like myself, these connections were nearly impossible to find, much less define, and seemed strategically ambiguous at best. An interorganizational chart would benefit governmental staff and their non-government audiences. This chart can show networks and connections in an online, interactive space accessible by both organizational members and lay audiences. This chart could be emailed out to USAID members at regular intervals when relationships change between organizational entities and/or introduced at employee orientations. By creating a chart labeling these connections and the essential food security activities of each organization, USAID might be able to more efficiently make a compelling case to Congress for future global food security legislation and funding.

\section{Limitations \& Strengths}

As may be expected, my case study has limitations that affect my analysis as well as the implications that might be drawn from the data. The main limitation results from participant recruitment. The sensitive nature of information my participants were working on related to food security policy-in-progress made them reluctant to speak with me. There is no public list of individuals working for the USAID Bureau of Food Security, so I had to rely upon the slow process of snowball sampling. Relying on others for introductions limited the number of individuals I could recruit within a specific time frame for the dissertation. However, I still managed to create trusting relationships with participants by recruiting them via email, phone calls, and in-person meetings, and I followed up with them after interviews. It is possible that I would gain new perspectives and interpretations from continuing to speak with other staff members from the Bureau for Food Security. 
A second limitation of this dissertation relates to study design. While I was able to triangulate findings from my interview data by reading through public government documents, policies, strategy reports, and research publications, I would have liked to have been able to interview more participants in-person. In being limited by location, time, and funding, I was able to take only one trip to Washington, D.C. for in-person interviews with two government participants. I did speak with another participant inperson who lived near Missouri, but because of the nature of USAID officers' work, as in they travel frequently to remote locations with limited phone/internet access, I reached a select number of individuals who had worked on the Global Food Security Act. To continue developing this research on discursive organizing around food security policy, I plan on staying in contact with my participants to see if I can gain access to congressional food security policymaking meetings in the future.

While this dissertation had certain limitations, it also had several strengths. Importantly, strengths and limitations are intertwined because difficulties in certain aspects of data collection (ex., the number of participants) led to achievements in other areas (ex., taking the time to get to know participants well before interviewing them). First, the breadth of participants I was able to gain access to who had worked for or with USAID stakeholder organizations proved valuable to securing a diversity of perspectives. I discovered that many of the individuals working on food security policy since the first draft Global Food Security Act failed in 2009 continued working on food security policy and advocacy for USAID or other related organizations. Because I spoke with a breadth of individuals who had, sometimes, decades-long histories of working for and with USAID, I was able to collect stories about the history, relationships, challenges, and 
successes of food security policymaking. For example, I interviewed participants with experience in universities, advocacy organizations, congressional staff members, USAID program managers, and private consultants. These individuals' experiences and stories gave me rich insight into the historical and contextual complexities of the inherently communicative nature of policymaking that goes on within and between organizations.

Second, the array of data I collected gave the findings a holistic and well-rounded thoroughness. Not only did I take time to conduct in-depth interviews with 24 individuals, I also collected data through observation and document analysis. I traveled to Des Moines, Iowa to attend the annual World Food Prize symposium. At the two-andhalf-day symposium, I attended several food security panels that featured USAID Bureau for Food Security speakers. These speakers discussed trends and challenges in the field of global development and food insecurity. I had a chance to introduce myself to participants I had previously only known via email or telephone. I took detailed observational field notes, intentionally cultivated conversations through ethnographic interviews, and reviewed booklets, pamphlets, flyers, and emails from the symposium's events. I spent hundreds of hours searching, reading, highlighting, taking notes, and drawing conclusions from organizational artifacts. These artifacts provided insight into USAID's operations and structure as well as its historical and contemporary communications. Overall, these multiple modes of data collection added to the credibility and resonance of the analysis (Tracy, 2010).

Lastly, a strength of this research includes the way I incorporated the research process, both my mental and physical experiences, into the written dissertation through the three "vignettes" between chapters. While Stake (1995) advocated for researchers to 
add vignettes into their case study reports so that readers would feel transported and moved by the data, I intentionally extended this methodological practice. In my vignettes between chapters, I created multiple meanings by taking on different voices and identities, putting the voices into conversation with each other (i.e., the researcher voice through data analysis, the poetic voice through two prose poems, the interpreter voice through a narrative description). Part of my expectation for those who read the report is that these multiple vignettes, or voices, might interrupt the reading flow and create some discomfort while trying to make sense of the case. As a researcher, I often felt uncomfortable or unsure during data collection, analysis, and writing up the case study report. Constructing and including the vignettes into this dissertation adds another layer to the research process: the vignettes share what the data collection process felt like for myself, the researcher. These research-in-action experiences and vignettes are valuable for readers. The vignettes create a different kind of transparency about the research process that is not typically seen in peer-reviewed journal articles or research publications. The three vignettes break up the linear process of asking and knowing "what is going here." While I suspect most researchers ask themselves this question as they examine a situation or the data surrounding an issue, the vignettes provide a different way for readers to understand how I was able to interpret the case study results.

\section{Future Research}

Since the writing up of the findings in this dissertation, I am pleased to say that the Global Food Security Act Reauthorization Act of 2018 has passed the House Foreign Affairs Committee and will soon be voted on by members of the US House and the Senate. This reauthorization bill calls for a two-year extension of the GFSA (2016); this 
call continues a bipartisan commitment to fighting global food insecurity. While the GFSA was an appropriation bill, a bill setting overall spending limits by the USAID, this bill would direct how federal funds should and should not be used (Global Food Security Reauthorization Act, 2018). As this bill continues to make its way through Congress, there are three key areas for future research I plan to pursue.

First, I plan to examine in more detail the role(s) that USAID Bureau for Food Security members play in drafting, commenting, and advocating for food security policy. From studying this case, I gained a better sense for how USAID communicatively constructs food security meanings through and with its interorganizational actors. However, there are still gaps in my understanding about the exact discursive interactions between USAID members and congresspersons. I am interested in discovering how USAID navigates the following organizational contradiction: USAID staff cannot advocate on its own behalf for the passage of food security legislation even though the organization is directly impacted. Questions that arise around this topic include: How does USAID's Bureau for Food Security advocate for policy? What discourses make advocacy possible through USAID's interorganizational connections? Investigating the answers to these questions could reveal new information about policymaking at the federal level of government.

Second, USAID has worked with thousands of individuals from dozens, if not hundreds, of food security and development organizations in the US and abroad. For a related research project, I would like to continue building my relationships with USAID's food security stakeholders including international governments, international universities, not-for-profits organizations, corporations etc. Most likely, I will rely upon the 
relationships I have already made over the past year to gain access to new stakeholders who have worked with USAID or received USAID funding to address global food insecurity. This type of project might take the form of an ethnography (Creswell, 2013). Participant \#3 from this dissertation study has already suggested that I work with the members from the Comprehensive Africa Agriculture Development Programme (CAADP), Africa's policy framework for agricultural transformation, wealth creation, food security and nutrition, and economic growth (United Nations, n.d.). I would expect to spend time observing how Africa's communicative food security policy practices differ from the US government system. This type of project would address the intercultural nature of food insecurity, and I would be able to examine how multiple meanings become prioritized and hidden within the CAADP organization.

Finally, I realized after conducting this study that I am still curious about the discursive/material relationship linking food insecurity and conflict, as well as how this relationship affects US defense, diplomacy and development. Since participants for this dissertation study were reluctant to expand upon the nature of these connections, I would like to explore an organizational discourse analysis with USAID (Fairhurst \& Uhl-Bien, 2012). An organizational discourse analysis would provide valuable insight into the ways in which specific discourses function and persuade organizational members about the potential or actual dangers of linkages between food insecurity and conflict. I bring up the discourse/materiality dialectic because I am also interested in the physicalmaterial—side of food insecurity and conflict. 


\section{Concluding Thoughts}

Fundamentally, policy as communication intrigues me because I believe that peaceful, democratic interactions, such as the partnership and collaboration through dialogue, are the only way to build a food secure future (Eisler, 1987). These future research directions will allow me to pursue intersecting and divergent paths related to the power of organizing through policy, and thereby, the power of communication to facilitate meaningful change. On the other hand, if humans cannot find peaceful, communicative pathways towards food security, humanity risks increased suffering and destruction. Policies frame the organizing rules and regulations for humans to peaceably solve problems together. I will continue to pursue the communicative constitution of supportive organizations tackling food insecurity. 


\section{Appendix I}

1.) What is your involvement (job/work entail) with food security?

2.) How did you get involved working with food security (food security issues)?

a. Why did you get involved in food security?

3.) What does the term "food security" mean to you?

a. What is the definition of food security?

4.) What factors cause food insecurity?

5.) What are the consequences of food insecurity?

6.) How is hunger related to food insecurity?

7.) Tell me about a time you used the term, "food security," and were misunderstood.

8.) Tell me the story, as you understand it, of how the Global Food Security Act (GFSA) was created and how it became law.

a. What was the biggest controversy around this act?

b. How was the GFSA different from previous food/hunger policies?

c. How is it similar?

d. How is it that the GFSA made it through Congress during a contentious time in our political system's history?

9.) How has the Global Food Security Act shifted the way food security has become discussed (in Congress and/or with your colleagues)?

10.) How has the GFSA shifted the way food security has been prioritized by the US government?

11.) How has the GFSA changed the way we talk about food security? 
12.) How does "food security" determine or guide the Congressional national/foreign agenda?

12a.) How does food security determine development funding abroad?

13.) What other events (local/international) have shifted food security priorities for US?

14.) What else do I need to know about the different ways food security is understood by congresspersons?

14a.) Other stakeholders?

Demographic Survey:

1. What is your age?

2. What is your race or ethnicity?

3. Where are you from?

4. Where do you currently live?

5. Job title?

6. Education/Major?

7. Parents' Education/Jobs?

8. How many hours do you work each week? 


\section{References}

Albala, K., Belasco, W., Bentley, A., Heldke, L., \& McIntosh, A. (2017). FCS editors' roundtable: Reflections on the twentieth anniversary of the journal. Food, Culture, \& Society, 20(1), 1-14. doi: 10.1080/15528014.2017.1272193

Alkon, A. H., \& Agyeman, J. (Eds.) (2011). Cultivating food justice: Race, class, and sustainability. Cambridge, MA: The MIT Press.

Alvesson, M., \& Kärreman, D. (2000a). Varieties of discourse: On the study of organizations through discourse analysis. Human Relations, 53(9), 1125-1149.

Alvesson, M., \& Kärreman, D. (2011b). Decolonializing discourse: Critical reflections on organizational discourse analysis. Human Relations, 64(9), 1121-1146. doi: $10.1177 / 0018726711408629$

Alvis, S., \& Demment, M. (2017). The challenge of change: Harnessing university discovery, engagement and learning to achieve food and nutrition security. APLU, Washington, D.C. Retrieved from http://www.aplu.org/library/thechallenge-of-change/File

Anderson, J. E. (2015). Public policymaking ( ${ }^{\text {th }}$ Edition). Stamford, CT: Cengage Learning.

Anderson, M. D., \& Cook, J. T. (1999). Community food security: Practice in need of theory? Agriculture and Human Values, 16(2), 141-150.

Ångman, E. (2013). Was this just for show? Discursive opening and closure in a public participatory process. Environmental Communication: A Journal of Nature and Culture, 7(3), 409-426.

Bargiela-Chiappini.F. (2004). Organizational discourse: Reflections on a new research 
paradigm. International Journal of the Sociology of Language, (166), 1-18.

Barker, J. R. (2008). Directions for thought leadership in discourse and communication: a commentary on Jian et al. Discourse \& Communication, 2(3), 333-337.

Barrett, C. B., \& Maxwell, D. G. (2005). Food aid after fifty years: Recasting its role. London, London, UK: Routledge.

Belasco, W. (2008). Food: The key concepts. New York, NY: Berg.

Booth, D. (2014, September). Agricultural policy choice: Interests, ideas and the scope for reform. International Institute for Environment and Development Working Paper. London, UK: IIED Natural Resources Group.

Bourdieu, P. (1991). Language and symbolic power. Boston, MA: Harvard University Press.

Broad, G. (2016). More than just food: food justice and community change (Vol. 60). Oakland, CA: University of California Press.

Bullis, C. (1993). Organizational socialization research: Enabling, constraining, and shifting perspectives. Communications Monographs, 60(1), 10-17.

Canary, H. E. (2010a). Structurating activity theory: An integrative approach to policy knowledge. Communication Theory, 20(1), 21-49.

Canary, H. E. (2010b). Constructing policy knowledge: Contradictions, communication, and knowledge frames. Communication Monographs, 77(2), 181-206.

Canary, H. E., Blevins, M., \& Ghorbani, S. S. (2015). Organizational policy communication research: Challenges, discoveries, and future directions. Communication Reports, 28(1), 48-64.

Canary, H. E., \& McPhee, R. D. (2009). The mediation of policy knowledge: An 
interpretive analysis of intersecting activity systems. Management Communication Quarterly, 23(2), 147-187.

Carbaugh, D. (2007). Cultural discourse analysis: Communication practices and intercultural encounters. Journal of Intercultural Communication Research, 36(3), 167-182.

Carlson, E. J., Poole, M. S., Lambert, N. J., \& Lammers, J. C. (2017). A study of organizational responses to dilemmas in interorganizational emergency management. Communication Research, 44(2), 287-315.

Chisholm, R. (2017). Interorganizational decision making. Abingdon, UK: Routledge.

Christensen, L. T., Morsing, M., \& Thyssen, O. (2015). Discursive closure and discursive openings in sustainability. Management Communication Quarterly, 29(1), 135144.

Clair, R. P. (1998). Organizing silence: A world of possibilities. New York: SUNY Press. Clapper, J. R. (2014, January). Worldwide threat assessment of the US intelligence community. Senate Select Committee on Intelligence. Washington, D. C.: Office of the Director of National Intelligence. Retrieved from https://www.dni.gov/files/documents/Intelligence\%20Reports/2014\%20WWTA\% 20\%20SFR_SSCI_29_Jan.pdf

Clark, E., \& Geppert, M. (2011). Subsidiary integration as identity construction and institution building: A political sensemaking approach. Journal of Management Studies, 48(2), 395-416.

Clegg, S. R. (1989). Frameworks of power. Thousand Oaks, CA: Sage.

Coates, J., Swindale, A., \& Bilinsky, P. (2007). Household Food Insecurity Access Scale 
(HFIAS) for measurement of food access: indicator guide. Washington, DC: Food and Nutrition Technical Assistance Project, Academy for Educational Development, 34 .

Coleman-Jensen, A., Gregory, C., \& Rabbitt, M. (2016, October 4). Frequency of food insecurity. United States Department of Agriculture Economic Research Service. Retrieved from https://www.ers.usda.gov/topics/food-nutrition-assistance/foodsecurity-in-the-us/frequency-of-food-insecurity/

Collins, P. H. (2000). Gender, black feminism, and black political economy. The Annals of the American Academy of Political and Social Science, 568(1), 41-53.

Committee on World Food Security. (2001, June 1). The world food summit goal and the millennium development goals. Twenty-seventh session. Food and Agriculture Organization. Retrieved from http://www.fao.org/docrep/MEETING/003/Y0688E.HTM

Cooren, F. (2004). Textual agency: How texts do things in organizational settings. Organization, 11(3), 373-393.

Cooren, F., Matte, F., Benoit-Barné, C., \& Brummans, B. H. (2013). Communication as ventriloquism: A grounded-in-action approach to the study of organizational tensions. Communication Monographs, 80(3), 255-277.

Cornelissen, J. P. (2012). Sensemaking under pressure: The influence of professional roles and social accountability on the creation of sense. Organization Science, 23(1), 118-137.

Craig, R. T. (1999). Communication theory as a field. Communication Theory, 9(2), 119161. 
Cramer, J. M., Greene, C. P., \& Walters, L. M. (Eds.). (2011). Food as communication: Communication as food. New York, NY: Peter Lang.

Creswell, J. W. (2013). Research design: Qualitative, quantitative, and mixed methods approaches. Thousand Oaks: Sage.

Davenport, S., \& Leitch, S. (2005). Circuits of power in practice: Strategic ambiguity as delegation of authority. Organization Studies, 26(11), 1603-1623.

Deetz, S. (1992). Democracy in an age of corporate colonization: Developments in communication and the politics of everyday life. Albany, NY: SUNY press.

Deetz, S. A., \& Eger, E. K. (2014). Developing a metatheoretical perspective for organizational communication studies. In L. Putnam \& D. Mumby (Eds.) The SAGE handbook of organizational communication: Advances in theory, research, and methods, 27-48.

Deleuze, G., \& Guattari, F. (1987). A thousand plateaus: Capitalism and schizophrenia. London, UK: Bloomsbury Publishing.

Department of State, USAID, \& Department of Defense. (2012, July 31). 3D Planning

Guide: Diplomacy, Development, Defense. Pre-decisional working draft. Retrieved from https://www.usaid.gov/sites/default/files/documents/1866/3D\%20Planning\%20Gu ide_Update_FINAL\%20\%2831\%20Ju1\%2012\%29.pdf

Dixon, M. A., \& Dougherty, D. S. (2010). Managing the multiple meanings of organizational culture in interdisciplinary collaboration and consulting. Journal of Business Communication, 47(1), 3-19.

Dixon, J., \& Dougherty, D. S. (2014). A language convergence/meaning divergence 
analysis exploring how LGBTQ and single employees manage traditional family expectations in the workplace. Journal of Applied Communication Research, 42(1), 1-19.

Doerfel, M. L., \& Taylor, M. (2004). Network dynamics of interorganizational cooperation: The Croatian civil society movement. Communication Monographs, 71(4), 373-394.

Doerfel, M. L., \& Taylor, M. (2017). The story of collective action: The emergence of ideological leaders, collective action network leaders, and cross-sector network partners in civil society. Journal of Communication, 67(6), 920-943.

Dougherty, D. S. (2011). The reluctant farmer: An exploration of work, social class, and the production of food. Leicester, UK: Troubador.

Dougherty, D. S., \& Goldstein Hode, M. (2016). Binary logics and the discursive interpretation of organizational policy: Making meaning of sexual harassment policy. Human Relations, 1-27. doi: 10.1177/0018726715624956.

Dougherty, D. S., Kramer, M. W., Klatzke, S. R., \& Rogers, T. K. (2009). Language convergence and meaning divergence: A meaning centered communication theory. Communication Monographs, 76(1), 20-46.

Dougherty, D. S., Mobley, S. K., \& Smith, S. E. (2010). Language convergence and meaning divergence: A theory of intercultural communication. Journal of International and Intercultural Communication, 3(2), 164-186.

Dougherty, D. S., Schraedley, M. K., Gist, A., \& Wickert, J. (2014, November). Revealing/concealing among the unemployed: Body and text discourses as classed indicators of food insecurity. National Communication Association 
annual conference meeting. Chicago, IL.

Dougherty, D. S., \& Smythe, M. J. (2004). Sensemaking, organizational culture, and sexual harassment. Journal of Applied Communication Research, 32(4), 293-317.

Dutta, M. J., Anaele, A., \& Jones, C. (2013). Voices of hunger: Addressing health disparities through the culture-centered approach. Journal of Communication, 63(1), 159-180.

Dutta, M. J., Thaker, J., \& Sun, K. (2014). Neoliberalism, neocolonialism, and communication for social change: A culture-centered agenda for the social sciences. Global Media Journal: American Edition, pp. 1-15.

Eisenberg, E. M. (1984). Ambiguity as strategy in organizational communication. Communication Monographs, 51(3), 227-242.

Eisler, R. (1987). The chalice and the blade: Our history, our future. San Francisco, CA: HarperCollins.

Fairhurst, G. T. (2007). Discursive leadership. Los Angeles, CA: Sage.

Fairhurst, G. T., \& Putnam, L. (2004). Organizations as discursive constructions. Communication Theory, 14(1), 5-26.

Fairhurst, G. T., \& Uhl-Bien, M. (2012). Organizational discourse analysis (ODA): Examining leadership as a relational process. The Leadership Quarterly, 23(6), 1043-1062.

FAO, IFAD, \& WFP. (2015). The state of food insecurity in the world 2015. Meeting the 2015 international hunger targets: Taking stock of uneven progress. Rome, Italy: FAO. Retrieved from http://www.fao.org/3/a-i4646e.pdf FAO, IFAD, UNICEF, WFP, \& WHO. (2017). The State of Food Security and Nutrition 
in the World 2017. Building resilience for peace and food security. FAO: Rome, Italy. Retrieved from http://www.fao.org/3/a-I7695e.pdf

Fineman, S. (Ed.). (2000). Emotion in organizations. Thousand Oaks, CA: Sage Publications.

Fisher, K., \& Hutchings, K. (2013). Making sense of cultural distance for military expatriates operating in an extreme context. Journal of Organizational Behavior, 34(6), 791-812.

Food and Agriculture Organization. (2011). Gender, food security and nutrition: Policy recommendations. Committee on World Food Security. Retrieved from http://www.fao.org/3/a-av040e.pdf

Feed the Future. (2017, January 25). What we do: Agriculture and food security. USAID: From the American people. Retrieved from https://www.usaid.gov/what-wedo/agriculture-and-food-security/increasing-food-security-through-feed-future

Gainer, A., Karumba, T., Taft-Morales, M., \& Flowers, K. (2010). USAID policy framework: 2011-2015. Retrieved from https://www.usaid.gov/sites/default/files/documents/ 1870/USAID\%20Policy\%20Framework\%202011-2015.PDF

Gelan, A. (2006). Cash or food aid? A general equilibrium analysis for Ethiopia. Development Policy Review, 24(5), 601-624.

Global Food Security Act. (2009). $111^{h}$ Congress of the US government. Retrieved from https://www.congress.gov/bill/111th-congress/senate-bill/384

Global Food Security Act of 2016. (2016, July 20). 114 th Congress of the US government. Retrieved from https://www.congress.gov/bill/114th-congress/senate-bill/1252 
Global Food Security Reauthorization Act of 2018. (2018). $115^{\text {th }}$ Congress of the US government. Retrieved from https://www.congress.gov/bill/115th-congress/housebill/5129/related-bills

Global Food Security Strategy FY 2017-2021. (2016, September). United States Agency for International Development. Retrieved from https://www.usaid.gov/what-wedo/agriculture-and-food-security/us-government-global-food-security-strategy

Gottlieb, R., \& Joshi, A. (2010). Food justice. Cambridge, MA: MIT Press.

Hadley, C., Lindstrom, D., Tessema, F., \& Belachew, T. (2008). Gender bias in the food insecurity experience of Ethiopian adolescents. Social Science \& Medicine, 66(2), 427-438.

Hardy, C., Grant, D., Oswick, C., \& Putnam, L. (2005). Book review: Diss-ing discourse? A response. Organization Studies, 26(5), 799-804.

Hardy, C., Phillips, N., \& Lawrence, T. B. (2003). Resources, knowledge and influence: An empirical study of the organizational effects of interorganizational collaboration. Journal of Management Studies, 40(2), 289-315.

Hauser, M. D., Chomsky, N., \& Fitch, W. T. (2002). The faculty of language: What is it, who has it, and how did it evolve? Science, 298(5598), 1569-1579.

Hochschild, A. R. (2016). Strangers in their own land: Anger and mourning on the American right. New York, NY: The New Press.

Hoddinott, J. (1999, March). Operationalizing household food security in development projects: An introduction. Washington, D.C.: International Food Policy Research Institute. Retrieved from http://pdf.usaid.gov/pdf_docs/Pnach723.pdf

Holmes, S. (2013). Fresh fruit, broken bodies: Migrant farmworkers in the United 
States (Vol. 27). Berkeley, CA: University of California Press.

hooks, B. (1981). Ain’t I a Woman. Black Women and Feminism. Boston, MA: South End.

International Food Policy Research Institute (IFPRI). (2012). 2011 Global food policy report. Washington, D.C.: International Food Policy Research Institute (IFPRI). http://dx.doi.org/10.2499/9780896295476

Jarosz, L. (2009). The political economy of global governance and world food crisis: The case of the FAO. Review: A Journal of the Fernand Braudel Center for the Study of Economies, Historical Systems, and Civilizations 32(1): 37-60.

Jarosz, L. (2011). Defining world hunger: scale and neoliberal ideology in international food security policy discourse. Food, Culture \& Society, 14(1), 117-139.

Jarosz, L. (2014). Comparing food security and food sovereignty discourses. Dialogues in Human Geography, 4(2), 168-181.

Jarzabkowski, P., Sillince, J. A., \& Shaw, D. (2010). Strategic ambiguity as a rhetorical resource for enabling multiple interests. Human Relations, 63(2), 219-248.

Jensen, K. B. (2013). The cultural contexts of media and communication. In K. B. Jensen (Ed.), A handbook of media and communication research: Qualitative and quantitative methodologies (pp. 203-218). New York, NY: Routledge.

Jian, G., Schmisseur, A. M., \& Fairhurst, G. T. (2008). Organizational discourse and communication: The progeny of Proteus. Discourse \& Communication, 2(3), 299320. doi: $10.1177 / 1750481308091912$

Kärreman, D., \& Alvesson, M. (2008). The communicative constitution of what? A response to Jian et al. Discourse \& Communication, 2(3), 321-325. 
Kirby, E., \& Krone, K. (2002). " The policy exists but you can't really use it": communication and the structuration of work-family policies. Journal of Applied Communication Research, 30(1), 50-77.

Knezevic, I., Hunter, H., Watt, C., Williams, P., \& Anderson, B. (2014). Food insecurity and participation: A critical discourse analysis. Critical Discourse Studies, 11(2), 230-245. doi: 10.1080/17405904.2013.866590

Koch, M. A., \& Compton, C. A. (2015). Discursive closures and the greenwashing of food discourse. In S. Boerboom (Ed.) The Political Language of Food, 227-250, Lanham, MD: Lexington Books.

L'Aquila Joint Statement on Global Food Security. (2009, July 10). L'Aquila food security initiative. G8 summit 2009. Retrieved from http://www.g8italia2009.it/static/G8_Allegato/LAquila_Joint_Statement_on_Glob al_Food_Security\%5B1\%5D,0.pdf

Lang, T. (1999). The complexities of globalization: The UK as a case study of tensions within the food system and the challenge to food policy. Agriculture and Human Values, 16(2), 169-185.

Lang, T., Barling, D., \& Caraher, M. (2009). Food policy: Integrating health, environment and society. Oxford, UK: OUP Oxford.

Lang, T., \& Heasman, M. (2015). Food wars: The global battle for mouths, minds and markets. New York, NY: Routledge.

LeGreco, M. (2012). Working with policy: Restructuring healthy eating practices and the circuit of policy communication. Journal of Applied Communication Research, 40(1), 44-64. 
LeGreco, M., \& Tracy, S. J. (2009). Discourse tracing as qualitative practice. Qualitative Inquiry, 15(9), 1516-1543. doi: 10.1177/1077800409343064

Leonardi, P. M., \& Jackson, M. H. (2004). Technological determinism and discursive closure in organizational mergers. Journal of Organizational Change Management, 17(6), 615-631.

Lewis, L., Isbell, M. G., \& Koschmann, M. (2010). Collaborative tensions: Practitioners' experiences of interorganizational relationships. Communication Monographs, 77(4), 460-479.

The Lugar Center. (2018). Solving global issues. Retrieved from http://www.thelugarcenter.org/

Lynch, O. H. (2009). Kitchen antics: The importance of humor and maintaining professionalism at work. Journal of Applied Communication Research, 37(4), 444-464.

Lyons, K. (2014). Urban food advocates' tactics to rebuild food systems: Convergence and divergence in food security and food sovereignty discourses. Dialogues in Human Geography, 4, 212-217. doi: 10.1177/204380614537163.

Maitlis, S., \& Christianson, M. (2014). Sensemaking in organizations: Taking stock and moving forward. The Academy of Management Annals, 8(1), 57-125.

Maxwell, S. (1996). Food security: a post-modern perspective. Food Policy, 21(2), 155170.

Merriam, S. B. (2009). Qualitative research: A guide to design and implementation: Revised and expanded from qualitative research and case study applications in education. San Francisco, CA: Jossey-Bass. 
Merriam-Webster. (2018). Equivocation. Retrieved from https://www.merriamwebster.com/dictionary/equivocate

Miles, M. B., \& Huberman, A. M. (1994). Qualitative data analysis: A sourcebook. Thousand Oaks, CA: Sage Publications.

Misselhorn, A. A. (2005). What drives food insecurity in southern Africa? A metaanalysis of household economy studies. Global environmental change, 15(1), 3343.

Mission, Vision and Values. (2018, February 16). United States Agency for International Development. Retrieved from https://www.usaid.gov/who-we-are/mission-visionvalues

Mittal, A. (2009, June). The 2008 food price crisis: Rethinking food security policies. G24 discussion paper no. 56. The United Nations. Retrieved from https://www.g24.org/wp-content/uploads/2016/01/56.pdf

Monge, P. R., Contractor, P. S., \& Contractor, N. S. (2003). Theories of communication networks. New York, NY: Oxford University Press.

Mortensen, C. D. (1997). Miscommunication. Thousand Oaks, CA: Sage Publications.

Mumby, D. K. (1998). Organizing men: Power, discourse, and the social construction of masculinity(s) in the workplace. Communication Theory, 8(2), 164-183.

Mumby, D. K. (2011). What's cooking in organizational discourse studies? A response to Alvesson and Kärreman. Human Relations, 64(9), 1147-1161.

Mumby, D. K., \& Stohl, C. (2007). (Re)disciplining organizational communication studies: A response to Broadfoot and Munshi. Management Communication Quarterly, 21(2), 268-280. doi: 10.1177/0893318907306038. 
Ogden, L. (2011). Swamplife: people, gators, and mangroves entangled in the Everglades. Minneapolis, MN: University of Minnesota Press.

O'Leary, M., \& Chia, R. (2007). Epistemes and structures of sensemaking in organizational life. Journal of Management Inquiry, 16(4), 392-406.

Piketty, T., \& Goldhammer, A. (Trans.). (2013). Capital in the $21^{\text {st }}$ century. Cambridge, MA: Harvard University Press.

Pinstrup-Andersen, P. (2009). Food security: Definition and measurement. Food Security, 1, 5-7. doi: 10.1007/s12571-08-0002-y

Phillips, R. (2009). Food security and women's health: A feminist perspective for international social work. International Social Work, 52(4), 485-498.

Phillips, N., Lawrence, T. B., \& Hardy, C. (2004). Discourse and institutions. Academy of Management Review, 29(4), 635-652.

Potter, J. (2003). Discursive psychology: Between method and paradigm. Discourse \& Society, 14(6), 783-794.

Potter, J., \& Wetherell, M. (1987). Discourse and social psychology: Beyond attitudes and behaviour. Thousand Oaks, CA: Sage.

Putnam, L. L. (2008). Images of the communication-discourse relationship. Discourse \& Communication, 2(3), 339-345. doi: 10.1177/175048130891916

Quadrennial Diplomacy and Development Review. (2015). Enduring leadership in a dynamic world. United States Agency for International Development. Retrieved from https://www.usaid.gov/sites/default/files/documents/1870/QDDR2015.pdf

Resnick, D., S. C., Babu, Haggblade, S., Hendriks, S., \& Mather, D. (2015). 
Conceptualizing drivers of policy change in agriculture, nutrition, and food security: The kaleidoscope model. International Food Policy Research Institute discussion paper. Washington, D.C.

Riley, B. (2017). The political history of American food aid: An uneasy benevolence. New York, NY: Oxford University Press.

Rivkin, J., \& Ryan, M. (Eds). (2017). Introduction. Literary theory: An anthology. John Wiley \& Sons: Oxford, UK.

Satterthwaite, D., McGranahan, G., \& Tacoli, C. (2010). Urbanization and its implications for food and farming. Philosophical Transactions of the Royal Society B: Biological Sciences, 365 (1554), 2809-2820. doi:

10.1098/rstb.2010.0136

Schanbacher, W. D. (2010). The politics of food: The global conflict between food security and food sovereignty. Santa Barbara, CA: Praeger.

Schiff, R. (2008). The role of food policy councils in developing sustainable food systems. Journal of Hunger \& Environmental Nutrition, 3(2-3), 206-228.

Shaw, D. (2007). World food security: A history since 1945. New York: Springer.

Sieben, B., \& Wettergren, Å. (Eds.). (2010). Emotionalizing organizations and organizing emotions-Our research agenda. In Emotionalizing organizations and organizing emotions, 1-20. London, UK: Palgrave Macmillan.

Sillince, J., Jarzabkowski, P., \& Shaw, D. (2012). Shaping strategic action through the rhetorical construction and exploitation of ambiguity. Organization Science, 23(3), 630-650.

Simmons, E. (2017, February). Recurring storms: Food insecurity, political instability, 
and conflict. A report of the Center for Strategic and International Studies Global Food Security Project. Washington, D.C.: Center for Strategic \& International Studies.

Singer, P., \& Mason, J. (2006). The ethics of what we eat: Why our food choices matter. Emmaus, PA: Rodale.

Smith, F. L., \& Dougherty, D. S. (2012). Revealing a master narrative: Discourses of retirement throughout the working life cycle. Management Communication Quarterly, 26(3), 453-478.

Stake, R. E. (1995). The art of case study research. Thousand Oaks, CA: Sage.

Stake, R., \& Trumbull, D. (1982). Naturalistic generalizations. Review Journal of Philosophy and Social Science, 7(1), 1-12.

The Sustainable Development Agenda. (2017). Sustainable development goals: 17 goals to transform our world. About. The United Nations. Retrieved from http://www.un.org/sustainabledevelopment/development-agenda/

Taylor, J. R. (2008). Communication and discourse: is the bridge language? Response to Jian et al. Discourse \& Communication, 2(3), 347-352. doi: $10.1177 / 1750481308091923$

Taylor, S. (2013). What is discourse analysis? London, UK: Bloomsbury Publishing. Taylor, B. C., Bean, H., O’Gorman, N., \& Rice, R. (2017). A fearful engine of power: conceptualizing the communication-security relationship. Annals of the International Communication Association, 41(2), 111-135.

Taylor, J. R., \& Robichaud, D. (2004). Finding the organization in the communication: Discourse as action and sensemaking. Organization, 11(3), 395-413. 
Teubert, W. (2010). Meaning, discourse, and society. Cambridge, UK: Cambridge University Press.

Thackaberry, J. A. (2004). "Discursive opening" and closing in organisational self-study: Culture as trap and tool in wildland firefighting safety. Management Communication Quarterly, 17(3), 319-359.

Thrush, G. \& Davenport, C. (2017, March 15). Donald Trump slashes funds for E.P.A. and State Department. The New York Times. Retrieved from https://www.nytimes.com/2017/03/15/us/politics/budget-epa-state-departmentcuts.html?_r=0

Thurow, R. (2012). The last hunger season: A year in an African farm community on the brink of change. New York, NY: PublicAffairs.

Title XII Report to Congress FY 2011. (2013, May). USAID. Retrieved from https://www.usaid.gov/documents/1867/title-xii-fy-2011-report-congress

Tracy, S. J. (2013). Qualitative research methods: Collecting evidence, crafting analysis, communicating impact. New York, NY: John Wiley \& Sons.

Tracy, S. J., Myers, K. K., \& Scott, C. W. (2006). Cracking jokes and crafting selves: Sensemaking and identity management among human service workers. Communication Monographs, 73(3), 283-308.

Trethewey, A., \& Ashcraft, K. L. (2004). Special issue introduction: Practicing disorganization: The development of applied perspectives on living with tension. Journal of Applied Communication Research, 32(2), 81-88.

Trethewey, A., Scott, C., \& LeGreco, M. (2006). Constructing embodied organizational identities: Commodifying, securing, and servicing professional bodies. In B. Dow 
\& J. T. Wood (Eds.), The handbook of gender and communication. Thousand Oaks, CA: Sage

Ulmer, R. R., \& Sellnow, T. L. (2000). Consistent questions of ambiguity in organizational crisis communication: Jack in the Box as a case study. Journal of Business Ethics, 25(2), 143-155.

USAID. (2016, September). US government global food security strategy: FY 2017-2021. Retrieved from https://www.usaid.gov/sites/default/files/documents/1867/USGGlobal-Food-Security-Strategy-2016.pdf

US Government Global Food Security Strategy Implementation Report. (2017). Feed the Future. Given to me by staff member of USAID.

Verwimp, P. (2012, January). Food security, violent conflict and human development: causes and consequences. United Nations Development Programme Working Paper, 1-13. Brussels, Belgium: African Human Development Report. Retrieved from http://www.undp.org/content/dam/rba/docs/Working\%20Papers/Food\%20Securit y\%20Violent\%20Conflict.pdf

von Grebmer, K., Torero, M., Olofinbiyi, T., Fritschel, H., Wiesmann, D., ... \& von Oppeln, C. (2011). 2011 Global Hunger Index The challenge of hunger: Taming price spikes and excessive food price volatility. Washington, D.C.: International Food Policy Research Institute.

Weick, K. E. (1995). Sensemaking in organizations (Vol. 3). Thousand Oaks, CA: Sage.

Weick, K. E., Sutcliffe, K. M., \& Obstfeld, D. (2005). Organizing and the process of sensemaking. Organization Science, 16(4), 409-421. 
What We Do. (2018). USAID: From the American People. Retrieved from https://www.usaid.gov/

Who We Are. (2012, May 31). Bureau for food security. USAID: From the American People. Retrieved from https://www.usaid.gov/who-weare/organization/bureaus/bureau-food-security

Who We Are. (2017, March 14). USAID history. USAID: From the American People. Retrieved from https://www.usaid.gov/who-we-are/usaid-history

Wilson, G. (2007). Title XII summary for the general public. Association of Public \& Land-Grant Universities: Projects \& Initiatives. Retrieved from http://www.aplu.org/projectsand-initiatives/international-programs/bifad/BIFAD_Library/title-xii-summaryfor-the-general-public

Wolters Kluwer Health. (2017). Food insecurity: It is more common than you think: Recognizing it can improve the care you give. Nutrition Today,52(5), E3-E4. doi: 10.1097/NT.0000000000000242

The World Bank. (1986). Poverty and hunger: Issues and options for food security in developing countries. Washington, D.C. Retrieved from http://documents.worldbank.org/curated/en/166331467990005748/pdf/multipage.pdf

Yin, R. K. (2009). Case study research: Design and methods ( $5^{\text {th }}$ Edition). Thousand Oaks: Sage.

Zero Hunger. (2017). World Food Programme. Retrieved from http://www1.wfp.org/zero-Hunger 


\section{VITA}

Megan K. Schraedley (B.A., Boston College; M.A. University of Missouri) has always been drawn to the people, creative processes, and issues surrounding food. In particular, she argues that the ways in which people construct personal meaning and identity through their foodways and the powerful messages that larger organizational systems replicate and disseminate—interfering with individuals' meaning-making processes—should be deeply interrogated. Food systems and the policies put in place to shape and control these global systems are not static; humans created these structures and can change them. Her research has investigated the material and discursive nature of social class through the lens of food insecurity as well as the discursive performance of grocery shopping, by individuals who constructed meaning around ambiguous concepts such as "all-natural" and "organic." In the future, Megan will continue to analyze and question organizational communication practices, especially as interorganizational power imbalances inevitably create inequitable conditions for food workers in a neoliberal world order. She hopes to shift individuals' foodways so that they critically consider the meaning and ethics behind their practices. 